\title{
User's Guide to ESME v. 8.1
}

\author{
J. MacLachlan \\ Fermi National Accelerator Laboratory \\ P.O. Box 500, Batavia, Illinois 60510
}

August 1993 


\section{Disclaimer}

This report was prepared as an account of work sponsored by an agency of the United States Government. Neither the United States Government nor any agency thereof, nor any of their employees, makes any warranty, express or implied, or assumes any legal liability or responsibility for the accuracy, completeness, or usefulness of any information, apparatus, product, or process disclosed, or represents that its use would not infringe privately owned rights. Reference herein to any specific commercial product, process, or service by trade name, trademark, manufacturer, or otherwise, does not necessarily constitute or imply its endorsement, recommendation, or favoring by the United States Government or any agency thereof. The views and opinions of authors expressed herein do not necessarily state or reflect those of the United States Government or any agency thereof. 
User's Guide to ESME v. 8.1

J. MacLachlan

August 26, 1993 


\begin{abstract}
ESME is a computer program to calculate the evolution of a distribution of particles in energy and azimuth as it is acted upon by the radio frequency system of a proton synchrotron. It provides for the modeling of multiple rf systems, feedback control, space charge, and many of the effects of longitudinal coupling impedance. The capabilities of the program are described, and the requirements for input data are specified in sufficient detail to permit significant calculations by an uninitiated user. The program is currently at version 8.1 and extensively modified since the previous user documentation. Changes since the 7.xx versions include a new command and associated parameters for mapping phase space flow lines, new names for a few parameters, and a few new parameters for old commands. Special attention has been given to features relating to calculation of the collective potential and the generation of phase space trajectories including its effects. The VAX-based code management convention has been modified slightly to permit pre-compile options to be used in the include files as well as the program source files. The biggest change from v. 8.0 to v. 8.1 is the addition of code for HIGZ-based graphics; the new code and that using DI3000/GRAFMAKER ${ }^{1}$ are alternatives selectable at compilation. Other changes relate to improved control of smoothing options in the calculation of collective potential, fourier spectra, and mountain range plots.
\end{abstract}

\footnotetext{
${ }^{1}$ HIGZ is member Q120 of the CERN Program Library and DI3000 and GRAFMAKER are products of Precision Visuals, Inc.
} 


\section{Contents}

1 Introduction $\quad 3$

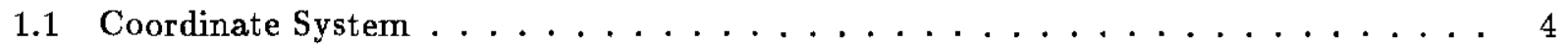

1.2 Difference Equations . . . . . . . . . . . . . . . . . . . . 4

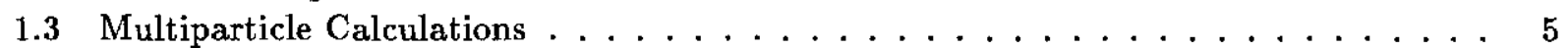

1.4 Flow Lines in Phase Space . . . . . . . . . . . . . . . . . 6

2 Program Organization and Data Requirements $\quad 7$

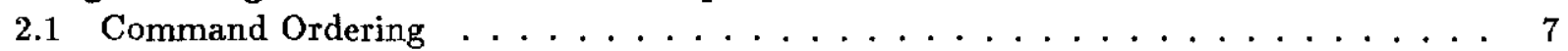

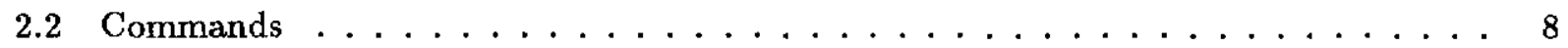

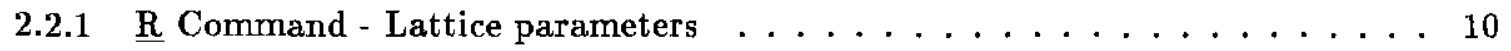

2.2.2 A Command - RF parameters . . . . . . . . . . . . . . 12

2.2.3 P Command - Initial distribution parameters . . . . . . . . . . . 15

2.2 .4 O Command - Graphical output options . . . . . . . . . . . . 17

2.2.5 T Command - Track distribution . . . . . . . . . . . . . . 20

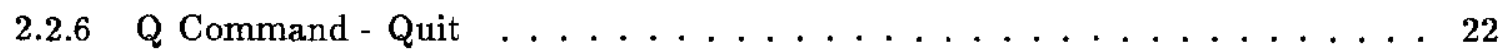

2.2 .7 D Command - Display . . . . . . . . . . . . . . . . . 22

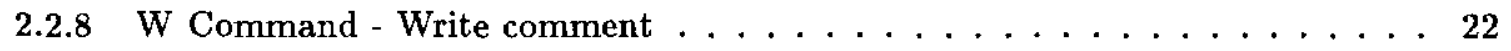

2.2 .9 H Command - History output . . . . . . . . . . . . . . 23

2.2.10 M \& N Commands - Save mountain range data \& Plot mountain range . . . 25

2.2.11 L Command - Low level feedback parameters . . . . . . . . . . . . . . 27

2.2.12 B Command - Beam-derived potential (self-force and $Z_{\|}$) . . . . . . 28

2.2 .13 F Command - Fourier transform . . . . . . . . . . . . . 30

2.2 .14 C Command - Flow contours . . . . . . . . . . . . . 31

2.2.15 K Command - Kill all or parts of the distribution . . . . . . . . . . . 32

2.2.16 0 - 9 Commands - User-written SHAZAM routines . . . . . . . . . 32

2.2.17 S Command - Save tracking parameters . . . . . . . . . . 33

2.2.18 G Command - Get tracking parameters . . . . . . . . . . . 33

3 Using The Program $\quad 34$

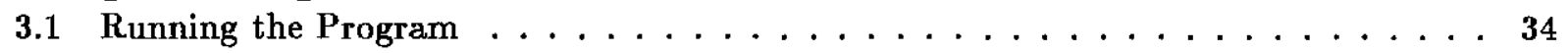

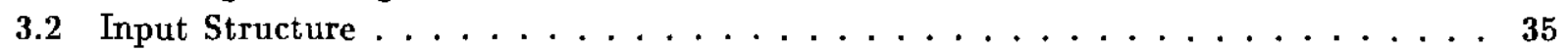

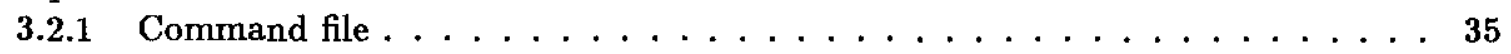

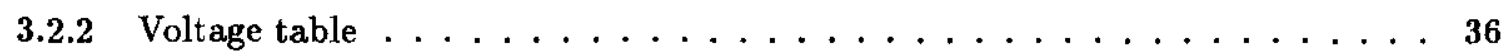

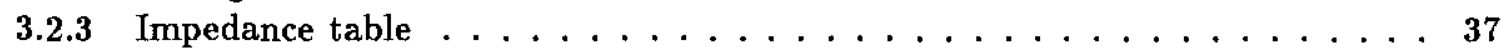

3.2 .4 Resonance table $\ldots \ldots \ldots \ldots \ldots \ldots$

4 Programming $\quad 30$

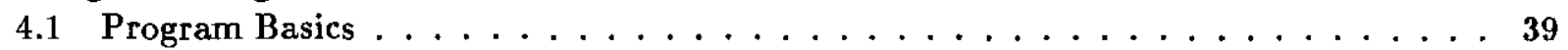

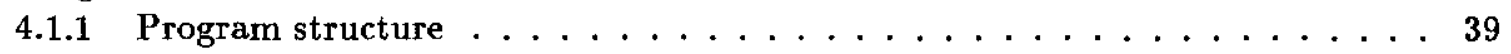

4.1 .2 Main tracking loop .................... 46 


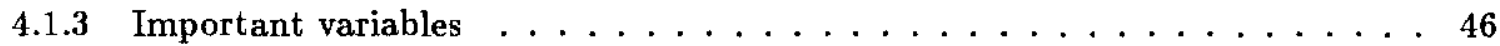

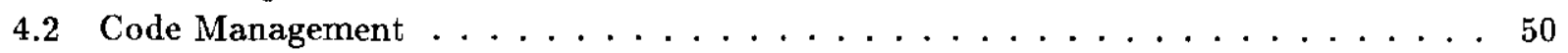

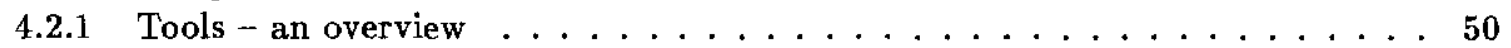

4.2 .2 Using the tools . . . . . . . . . . . . . . . . 51

A Post-Processing $\quad \mathbf{5 3}$

$\begin{array}{lc}\text { B Command Table Summary } & 58\end{array}$ 


\section{Chapter 1}

\section{Introduction}

The program ESME has been developed to model those aspects of beam behavior in a proton synchrotron that are governed by the radio frequency systems. It follows the evolution of a distribution in energy-azimuth coordinates turn-by-turn by iterating a map corresponding to the single-particle equations of motion. The map parameters may be updated each turn to reflect the action of the beam current on the individual particles through feedback loops, space charge, coupling impedance, etc. The code was initially developed during the years 1981-82 for the design of the Tevatron I Antiproton Source ${ }^{1}$ and documented for general use in $1984 .{ }^{[4]}$ In 1986 provisions were made for longitudinal coupling and space charge ${ }^{[5]}$ to investigate the usefulness of a $\gamma_{\mathrm{T}}$-jump in the Fermilab Booster. ${ }^{2}$ This version was adapted from the Cyber machines to the FPS-164 by Peter Lucas who made in the process a number of the improvements which entered into what was designated as v. 6.

The improvements made through 1987 were more or less incremental changes to the 1981 code. Version 7 was begun in 1987 to implement capabilities for simultaneous operation of more than two independent rf systems, explicit control over the separation between the accelerator reference orbit and the synchronous trajectory, and input using time units rather than beam turn number, ${ }^{[10]}$ a task in which Steve Stahl played a big part.

The initial motivation for v. 8 was to make plots of flow lines in phase space, either as the principal object or for additional information to be included on a scatter plot of the particle distribution. The decision to optionally include the effects of the collective potential on the flow lines has led to a careful rework of the routines for generating phase space curves and the routines for evaluating the collective potential. Benefits of this work extend beyond the new features. Although nearly all functions have been retained and data requirements are similar, the new code may not work with data prepared for earlier versions. The conceptual basis of ESME is discussed at length elsewhere. ${ }^{[11]}$ Version 8.1 differs from v. 8.0 primarily in the addition of an alternative to the graphics based on Precision Visuals DI3000 and GRAFMAKER products. It is possible to compile the code to use either these or HIGZ from the CERN Program Library according to a pre-compiler option. Some new parameters have been added to the $\mathbf{B}, \mathbf{F}$, and $\mathbf{N}$ commands to control optional smoothing in the collective potential calculation, the fourier analysis of the beam current, and the so-called mountain range plots, respectively. New parameters for the $\mathbf{R}$ command allow the magnetic field ramp to be specified either with respect to momentum or with respect to kinetic energy as in earlier versions of the program. This last addition exposed an area where the program design had been violated, complicating the implementation of a basically simple feature. The cleanest and least disruptive fix has been to rename a few parameters of the $\mathbf{R}$ command.

\footnotetext{
${ }^{1}$ Instructive examples of the capabilities of ESME can be found in reports relating to TeV I. Some of these will not be cited directly in the text but are included in the references. See for exarnple refs. [1], [2], and [3].

${ }^{2}$ There are examples of the calculation of collective effects resulting from the Booster studies. See refs. [6], [7], [8], and $[9]$.
} 
Unfortunately, this does mean that minor changes will be required for nearly all existing data sets. Versions 8.05 and 7.32 will remain available for a considerable period, but only outright errors will be corrected. All relevant and current material from the v. 8.0 User's Guide $^{[12]}$ and the update for v. $8.05^{[13]}$ are included in this writeup.

ESME has been used frequently to assess the efficiency of a given $\mathrm{rf}$ beam manipulation or to optimize system parameters. In this mode the user needs to specify fully technical details of various subsystems and derive various numerical measures of system performance from the particle distribution. Thus, many data are required, and the program must include numerical analysis features. Equally useful, however, are qualitative calculations designed to illustrate a concept or explore the feasibility of a novel approach. For such use the code should require a minimum of system-specific data and provide easy access to a variety of graphical output. When a qualitative investigation has been fruitful it is natural to proceed in steps of greater realism and specificity to a thorough modeling of the process. ESME is intended to serve effectively over a wide range of problem specificity by separating distinct functions so that each is invoked only as needed and by establishing reasonable defaults so that generic systems can be represented by a few data. Thus, a few lines of data may serve to get a first look at a system which can be studied in greater detail by overriding defaults with specific input and by invoking additional functions like, for example, those related to collective behavior or those related to numerical evaluation of the properties of the distribution.

\subsection{Coordinate System}

The basic coordinates internal to ESME are the azimuth of the particles and the difference of their energy from the synchronous energy at the time the radio frequency is passing through its synchronous phase. The azimuth is measured positive and negative with respect to a location where the rf voltage is applied:

$$
-180^{\circ} \leq \Theta_{i, n} \leq 180^{\circ},
$$

where $i$ is the particle index and $n$ is the turn number. The sense of $\Theta$ is clockwise positive, but the sense of the beam circulation is in the $-\Theta$ direction, counterclockwise. Typically a well-behaved bunch will be centered near $\Theta=0 \bmod 180 / h$. When there are $h$ equivalent bunches it is generally efficient to calculate for a single bunch with periodic boundaries set at $\Theta= \pm 180^{\circ} / h$. The unit for energy is $\mathrm{MeV}$; the unit for azimuth is radian internally but degree for input and output. The basic time unit of the difference equations is the turn number, but all input specification of parameter time dependence is for time in seconds.

One of the more difficult matters in using a general program for a wide range of problems is being able to specify the proper phases for all of the rf systems and the desired dependence of them on time or bunch centroid position. In v. 8.1 of ESME, where there may be systems with several different harmonic numbers all running at the same time, the phases of all systems are defined as their absolute phase at the synchronous time, i.e., the time when a particle acted upon by all of the rf systems receives the energy matched to the specified energy and/or radial position change for the turn. Options are selected to indicate whether phases are to be controlled by an input program, to follow $\dot{B}$, to follow a radial offset program, to maintain a system as Landau cavity, etc. Many common options have been provided; the program structure easily accommodates other schemes which one is willing to specify in a FORTRAN subroutine.

\subsection{Difference Equations}

The basis of the program is the pair of single particle difference equations

$$
\vartheta_{i, n}=\left[\frac{\tau_{s, n-1}}{\tau_{s, n}} \vartheta_{i, n-1}+2 \pi\left(\frac{\tau_{i, n}}{\tau_{s, n}}-1\right)\right]_{\bmod (\pi)}
$$




$$
E_{i, n}=E_{i, n-1}+e V\left(\varphi_{s, n}+h \vartheta_{i, n}\right)-e V\left(\varphi_{s, n}\right)
$$

giving the change in the azimuth and energy of particle $i$ during the $n$-th turn of the synchronous particle. The $n$-th energy increment comes at the end of the $n$-th turn. The relation between the synchronous beam circulation period $\tau_{s, n}$ and that of the $i$-th particle $\tau_{i, n}$ is treated exactly. Thus, the kinematic nonlinearity is treated exactly; this feature can be very important if the synchronous energy is close to the transition energy. The lattice nonlinearity is expressed as the dependence of $\gamma_{\mathrm{T}}$ on the momentum difference $\Delta p / p$ between the particle and the synchronous momentum. The rf potential is the sum of one or more sinusoidal terms so that the dynamic nonlinearity of a simple waveform is treated exactly and other forms of potential are treated in a fourier expansion of ten or fewer terms. ${ }^{3}$ The equation used in the program is generalized somewhat to permit multiple evenly spaced cavities per turn as an option and to allow the drift between cavities to be subdivided for more frequent application of the space charge kicks if the dynamics require it. The program ignores a slightly subtle distinction between $\vartheta_{i, n}$, the azimuthal variable in the mapping, and the periodic spatial variable $-\pi \leq \Theta_{i, n} \leq \pi$ which differs from it by an amount generally of no practical importance. The conversion from the mapping variable to the true azimuth $\Theta_{i, n}$ of the particle is

$$
\Theta_{i, n}=\frac{\tau_{s, n}}{\tau_{i, n}} \vartheta_{i, n} \approx\left(1-\eta \frac{\Delta p}{p}\right) \vartheta_{i, n}
$$

For most applications to a high energy synchrotron the $\eta$-term is small compared to one. There may be some case for which the distinction between $\vartheta$ and $\Theta$ will be important.

The treatment starts from the specification of a reference orbit of average radius $R_{e q}$ on which the mean normal magnetic field $\left\langle B_{y}\right\rangle$ is known. A particle which would follow the reference orbit has the reference momentum $p_{o}=2.997925 \cdot 10^{2}\left\langle B_{y}\right\rangle R_{e q}$ with $p_{o}$ in $\mathrm{MeV} / \mathrm{c}, R_{e q}$ in $\mathrm{m}$, and $\left\langle B_{y}\right\rangle$ in Tesla. The angular frequency of beam circulation on this orbit is $\Omega_{o}=\beta_{o} c / R_{e q}$ where $\beta_{o}$ is the Lorentz $\beta$. The variation of the guide field away from the reference orbit is completely characterized for the purposes of describing longitudinal motion by the momentum dependence of the path length for fixed guide field. At a minimum one need only specify $\gamma_{T}=$ const., a choice adequate in many instances. In many problems it is also correct to identify the radius of the synchronous trajectory $R_{s}$ with the reference radius $R_{e q}$. However, in applications like stacking or displacement acceleration where the synchronous trajectory may be offset radially, or even out of the beampipe entirely, it is necessary to take explicit account of the difference between them. ESME calculates all motion relative to a hypothetical synchronous particle. The synchronous frequency is calculated from momentum and radius. The momentum dependence of path length at the synchronous radius is determined from that given for the reference orbit.

In the section on parameters for the tracking routine there is mention of a parameter for choosing alternative versions of the difference equations. There are two choices, one which calculates $\Delta \vartheta$ as indicated above and one that equates it to the familiar approximation $-2 \pi \eta \Delta p / p$. Substantial time can be saved by using the simple difference equation if it is sufficient.

\subsection{Multiparticle Calculations}

The particle distribution at each turn is calculated from that on the prior turn by a single turn map applied to each particle independently. The program provides three general types of optional calculation on the properties of the distribution as a whole. The most common calculations are those which serve to quantify the properties of the distribution so that one can plot them as functions of time. Examples of such properties are first and second moments, emittance, fourier spectrum

\footnotetext{
${ }^{3}$ A little-used option mentioned in ref. [4] to provide a perfectly linear sawtooth waveform has been dropped because of severe conflict with the mechanism by which the new code finds the synchronous phase.
} 
of beam current, etc. Another type of calculation involves calculating feedback contributions to rf system parameters. ESME provides for phase feedback and feedback to rf amplitude. The third general class of collective calculation is the evaluation of beam induced voltages from space charge and longitudinal coupling impedance. The space charge calculation is based on a constant geometric factor relating average beam radius and average beampipe size. The longitudinal impedance can be characterized by an arbitrary table of real and imaginary part vs. frequency and/or a table of resonances defined by resonant frequency, $Q$, and real part at resonance.

When a resonance is represented by an impedance, the transient part of the excitation is neglected. However, this treatment does not realistically represent the driving terms for certain types of collective bunch motion. Therefore, response of a high- $Q$ resonator may also be modeled in the time domain (see ref. [14]). Reference [17] describes the use of this facility in modeling the coupled bunch instability.

\subsection{Flow Lines in Phase Space}

Although the emphasis during the development of ESME has been on the evolution of distributions, the plotting of flow lines is a complementary approach to visualizing phase space motion which can either replace or enhance scatter plots of the distribution. There are several variants on the contour plotting approach which have been added to the program at v. 8:

1. At selected intervals through the acceleration cycle one can produce a flow line map. If a distribution is tracked, it may be plotted along with the flow lines or its plotting can be suppressed. If no distribution is tracked between the times at which the flow line displays are generated, the flow lines can not reflect the action of a collective potential.

2. An initial set of flow lines can be generated and then tracked as a distribution itself, either with or without an accompanying finite emittance distribution. If a collective potential is calculated with such a composite distribution, the flow line component is ignored, but the evolution of the flow line component will include the effect of the collective potential.

3. A fine grain visualization of the result of non-adiabatic motion can be obtained by tracking a flow line type of distribution and plotting it along with flow lines representing the final system parameter values. The regions of phase space where non-adiabatic motion has been significant will show up as areas where the tracked and the freshly generated contours differ.

4. A specialized variant of the tracking of a contour-like distribution is available as an option to the command which sets up the initial phase space distribution. A distribution of particles just inside and just outside the bucket is available. It can be helpful, for example, in understanding the effects of small perturbations on particle loss. This is an enhanced version of a feature which had been available in versions v. 6.5 and before.

The difference equations are used to generate lines of flow in phase space corresponding to the $\mathrm{rf}$ and lattice parameters at a fixed time. If the flow lines are to reflect the influence of the collective potential derived from the charge distribution, there is an intrinsic contradiction when the longitudinal coupling impedance $Z_{\|}$has a real part because parameters change with time as the trajectory generating particle delivers or receives net energy to the impedance. Such a spiralling flow line does not represent what is happening to particles in the distribution because, in the usual case, the synchronous phase is adjusted slightly to keep the the bunch on the reference orbit. Therefore, when a single particle trajectory is calculated, the collective potential is reduced by its average value so that bounded trajectories will close. In the absence of a real component of impedance the flow lines are exactly lines of Hamiltonian flow. 


\section{Chapter 2}

\section{Program Organization and Data Requirements}

Data for ESME are generally acquired by NAMELIST reads dispersed among subroutines which segregate different program functions as much as practical. The subroutine reading a particular class of data will be called only if there is in the input stream a single-character command requesting the related program function. The data relating to different program functions or accelerator subsystems are also stored in different FORTRAN COMMON blocks. These blocks are initialized with values or switches to allow the code to proceed on the basis of a few input data. The initial values, or those read in over them, are retained unaltered ${ }^{1}$ so that a command may be repeated without reentering data that remain apropos. There are default values provided even for some quantities which are nearly always problem-specific so that the program may continue execution far enough to expose more than a single data error in a test run.

The following subsection calls attention to requirements on command ordering arising from data dependencies. Next is a subsection listing all of the ESME command characters with a short description of their functions. The subsection following the listing of the command codes contains in the same ordering the NAMELIST's associated with the commands and a brief description of the function of each input datum.

\subsection{Command Ordering}

The order in which the commands may appear in the data will generally be logically apparent. For example the $\mathbf{R}$ command which initiates the input of the basic lattice parameters and energy scale usually will appear before any other command. Several commands require this information to perform their own functions. The $\mathbf{A}$ command which brings in the rf parameters is generally the second command to appear. The command $\mathbf{P}$ which establishes the initial phase space distribution generally needs to be preceded by both. The command $\mathbf{B}$ which sets up the machinery for longitudinal impedance calculations needs the initial distribution to get the initial beam current distribution. Although by detailed knowledge of the internal organization of the program or by exploiting some specialized facilities it is possible to create correct data sets that do not observe a typical command ordering, it is generally safer to adhere to the order $\mathbf{R}, \mathbf{A}, \mathbf{P}, \mathbf{B}$ of first appearance for these commands. The $\mathbf{C}$ command, which generates phase space flow lines, must follow $\mathbf{R}$ and $\mathbf{A}$; if the flow lines are to take account of the collective potential produced by a bunch, it must follow $\mathbf{P}$ and $\mathbf{B}$ also. Other commands can usually be ordered arbitrarily.

\footnotetext{
${ }^{1}$ There are exceptions introduced to protect the unwary; see the $\mathbf{O}, \mathbf{T}$, and $\mathbf{K}$ commands.
} 


\subsection{Commands}

The principal functions of the program are activated by single-character commands appearing in the first position of a data record. Starting in the fifth position is an optional character field which serves to annotate the dataset itself and appears in the program output as a useful indication of the motivation for each step. The commands initiate a problem data read and/or an action upon available data. If data are requested by a subroutine invoked by the command, data in NAMELIST form will follow in the next record(s). Exceptions to this general rule can occur if the command is to call one of the optional user-coded subroutines and that subroutine uses another input technique. Also the title for graphical output which may be read as the result of an $\mathbf{O}$ command follows the /GRAPH/ namelist input data as a formatted character string.

The data requested or process initiated by a command is related to a separable subsystem of the accelerator or a distinct phase of the calculation. The course of program execution is governed by the order of the commands in the data stream; that is, the program is what is sometimes called "data-driven". Since the data are stored in functionally segregated common blocks, any subroutine that declares the appropriate common has access to any input datum.

Commands are listed below in four groups. The first group consists of the commands that will appear in almost every problem data set. They are listed in the order in which they are generally used. Interesting calculations may be made using these commands only. The second group contains commands to select output options. Those in the third group invoke special calculations, including if desired ones written by the user. The fourth pair is a save/restore pair for the entire state of the calculation so that a long calculation can be protected by check-pointing or a group of calculations sharing a common initial segment can proceed from the conditions at the end of that segment. Commands with strong order dependence are underlined. In the description of a command the first letter of a keyword is indicated in bold face to call attention to an association between the command character and its function. Because of evolution of the code over more than ten years some of the mnemonic connections are a bit weak, but less confusion is to be expected if old command names are not changed.

\section{List of Commands}

$\underline{\mathbf{R}}$ read in the lattice (Ring) parameters, magnetic field ramp, problem energies, etc. according to NAMELIST /RING/.

A read in the radio frequency (Acceleration) parameters according to NAMELIST /RF/.

P Populate the phase space with the initial distribution described by parameters read according to NAMELIST /POPUL8/.

O Select graphical Output options using parameters in NAMELIST /GRAPH/.

T Track distribution according to parameters read in NAMELIST /CYCLE/.

Q Quit the program.

D Display graphical output.

W Write comment into printed output.

H Select quantities to be plotted from History records according to NAMELIST /HISTRY/.

M Save azimuthal histograms of distribution for composition of Mountain-range plot. 
N Plot mountain-range data.

$\underline{L}$ Set Low-level parameters (to control feedback, $\gamma_{T^{-j u m p}}$, etc.) in NAMELIST /LLRF/.

B Setup collective potential calculation; read in Beam parameters in NAMELIST /SCHG/.

F Setup the fast Fourier transform of the theta distribution, control parameters in NAMELIST $/ \mathrm{FFT} /$.

C Form flow line Contours at time intervals or as initial distribution, control parameters in NAMELIST /FLOW/.

K Kill all or selected parts of the phase space distribution according to control parameters in the NAMELIST /KUTS/.

0-9 Enter subroutine SHAZAM at SHAZAM, SHAZAM1, SHAZAM2, ... to manipulate any quantity in COMMON storage in the program.

S Save tracking and control data.

G Get tracking and control data from a previous run. 


\subsubsection{R Command - Lattice parameters}

\begin{tabular}{|c|c|c|c|}
\hline \multicolumn{4}{|r|}{ R Command, Namelist/RING/ } \\
\hline \multirow[b]{2}{*}{ Variable } & \multicolumn{2}{|c|}{ Default } & \multirow[b]{2}{*}{ Description } \\
\hline & Value & Unit & \\
\hline REQ & None & $\mathrm{m}$ & The reference radius for the central orbit \\
\hline GAMMAT & None & - & Transition $\gamma$ \\
\hline ALPHA1 & None & - & $\begin{array}{l}\text { Coefficient of } \Delta p / p \text { in series expansion for length difference be- } \\
\text { tween particle trajectory and reference orbit }\end{array}$ \\
\hline ALPHA2 & None & - & Coefficient of $(\Delta p / p)^{2}$ in series for path length difference \\
\hline ALPHA3 & None & - & Coefficient of $(\Delta p / p)^{3}$ in series for path length difference \\
\hline W0I & None & $\mathrm{MeV}$ & Kinetic energy on the central orbit at $\mathrm{T}=\mathrm{TI}$ \\
\hline WOF & 0.0 & $\mathrm{MeV}$ & Kinetic energy on the central orbit at $\mathrm{T}=\mathrm{TF}$ \\
\hline P0I & None & $\mathrm{MeV} / \mathrm{c}$ & Momentum on the central orbit at $\mathrm{T}=\mathrm{TI}$ \\
\hline $\mathrm{P} 0 \mathrm{~F}$ & 0.0 & $\mathrm{MeV} / \mathrm{c}$ & Momentum on the central orbit at $T=T F$ \\
\hline TI & 0.0 & $\mathbf{s}$ & Start time of magnetic field change \\
\hline $\mathrm{TF}$ & 0.0 & s & End time of magnetic field change \\
\hline TSTART & 0.0 & s & Time at which tracking begins \\
\hline FRAC & 1. & - & $\begin{array}{l}\text { Determines azimuthal periodicity, calculation restricted to } \\
-180^{\circ} / \text { FRAC } \leq \vartheta \leq 180^{\circ} / \text { FRAC }\end{array}$ \\
\hline NCAV & 1 & - & Number of rf locations (default usually adequate) \\
\hline PIPRAD & 1.0 & $\mathrm{~m}$ & Radius of beam pipe for particle loss \\
\hline EBDRY & F & - & Sets absorbing beam pipe walls at REQ \pm PIPRAD \\
\hline DES & 0.0 & $\mathrm{MeV}$ & Energy offset of synchronous orbit relative to reference orbit \\
\hline KURVEB & 1 & - & $\begin{array}{l}\text { Magnetic field ramp from W0I to W0F or P0I to P0F: } \\
1 \text { - Linear } \\
\text { 2 - Increasing parabolic } \\
\text { 3 - Biased sinusoidal } \\
4 \text { - Decreasing parabolic } \\
5 \text { - Parabolic with final slope W0FDOT } \\
6 \text { - Parabolic with final slope P0FDOT } \\
7 \text { - Cubic with zero initial slope and curvature }\end{array}$ \\
\hline W0IDOT & 0.0 & $\mathrm{MeV} / \mathrm{s}$ & Slope of parabolic ramp at TI \\
\hline WOFDOT & 0.0 & $\mathrm{MeV} / \mathrm{s}$ & Slope of parabolic ramp at TF \\
\hline POIDOT & 0.0 & $\mathrm{MeV} / \mathrm{c} / \mathrm{s}$ & Slope of parabolic ramp at TI \\
\hline POFDOT & 0.0 & $\mathrm{MeV} / \mathrm{c} / \mathrm{s}$ & Slope of parabolic ramp at TF \\
\hline JNRAMP & F & - & $\begin{array}{l}\text { Establishes starting point of ramp as point at which program } \\
\text { finds itself-for smoothly piecing ramp segments together }\end{array}$ \\
\hline GMAJMP & $\mathbf{F}$ & - & Set $\gamma_{T^{-} \text {jump on }}$ \\
\hline KINDG & 1 & - & $\begin{array}{l}\text { Type of } \gamma_{\mathrm{T}} \text { variation: }{ }^{a} \\
1-\operatorname{Linear}\left(\gamma_{\mathrm{T}}=\operatorname{GAMPAR}(1)+\operatorname{GAMPAR}(2) * \mathrm{~T}\right) \\
2 \text { - Decreasing exponential } \\
\left(\gamma_{\mathrm{T}}=\operatorname{GAMPAR}(1)+\operatorname{GAMPAR}(3) *\left(1-e^{-\mathrm{T} / \operatorname{GAMPAR}(2)}\right)\right)\end{array}$ \\
\hline GAMPAR $(1: 3)$ & 0.0 & - & Coefficients for $\gamma_{\mathrm{T}}$ variation \\
\hline
\end{tabular}

${ }^{a} \mathrm{~T}=0$ corresponding to time at which $\mathbf{R}$ command is invoked with GMAJMP $=$. TRUE. 
The members of NAMELIST /RING/ are stored in COMMON /RINGP/ by SUBROUTINE RINGPAR, which also derives quantities like $\eta, \gamma_{\mathrm{T}}$, etc. depending only on lattice parameters. It is possible to distinguish the reference trajectory, of energy $E_{0}$, from the synchronous trajectory, of energy $E_{s}$, by specifying an offset from the reference energy. An example of a "minimum" $\mathbf{R}$ command might be:

$$
\$ \text { RING REQ }=1000 ., \text { GAMMAT }=18.75, \text { W0I }=150000 ., \text { FRAC }=159 . \$ E N D
$$

in which the lattice is characterized simply by a radius, $\gamma_{\mathrm{T}}$ value, and a field which corresponds to a reference energy of $150 \mathrm{GeV}$. FRAC is useful for restricting the range of consideration of ESME to a suitable period of the ring. In this case, since W0F is not specified, the default, W0F $=0.0$, indicates that the guide field does not change. In addition, the start time for this run is taken to be zero.

For TSTART $\leq$ TI the energy of the reference orbit is taken to be WoI, while for TSTART $\geq$ TF the energy of the reference orbit is WOF. Note that PIPRAD has no effect unless EBDRY $=$ T. If the $\gamma_{T^{-j u m p}}$ option has been invoked, then the $\gamma_{\mathrm{T}}$ is varied until the $\mathbf{R}$ command is issued with GMAJMP $=$ F. 


\subsubsection{A Command - RF parameters}

\begin{tabular}{|c|c|c|c|}
\hline \multicolumn{4}{|r|}{ A Command, Namelist / RF / } \\
\hline \multirow[b]{2}{*}{ Variable } & \multicolumn{2}{|c|}{ Default } & \multirow[b]{2}{*}{ Description } \\
\hline & Value & Unit & \\
\hline NRF & 1 & - & Number of active RF sources \\
\hline $\mathrm{H}(1: 10)$ & 1 & - & Harmonic numbers of sources (integers) \\
\hline $\mathrm{HW}(1: 10)$ & 1 & - & Voltage sources will be "active" for $-180^{\circ} / \mathrm{HW} \leq \theta \leq 180^{\circ} / \mathrm{HW}$ \\
\hline ISYNC & 0 & - & $\begin{array}{l}\text { Indicates synchronism condition to be imposed on RF: } \\
0 \text { - None, voltages and phases remain as programmed } \\
1 \text { - Phase of RF waveform shifted to synchronous, stable point } \\
2 \text { - Magnitude of RF waveform scaled to give correct synchronous } \\
\text { energy gain } \\
3 \text { - Source } 2 \text { Landau cavity to source } 1 \text {, synchronism assured only } \\
\text { for sources } 1 \text { and } 2\end{array}$ \\
\hline $\mathrm{VI}(1: 10)$ & 0.0 & MV & Voltage of source I at time TVBEG(I) \\
\hline $\mathrm{VF}(1: 10)$ & 0.0 & MV & Voltage of source I at time TVEND(I) \\
\hline TVBEG(1:10) & 0.0 & s & Time corresponding to beginning of $\mathrm{RF}$ voltage change \\
\hline TVEND $(1: 10)$ & 0.0 & $\mathbf{s}$ & Time corresponding to end of $\mathrm{RF}$ voltage change \\
\hline KURVE(1:10) & 0 & - & $\begin{array}{l}\text { Specifies type of RF voltage variation between times TVBEG } \\
\text { and TVEND: } \\
0 \text { - None, voltage maintained at VI(I) } \\
1 \text { - Linear } \\
2 \text { - Isoadiabatic } \\
3 \text { - Sigmoid } \\
4 \text { - Fit and cubic spline interpolation of voltage table }\end{array}$ \\
\hline VKON & $\mathrm{T}$ & - & Indicates whether programmed voltage curves are to be active \\
\hline $\operatorname{PSII}(1: 10)$ & 0 & $\operatorname{deg}$ & Phase of source I at time TPBEG(I) \\
\hline PSIF(1:10) & 0 & $\operatorname{deg}$ & Phase of source I at time TPEND(I) \\
\hline TPBEG(1:10) & 0.0 & $\mathbf{s}$ & Time corresponding to beginning of $\mathrm{RF}$ phase change \\
\hline TPEND(1:10) & 0.0 & s & Time corresponding to end of $\mathrm{RF}$ phase change \\
\hline $\operatorname{KURVP}(1: 10)$ & 0 & - & $\begin{array}{l}\text { Specifies type of RF phase variation between times TPBEG and } \\
\text { TPEND: } \\
0 \text { - None, phase maintained at PSII(I) } \\
1 \text { - Linear } \\
2 \text { - Quadratic } \\
4 \text { - Fit and cubic spline interpolation of phase table }{ }^{a}\end{array}$ \\
\hline PHKON & $\overline{\mathbf{F}}$ & - & Indicates whether or not phase curves are to be active \\
\hline
\end{tabular}

${ }^{a}$ Fit to values read from file. See Section3.2.2. 


\begin{tabular}{|c|c|c|c|}
\hline \multicolumn{4}{|c|}{ A Command, Namelist /RF/, continued } \\
\hline \multirow[b]{2}{*}{ Variable } & \multicolumn{2}{|c|}{ Default } & \multirow[b]{2}{*}{ Description } \\
\hline & Value & Unit & \\
\hline FRI $(1: 10)$ & & $\mathrm{MHz}$ & Frequency of source I at time TFBEG(I) \\
\hline FRF $(1: 10)$ & & $\mathrm{MHz}$ & Frequency of source I at time TFEND(I) \\
\hline TFBEG(1:10) & 0.0 & $\mathbf{s}$ & Time corresponding to beginning of frequency change \\
\hline $\operatorname{TFEND}(1: 10)$ & 0.0 & s & Time corresponding to end of frequency change \\
\hline KURVF $(1: 10)$ & 0 & - & $\begin{array}{l}\text { Specifies type of frequency variation between times TFBEG and } \\
\text { TFEND: } \\
0 \text { - None, frequency maintained at FRI(I) } \\
1 \text { - Linear } \\
2 \text { - Quadratic } \\
4 \text { - Fit and cubic spline interpolation of frequency table }\end{array}$ \\
\hline FRKON & $\mathbf{F}$ & - & Indicates whether frequency curves are to be active \\
\hline CNTINU & F & - & $\begin{array}{l}\text { Sets the starting voltage, phase and/or frequency for any active } \\
\text { sources as the current values-for smoothly piecing curve segments } \\
\text { together }\end{array}$ \\
\hline VMATCH(1:10) & $\mathrm{F}$ & - & $\begin{array}{l}\text { For source } \mathrm{I} \text {, VMATCH }(\mathrm{I})=\mathrm{T} \text { results in the } \mathrm{VI}(\mathrm{I}) \text { being set so } \\
\text { that source } \mathrm{I} \text { is matched to the current distribution emittance }{ }^{b}\end{array}$ \\
\hline HOLDBH & $\mathrm{F}$ & - & $\begin{array}{l}\text { If true, then voltage is to be varied so that bucket height due to } \\
\text { source } 1^{c} \text { is multiplied by HDECR on successive turns }\end{array}$ \\
\hline $\mathrm{HDECR}$ & 1.0 & - & $\begin{array}{l}\text { Factor by which bucket height (for source } 1 \text { ) is to be adjusted on } \\
\text { successive turns if HOLDBH }=\mathrm{T}\end{array}$ \\
\hline HOLDBA & $\mathbf{F}$ & - & $\begin{array}{l}\text { If true, then voltage is to be varied so that bucket area due to } \\
\text { source } 1^{c} \text { is multiplied by SDECR on successive turns }\end{array}$ \\
\hline SDECR & 1.0 & - & $\begin{array}{l}\text { Factor by which bucket area (for source } 1 \text { ) is to be adjusted on } \\
\text { successive turns if HOLDBA }=T\end{array}$ \\
\hline PHISLIM & .95 & - & $\begin{array}{l}\text { Voltage may not be reduced such that } \sin \phi_{s}>\text { PHISLIM using } \\
\text { options HOLDBH and HOLDBA }\end{array}$ \\
\hline PHSLIP & $\mathbf{F}$ & - & $\begin{array}{l}\text { Flag indicating that the phase of at least one source is to be varied } \\
\text { to correspond to a momentum offset from the synchronous value } \\
\text { (see DELTRF) }\end{array}$ \\
\hline DELTRF $(1: 10)$ & 0.0 & - & Momentum offset $(\Delta p / p)$ at which source $\mathrm{I}$ is to be operated \\
\hline
\end{tabular}

Values read from fle. See Section 3.2 .2 .

${ }^{b}$ Which means, in this instance, that the $\mathrm{P}$ command, or its equivalent, should precede the $\mathrm{A}$ command.

'The algorithms used to maintain the bucket height and area consider only a single source.

The members of NAMELIST /RF / are read in SUBROUTINE RFPROG, and stored in COMMON /RFP/. Up to 10 independent voltage sources may be specified. An example of a minimum A command might be:

$$
\$ R F \mathrm{H}(1)=1113, \mathrm{VI}(1)=.100, \mathrm{PSII}(1)=235.0 \$ \mathrm{END}
$$

Here, one voltage is specified by a minimum set of parameters. Note that $H(I)$ is an integer (as is $\mathrm{HW}(\mathrm{I}))$. Since RF manipulations are at the heart of ESME, this command can become rather lengthy and involved; the example given above is exceptionally brief. Just as in the case of the magnetic field ramp - specified in the $\mathbf{R}$ command - at times prior to the start of a programmed variation the relevant quantity is maintained at the initial value, while at times after the indicated 
end of a programmed curve, the quantity is maintained at the final value. This makes it easier to specify multiple curves in unequal time steps.

The values of the programmed phase curves are to be distinguished from the phase of a given harmonic at the synchronous particle, though they may be the same. For example, a user could represent any periodic waveform (in a Fourier expansion of up to 10 terms) simply by specifying the correct relative phases and amplitudes of the voltages. The waveform could be modified over time by specifying the variations of the voltages, phases, and/or frequencies. ${ }^{2}$ Finally, the user could specify that the program search for a "synchronous" point on the resultant waveform using ISYNC. Option ISYNC $=1$ will result in the program searching for a stable value of the phase, stored internally in the program as PHIS, in units of $2 \pi$ around the ring, and output as degrees of "shift" of the sum voltage waveform. Option ISYNC $=2$ will cause the resultant waveform to be scaled to give only the correct magnitude of voltage at the synchronous particle, not necessarily at a stable slope, since the phases of the voltage sources at the synchronous particle remain at their programmed values. The Landau cavity option, ISYNC $=3$, will vary the phases of voltage sources 1 and 2 , and the magnitude of voltage source 2 , so that the first and second derivatives of the voltage vanish at the synchronous particle. The phases and magnitudes of other voltages are not altered, though they will be included in the iteration of the difference equation if NRF $>2$. As noted in the table, the options activated by HOLDBH and HOLDBA only apply to source 1.

\footnotetext{
${ }^{2}$ In cases in which a frequency and a phase variation are specified for the same source, the phase variation takes precedence.
} 


\subsubsection{P Command - Initial distribution parameters}

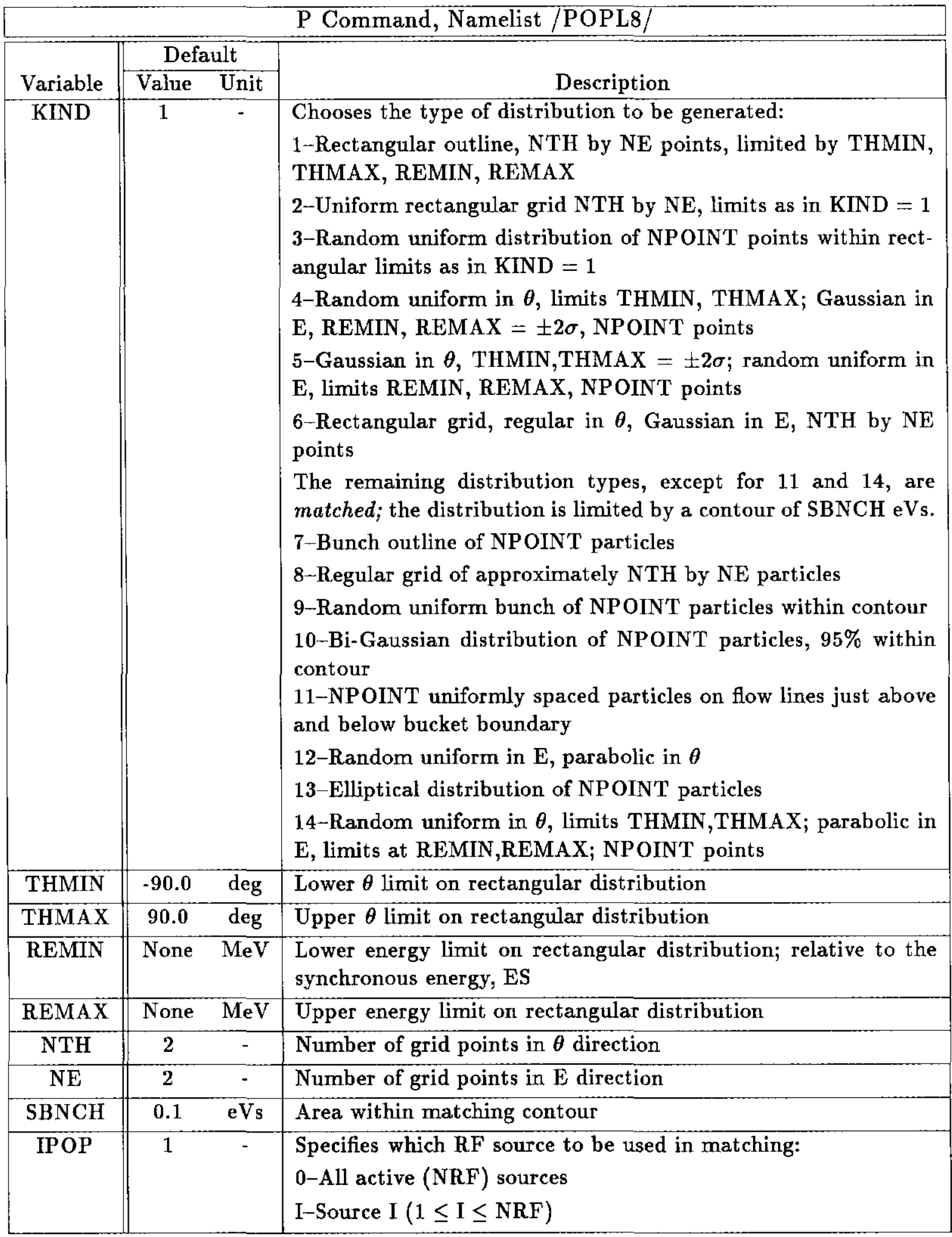




\begin{tabular}{|c|c|c|c|}
\hline \multicolumn{4}{|c|}{ P Command, Namelist /POPL8/, continued } \\
\hline \multirow[b]{2}{*}{ Variable } & \multicolumn{2}{|c|}{ Default } & \multirow[b]{2}{*}{ Description } \\
\hline & Value & Unit & \\
\hline THOFF & & $\operatorname{deg}$ & $\begin{array}{l}\text { Amount to displace distribution generated in current call to } \\
\text { POPUL8 in } \theta \text { direction }\end{array}$ \\
\hline EOFF & 0.0 & $\mathrm{MeV}$ & $\begin{array}{l}\text { Amount to displace currently generated distribution in } \mathrm{E} \text { direc- } \\
\text { tion }\end{array}$ \\
\hline THTRAN & 0.0 & $\operatorname{deg}$ & $\begin{array}{l}\text { Amount to displace all particles (generated in this and previous } \\
\text { calls to POPUL8) in } \theta \text { direction }\end{array}$ \\
\hline ETRAN & 0.0 & $\mathrm{MeV}$ & Amount to displace all particles in $\mathrm{E}$ direction \\
\hline NPOINT & 1 & - & $\begin{array}{l}\text { Number of particles generated for all distributions except } \\
\text { KIND }=1,2,6,8 \text {, in which NTH and NE are used }\end{array}$ \\
\hline PARTION & $\mathrm{F}$ & - & $\begin{array}{l}\text { "Partition" distribution into separate classes;" each separate use } \\
\text { of the } \mathbf{P} \text { command with PARTION = T introduces a new parti- } \\
\text { tion }\end{array}$ \\
\hline RENORM & $\mathrm{T}$ & - & $\begin{array}{l}\text { Calculate ANORM for matched bunch so that EPSILON } \equiv \\
\text { SBNCH }^{b}\end{array}$ \\
\hline SEED & .314159 & - & Seed for random distributions \\
\hline
\end{tabular}

${ }^{a}$ Different classes of particles may be plotted with distinct symbols.

${ }^{b}$ Default resets to .FALSE. after first bunch.

The members of NAMELIST /POPL8/ are read in SUBROUTINE POPUL8, and stored in COMMON /POPLATE/. If one wanted to populate a bi-Gaussian distribution of 100 particles, with an emittance (95\%) matched to RF source 1 of $.02 \mathrm{eV}$-s, then the $\mathbf{P}$ command would be:

$\$ P O P L 8 \mathrm{KIND}=10, \mathrm{NPOINT}=100, \mathrm{IPOP}=1, \mathrm{SBNCH}=.02 \$ \mathrm{END}$

For multi-bunch simulations, in which several distributions are needed with the same parameters but in different positions, it is sufficient to simply re-issue the $\mathbf{P}$ command with only the desired position offset. For example:

$$
\text { \$POPL8 THTRAN }=45.0, \text { ETRAN=0.0 } \$ E N D
$$

Since NAMELIST members which do not appear in the input remain unchanged, one may exploit this property to abbreviate the amount of input. In particular, expeditious use of THTRAN and ETRAN can make it unnecessary to explicitly declare the position of each group of particles.

The switch RENORM will default to true only for the first generation of a matched bunch, because it will generally be necessary to get the proportionality between rms emittance and $95 \%$ containment area once. One should be aware of this feature of the program to avoid confusion about the meaning of the reported emittance and remember that it can be kept under user control by explicit setting of RENORM. 


\subsubsection{O Command - Graphical output options}

\begin{tabular}{|c|c|c|c|}
\hline \multicolumn{4}{|r|}{ O Command, Namelist /GRAPH/ } \\
\hline \multirow[b]{2}{*}{ Variable } & \multicolumn{2}{|c|}{ Default } & \multirow[b]{2}{*}{ Description } \\
\hline & Value & Unit & \\
\hline MPLOT & 1000 & turn & Output every MPLOT turns \\
\hline IDEV & 1 & - & Virtual device number for graphical output ${ }^{a}$ \\
\hline POSTP & $\mathbf{F}$ & - & $\begin{array}{l}\text { Write all data in COMMON blocks to unit } 18 \text {; do not call plotting } \\
\text { routine. }\end{array}$ \\
\hline TITLE & $\mathrm{F}$ & - & $\begin{array}{l}\text { Indicates that line immediately following NAMELIST input is to } \\
\text { be used as a plot title } e^{b}\end{array}$ \\
\hline PLTSW & & & Select plot options: \\
\hline (1) & $\mathrm{T}$ & - & Draw phase space plot \\
\hline$(2)$ & $\mathbf{T}$ & - & Plot phase space points (different symbol for each class) \\
\hline (3) & $\mathbf{F}$ & - & Interconnect points within each class \\
\hline (4) & $\mathrm{F}$ & - & Draw lines at centroid and $\pm \sigma$ \\
\hline (5) & $\mathrm{F}$ & - & Draw voltage waveform \\
\hline (6) & $\mathrm{F}$ & - & Set plot boundaries to turning points of contour \\
\hline (7) & $\mathbf{F}$ & - & Suppress captions, axis labels, etc. \\
\hline (8) & $\mathbf{T}$ & - & Plot $\theta$ histogram \\
\hline (9) & $\mathrm{F}$ & - & Set $\theta$ histogram limits to turning points of contour \\
\hline$(10)$ & $\mathrm{T}$ & - & Plot E histogram \\
\hline (11) & $\mathrm{F}$ & - & Set $\mathrm{E}$ histogram limits to turning points of contour \\
\hline$(12)$ & F & - & Plot fourier amplitudes \\
\hline (13) & $\mathbf{F}$ & - & Include phases in plot of fourier spectrum \\
\hline (14) & $\mathbf{F}$ & - & Plot space charge energy loss (per turn) vs. $\theta$ \\
\hline (15) & $\mathbf{F}$ & - & Include distribution histogram on space charge plot \\
\hline$(16)$ & $\mathrm{F}$ & - & Plot high-Q resonator voltage \\
\hline$(17)$ & $\mathrm{T}$ & - & Start bucket contour at unstable fixed point ${ }^{c}$ \\
\hline$(18)$ & $\mathrm{T}$ & - & Start bucket contour at stable fixed point at $\mathrm{E}=\mathrm{E}_{\mathbf{s}}+\mathrm{H}_{\text {bckt }}$ \\
\hline (19) & $\mathbf{F}$ & - & Plot flow line points (different symbol for each class) \\
\hline$(20)$ & $\mathbf{F}$ & - & Interconnect flow line points within each class \\
\hline NPJMP & 1 & - & In phase space plot, plot only every NPJMPth point \\
\hline KLPLOT & 0 & - & $\begin{array}{l}\text { Select classes in phase space plot and projections (see Sec. 2.2.3) } \\
0 \text {-All classes plotted } \\
1 \leq \text { KLPLOT } \leq \text { KLASSES-Plot class KLPLOT only }\end{array}$ \\
\hline IRF & 1 & - & $\begin{array}{l}\text { Selects voltage source for contour plotting: } \\
<0 \text {-No contour plotted } \\
0 \text {-All active (NRF) sources } \\
1-10 \text {-Source IRF }(1 \leq \mathrm{IRF} \leq \mathrm{NRF})\end{array}$ \\
\hline
\end{tabular}

${ }^{a}$ DI-3000 specific; see 3.1 .

${ }^{6}$ This is an exception to the maintenance of NAMELIST input; TITLE is set to .FALSE. after every execution of the $O$ command.

${ }^{c}$ At least one of PLTSW(17) or PLTSW(18) must be true for ICONTUR=1 else program sets both .TRUE. 


\begin{tabular}{|c|c|c|c|}
\hline \multicolumn{4}{|c|}{ O Command, Namelist /GRAPH/, continued } \\
\hline \multirow[b]{2}{*}{ Variable } & \multicolumn{2}{|c|}{ Default } & \multirow[b]{2}{*}{ Description } \\
\hline & Value & Unit & \\
\hline ICONTUR & 1 & - & $\begin{array}{l}\text { Select the type of reference contour to plot on phase space plot } \\
0 \text {-No contour } \\
\text { 1-Bucket contour } \\
\text { 2-Contour of initial bunch area SBNCH } \\
\text { 3-Contour of the specified area REFAREA } \\
\text { 4-Contour containing } 95 \% \text { of the particles } \\
\text { 5-Flow lines chosen by LINES, ELMIN, and ELMAX }\end{array}$ \\
\hline REFAREA & 0.1 & $\mathrm{eVs}$ & Area of reference contour for ICONTUR $=3$ \\
\hline LINES & 1 & - & Number of flow lines for ICONTUR $=5$ \\
\hline ELMIN & 0. & $\mathrm{MeV}$ & Energy above $E_{s}$ for first flow line ${ }^{a}$ \\
\hline ELMAX & 1. & $\mathrm{MeV}$ & Energy of top flow line \\
\hline THPMIN & $0.0^{b}$ & $\operatorname{deg}$ & Lower $\theta$ limit for phase space plot \\
\hline THPMAX & 0.0 & deg & Upper $\theta$ limit for phase space plot \\
\hline DEPMIN & $0.0^{c}$ & $\mathrm{MeV}$ & Lower E limit for phase space plot \\
\hline DEPMAX & 0.0 & $\mathrm{MeV}$ & Upper E limit for phase space plot \\
\hline IEREF & 1 & - & $\begin{array}{l}\text { Determines energy origin for phase space: } \\
\text { 1-E0, the reference energy (often = ES) } \\
\text { 2-ES, the synchronous energy } \\
\text { 3-EBAR, the average particle energy } \\
\text { 4-EREF, the reference particle energy }\end{array}$ \\
\hline NBINTH & 50 & - & The number of bins for the $\theta$ histogram \\
\hline THBMIN & $0.0^{e}$ & deg & Lower limit for $\theta$ histogram \\
\hline THBMAX & 0.0 & $\operatorname{deg}$ & Upper limit for $\theta$ histogram \\
\hline NBINE & 50 & - & The number of bins for the E histogram \\
\hline EBMIN & $0.0^{f}$ & $\mathrm{MeV}$ & Lower limit for $\mathrm{E}$ histogram \\
\hline EBMAX & 0.0 & $\mathrm{MeV}$ & Upper limit for E histogram \\
\hline IFBMIN & 1 & - & Lower limit for FFT plot \\
\hline IFBMAX & $0^{g}$ & - & Upper limit for FFT plot \\
\hline SCBMIN & $0.0^{h}$ & - & Lower $\theta$ limit for space-charge plot \\
\hline SCBMAX & 0.0 & - & Upper limit for space-charge plot \\
\hline RBMIN & $0.0^{i}$ & - & Lower $\theta$ limit for resonator voltage plot \\
\hline RBMAX & 0.0 & - & Upper limit for resonator voltage plot \\
\hline DTHCURV & 0.0 & $\operatorname{deg}$ & Amount by which contour will be moved in $\theta$ direction \\
\hline DECURV & 0.0 & $\mathrm{MeV}$ & Amount by which contour will be moved in $\mathrm{E}$ direction \\
\hline
\end{tabular}

${ }^{a}$ Program will modify ELMIN $<0$.

${ }^{b}$ THPMIN and THPMAX both 0.0 results in a pllotting range $-180^{\circ} / \mathrm{FRAC} \leq \theta \leq 180^{\circ} / \mathrm{FRAC}$.

${ }^{c} D E P M I N$ and DEPMAX both 0.0 results in a plotting range approximately the range of particle energies

${ }^{d} \mathrm{~A}$ particle which ESME tracks from the origin $(0, \mathrm{ES})$ as a reference.

'Limits of 0.0 for both THBMIN and THBMAX result in the plot range being the same as for the phase space plot.

${ }^{f}$ Limits of 0.0 for both EBMIN and EBMAX result in the plot range being the same as for the phase space plot.

${ }^{g}$ IFBMAX $=0$ results in the upper limit being the greatest Fourier harmonic computed.

${ }^{h}$ Limits of 0.0 for both SCBMIN and SCBMAX result in the range for the plot being $\pm 180^{\circ} / \mathrm{FRAC}$.

'Limits of 0.0 for both RBMIN and RBMAX result in the range being $\pm 180^{\circ} / \mathrm{FRAC}$. 


\begin{tabular}{|c|c|c|c|}
\hline \multicolumn{4}{|c|}{ O Command, Namelist / GRAPH/, continued } \\
\hline \multirow[b]{2}{*}{ Variable } & \multicolumn{2}{|c|}{ Default } & \multirow[b]{2}{*}{ Description } \\
\hline & Value & Unit & \\
\hline DELCON & .01 & - & Determine bucket to precision DELCON ${ }^{*} 360^{\circ} \mathrm{w} / \mathrm{RF}$ \\
\hline KNTLIM & 500000 & - & $\begin{array}{l}\text { Number of iterations of difference equation which will be at- } \\
\text { tempted to close contour }\end{array}$ \\
\hline IMETA & 0 & & $\begin{array}{l}\text { Directs graphic output (HIGZ only): } \\
<0 \text { - Output written to HIGZ metafile } \\
0 \text { - Output to device selected by IDEV }{ }^{a} \\
>0 \text { - Output to both HIGZ metafile and selected IDEV }\end{array}$ \\
\hline XCRNR & 135. & 0.001 & $\begin{array}{l}\text { Fraction of full width of plot frame between lefthand edge and } \\
\text { bottom left corner of plot }\end{array}$ \\
\hline YCRNR & 69.0 & 0.001 & $\begin{array}{l}\text { Fraction of full height of plot frame between bottom edge and } \\
\text { bottom of plot }\end{array}$ \\
\hline XAXISL & 750. & 0.001 & Plot width as a fraction of frame width \\
\hline YAXISL & 475 . & 0.001 & Plot height as a fraction frame height \\
\hline
\end{tabular}

${ }^{a}$ can be DI3000 metafile if HIGZ_DI3000 is used

The members of NAMELIST /GRAPH/ are read in SUBROUTINE GRAFSET, and stored in COMMON /GRAFIX/. The actual graphical output can be generated either during or after processing. The plotting routines written specifically for this version of ESME use GRAFMAKER under DI-3000. ${ }^{3}$ The post-processor is described later in Appendix A. Users wishing to process ESME data independently or with different graphics routines may find it of some use.

The options enabled by the $\mathbf{O}$ command are largely self-explanatory; the default PLTSW settings result in the output of a phase space plot of the distribution and the bucket due to RF source 1 , as well as plots of the projections of the distribution along the $\theta$ and $E$ directions. An example of an $O$ command requesting such output every 100 turns might be:

\begin{tabular}{|ll|}
\hline \$GRAPH & $\begin{array}{l}\text { MPLOT }=100, \text { THPMIN }=-10.0, \\
\text { DEPMMAX }=10.0\end{array}$ \\
\end{tabular}

in which the limits are appropriate ones chosen by the user. In addition to the graphical output generated as a result of the $O$ command, the first and second moments of the distribution are computed and output, as well as a number of other system parameters. The moments included on the plots are derived from the particles which are in the class(es) being plotted and within the plot limits. The moments printed in the standard output are those for the entire distribution. The "default" limits for many of the plots serve as flags to the plotting routine to choose reasonable limits. Note that the limits of the phase space projection plot (THBMIN, EBMIN, etc.) are necessary only if they are different from the phase space plot limits. The parameter DELCON is included to allow the user to either determine the separatrix arbitrarily closely or to save processing time, since in certain situations the routine which determines the "bucket" in ESME is required to perform many iterations of the difference equations in order to determine the separatrix to the specified accuracy. In those instances in which the contour-drawing routine is unacceptably slow (or unable) to find a contour, it may be useful to set KNTLIM to some lower number. The last five entries in the table apply only to the HIGZ version of the graphics. The default values give a satisfactory result for portrait orientation on an $8.5 \times 11$ sheet, but may need to be adjusted for other devices.

\footnotetext{
${ }^{3}$ GRAFMAKER and DI-3000 are trademarks of Precision Visuals, Inc.
} 


\subsubsection{T Command - Track distribution}

\begin{tabular}{|c|c|c|c|}
\hline & & & Jommand, Namelist /CYCLE/ \\
\hline & $\overline{\text { Defa }}$ & & \\
\hline Variable & Value & Unit & Description \\
\hline TSTOP $^{a}$ & 0.0 & $\mathbf{s}$ & Time at which to stop tracking \\
\hline TTRACK $^{b}$ & 0.0 & s & Duration of time to track \\
\hline MSTEP & 100 & - & Number of tracking steps (minimum) per synchrotron period \\
\hline ACCELO & 1.0 & - & Number of beam turns per tracking step (maximum) ${ }^{c}$ \\
\hline LGRTHM & 1 & - & $\begin{array}{l}\text { Select difference equations used in tracking } \\
\text { 1-Complete kinematics, expand path length to maximum order } \\
\text { using input coefficients ALPHAn }{ }^{d} \\
\text { 2-Use the simplified difference equation } \\
\vartheta_{i, n}=\frac{\tau_{d, n}}{\tau_{d, n-1}} \vartheta_{i, n-1}+2 \pi \eta \frac{\Delta p}{p}\end{array}$ \\
\hline $\operatorname{ITRAP}(1: 4)$ & 0 & - & $\begin{array}{l}\text { Indicates a condition for which tracking should be interrupted } \\
\text { before time indicated by TTRACK or TSTOP: } \\
\text { 0-No trap } \\
\text { 1-Trap on minimum bunch width } \\
\text { 2-Trap on minimum bunch height } \\
\text { 3-Trap for } \eta=\text { ETATRP (tolerance } \Delta \eta / \eta= \pm .01 \text { ) } \\
\text { 4-Trap for }\left|\phi_{s}\right|=\text { PHISTRP (tolerance } \Delta \phi_{s}= \pm .005 \text { ) } \\
\text { 5-Trap for } \eta>0 \text { (transition crossing) } \\
\text { 10-19-Call SUBROUTINE SHAZAM, enter at SHAZAM, } \\
\text { SHAZAM1, SHAZAM2, .. following every iteration of the dif- } \\
\text { ference equations }\end{array}$ \\
\hline ETATRP & .001 & - & For ITRAP $=3$; tracking stopped when $\eta=$ ETATRP \\
\hline PHISTRP & .95 & - & For ITRAP $=4$; tracking stopped when $\left|\sin \phi_{s}\right|=$ PHISTRP \\
\hline MGRACE & 0 & - & $\begin{array}{l}\text { Allow a "grace period" of MGRACE turns before trapping con- } \\
\text { ditions are checked }\end{array}$ \\
\hline HISTRY & $\mathrm{F}$ & - & $\begin{array}{l}\text { Write a history record to unit } 9 \text { following every iteration of the } \\
\text { difference equations }\end{array}$ \\
\hline MOMNTS & $\mathbf{F}$ & - & $\begin{array}{l}\text { Compute the moments of the distribution following every itera- } \\
\text { tion of the difference equations }\end{array}$ \\
\hline BBDRY & $\mathbf{F}$ & - & $\begin{array}{l}\text { Remove particles tracked outside of region }-180^{\circ} / \text { FRAC } \leq \theta \leq \\
180^{\circ} / \text { FRAC }\end{array}$ \\
\hline
\end{tabular}

a TSTOP is set to 0.0 when tracking is completed, or interrupted by an ITRAP option.

${ }^{b}$ TSTOP takes precedence; if TSTOP $=0.0$, then TTRACK determines duration of tracking.

'Tracking will proceed at the nearest integer to ACCELO (not $<1$ ), limited by MSTEP.

${ }^{d}$ See $\mathrm{R}$ command

See Section 3.2

The members of NAMELIST /CYCLE/ are read in SUBROUTINE CYCPROG and stored in COMMON /CYCLP/. The options in the $\mathbf{T}$ command direct the flow of processing in SUBROUTINE CYCPROG, which iterates the difference equations for the particles. A typical $\mathbf{T}$ command line might be:

$$
\text { \$CYCLE TTRACK =.001, LGRTHM =2, HISTRY =T, MOMNTS =T \$END }
$$

in which tracking is specified to take place for .001 seconds of simulated time, with a calculation 
of distribution moments and a write to the history file at every iteration of the difference equations. Note that either TSTOP or TTRACK may be used to specify the duration of tracking, though TSTOP takes precedence. Also, since an interruption in tracking by an ITRAP option (for ITRAP $<6$ ) results in TSTOP being set equal to 0.0 , the stop time must be re-specified in a subsequent $\mathbf{T}$ command. Any condition which halts or interrupts tracking is checked at most once per turn, so tracking duration may be as much as one beam circulation period longer than specified by TSTOP or TTRACK. Four ITRAP variables are provided to allow for multiple traps and/or calls to SHAZAM routines during tracking. If $10 \leq$ ITRAP $\leq 19$, then a call is made to the appropriate SHAZAM entry point following every turn (or ACCEL turns, if ACCEL0 > 1). Tracking is not stopped. 


\subsubsection{Q Command - Quit}

The $\mathbf{Q}$ command directs ESME to cease processing. No more commands are read.

\subsubsection{Command - Display}

The $\mathbf{D}$ command directs ESME to generate graphical output at the point at which the command is issued. The form of the output is specified by the most recent $\mathbf{O}$ command. The $\mathbf{D}$ command is useful for generating output at a particular point in a calculation, since the $\mathbf{O}$ command itself only provides output every MPLOT turns.

\subsubsection{W Command - Write comment}

The $\mathbf{W}$ command simply directs the program to echo the characters following $\mathrm{W}$ (on the same line and after four spaces) to the standard output. It is intended to provide the user with the ability to insert comments into an input dataset which appear as comments in the output file also. 


\subsubsection{H Command - History output}

\begin{tabular}{|c|c|c|c|}
\hline \multicolumn{4}{|r|}{ H Command, Namelist/HISTRY/ } \\
\hline \multirow[b]{2}{*}{ Variable } & \multicolumn{2}{|c|}{ Default } & \multirow[b]{2}{*}{ Description } \\
\hline & Value & Unit & \\
\hline IDEV & 1 & - & The virtual device number for output ${ }^{a}$ \\
\hline $\operatorname{NPLT}(1: 2,1: 50)$ & & - & 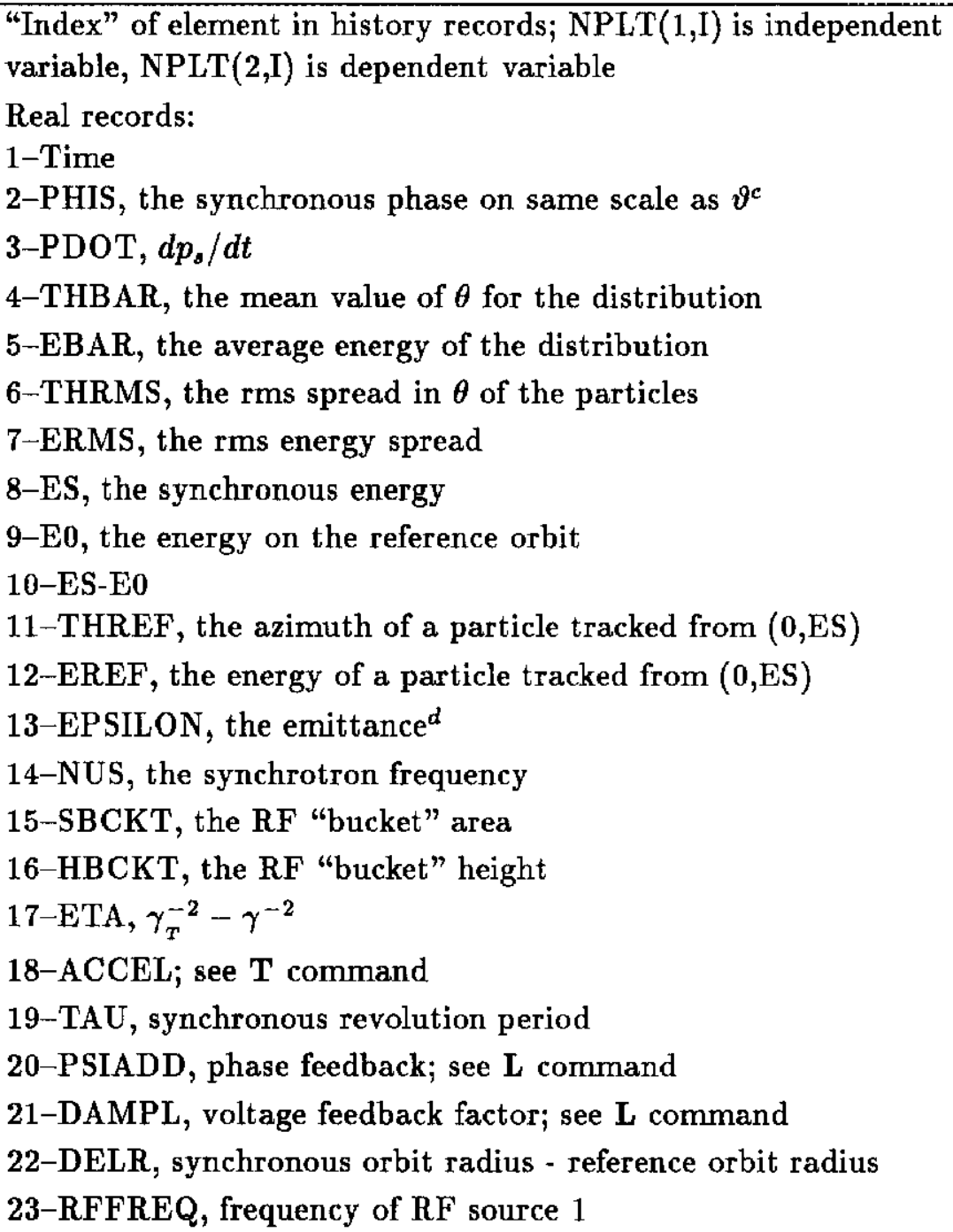 \\
\hline & & & $\begin{array}{l}\text { Integer records: } \\
\text { 31-TURN NUMBER } \\
\text { 32-KNTSC, number of particles in } \varepsilon_{\ell} \neq 0 \text { partition of distribu- } \\
\text { tion }\end{array}$ \\
\hline
\end{tabular}

${ }^{a}$ DI-3000 specific; see Section 3.1.

'The default value of 0 indicates to SUBROUTINE HISTORY that all of the desired history plots have been generated; so only the first set of consecutive nonzero entries to array NPLT will generate plots.

${ }^{c}$ See A command description.

${ }^{d} \mathrm{EPSILON}=\mathrm{ANORM} \tau\left(\sqrt{\sum \theta_{i}^{2} \sum E_{i}^{2}-\left(\sum \theta_{i} E_{i}\right)^{2}}\right) / N$ eVs; see text for ANORM. 


\begin{tabular}{|c|c|c|}
\hline \multicolumn{3}{|r|}{ H Command, Namelist /HISTRY/, continued } \\
\hline \multirow[b]{2}{*}{ Variable } & Default & \multirow[b]{2}{*}{ Description } \\
\hline & Value Unit & \\
\hline & & $\begin{array}{l}\text { Array records: } \\
51-60-\operatorname{SPARE}(1-10) \\
101-110-\mathrm{EV}(1-10) \\
111-120-\mathrm{PSI}(1-10) \\
121-130-\mathrm{FREQ}(\mathrm{I})-\mathrm{FRI}(\mathrm{I}), \text { Change in frequency of source I } \\
201-250-\mathrm{FAMPL}(1-50), \text { Fourier amplitudes; see } \mathbf{F} \text { command } \\
251-300-\mathrm{FAZE}(1-50), \text { Fourier phases; see } \mathbf{F} \text { command }\end{array}$ \\
\hline
\end{tabular}

The members of NAMELIST /HISTRY/ are read in subroutine HISTORY. The emittance EPSILON logged by the $\mathbf{H}$ command is the rms area of the entire distribution converted to units of $\mathrm{eVs}$ and multiplied by a normalization ANORM. If the distribution was generated initially as a matched bunch, ANORM is calculated by default to make EPSILON equal to the requested emittance SBNCH for the first matched bunch generated. This value of ANORM is retained and used from then on. If the initial distribution was not matched, ANORM is set to produce agreement for a gaussian bunch. There is a switch RENORM for the $\mathbf{P}$ command which can control when or if this adjustment of ANORM is made. Although this normalization is a little tricky because it is handled by the program, it seems as good a solution as any to relating rms and full emittances for arbitrary bunch distributions.

The output produced by the $\mathbf{H}$ command, as implied by the simplicity of the /HISTRY/ NAMELIST, is not as fiexible as the output produced by the $\mathbf{O}$ command. The user simply specifies pairs of values to be plotted using the indices above in array NPLT, and optionally the device number, and the program produces a history plot for each pair of inputs assembled sequentially from the entire history record (i.e., there is no choice of a range for any axis). For example, suppose that a simulation has run for 10,000 turns, and the desired output is a record of the distribution moments $v s$. time over that period. The $\mathbf{H}$ command might appear as:

\section{$\$ H I S T R Y$ NPLT $=1,4,1,5,1,6,1,7,4,5 \$ E N D$}

This command will generate plots of THBAR, EBAR, THRMS, and ERMS vs. time, as well as a plot of EBAR vs. THBAR. The manner in which FORTRAN array indices cycle is exploited to avoid explicit reference to the indices; this is the recommended manner of input. Because the frequency of write operations to the history tape may be modified by the program, ${ }^{4}$ and because of a culling procedure applied to the data points by the plotting routine, not every turn will be included in the plot for simulations of more than several thousand turns.

\footnotetext{
${ }^{4}$ See Appendix A
} 
2.2.10 M \& N Commands - Save mountain range data \& Plot mountain range

\begin{tabular}{|c|c|c|c|}
\hline \multicolumn{4}{|r|}{ M Command, Namelist/MRANGE/ } \\
\hline \multirow[b]{2}{*}{ Variable } & \multicolumn{2}{|c|}{ Default } & \multirow[b]{2}{*}{ Description } \\
\hline & Value & Unit & \\
\hline TMBEGIN & 0.0 & $\mathbf{s}$ & Time at which to start saving mountain range data \\
\hline TMEND & 0.0 & s & Time after which to stop saving mountain range data \\
\hline MRMPLOT & 1 & turn & Turn interval at which to record mountain range data \\
\hline MRNBIN & 100 & - & Number of bins in interval MRTHBMIN - MRTHBMAX \\
\hline MRTHBMIN & & $\operatorname{deg}$ & Minimum value of $\theta$ for mountain range \\
\hline MRTHBMAX & & deg & Maximum value of $\theta$ for mountain range \\
\hline
\end{tabular}

Defaults to $-180^{\circ} /$ FRAC.

${ }^{b}$ Defaults to $180^{\circ} /$ FRAC.

\begin{tabular}{|c|c|c|c|}
\hline \multicolumn{4}{|r|}{ N Command, Namelist /MRPLOT/ } \\
\hline \multirow[b]{2}{*}{ Variable } & \multicolumn{2}{|c|}{ Default } & \multirow[b]{2}{*}{ Description } \\
\hline & Value & Unit & \\
\hline MRTHPMIN & $0.0^{a}$ & $\operatorname{deg}$ & Minimum $\theta$ value for mountain range plot \\
\hline MRTHPMAX & 0.0 & $\operatorname{deg}$ & Maximum $\theta$ value for mountain range plot \\
\hline NTRACE & 100 & - & Number of traces on a page \\
\hline NSKIP & 0 & - & Number of records to be skipped between each trace \\
\hline TOPTOB & 0.7 & - & $\begin{array}{l}\text { The fraction of the vertical range over which NTRACE traces } \\
\text { are to be plotted (approximate if TBASE }=\mathrm{T} \text { ) }\end{array}$ \\
\hline SCALE & 0.3 & - & $\begin{array}{l}\text { The height of the first trace, in units in which the entire vertical } \\
\text { range of the plot is } 1.0\end{array}$ \\
\hline MSTART & $0^{b}$ & - & Turn number at which to start plots \\
\hline MSTOP & 0 & - & Turn number at which to stop plots \\
\hline TMSTART & 0.0 & s & Time at which to start plots \\
\hline TMSTOP & 0.0 & s & Time at which to stop plots \\
\hline TBASE & $\mathbf{F}$ & - & Switch causing plot trace separation to be proportional to time \\
\hline NRNBIN & 400 & - & Number of points to plot on a trace \\
\hline IDEV & 1 & - & Output device \\
\hline SMOOTH & 0 & - & $\begin{array}{l}\text { Smoothing option } \\
-1-1-2-1 \text { averaging of adjacent bins } \\
0-\text { No smoothing } \\
1-\text { Bernstein polynomial smoothing }\end{array}$ \\
\hline OBJWGT & 0.05 & - & $\begin{array}{l}\text { Weight of fitting term of object function w/ smoothing term for } \\
\text { polynomial smoothing }\end{array}$ \\
\hline ITNO & 1 & & Number of iterations for either $1-2-1$ or Bernstein smoothing \\
\hline LIM & $\bar{F}$ & - & $\begin{array}{l}\text { Switch for plotting dotted lines connecting leftmost and right- } \\
\text { most non-zero points of consecutive traces }{ }^{c}\end{array}$ \\
\hline
\end{tabular}

\footnotetext{
${ }^{a}$ Defaults of 0.0 for MRTHPMIN and MRTHPMAX imply that data is to be plotted over its entire range.

${ }^{b}$ The defaults of 0 for MSTART and MSTOP, or 0.0 for TMSTART and TMSTOP, imply that all mountain range records are to be plotted

${ }^{c} \mathrm{SMOOTH}=1$ also required.
} 
The members of NAMELIST /MRANGE/ are read in subroutine MRINIT and stored in the common block /MRANGE/ in response to the $\mathbf{M}$ command. The members of NAMELIST /MRPLOT/ are read in the subroutine MRPLT in response to the $\mathbf{N}$ command and also stored in /MRANGE/.

The $\mathbf{M}$ and $\mathbf{N}$ commands are intended to provide plots similar to the display provided by an oscilloscope recording successive traces from a beam current pickup, each trace vertically displaced from the previous one. The resultant display depicts the time evolution of the azimuthal projection of a distribution in a manner which somewhat resembles a mountain range, hence the name. The $\mathbf{M}$ command directs the program to save the data, while the $\mathbf{N}$ command directs the program to process the data which have been saved in a file and produce mountain range plots.

A typical pair of $\mathbf{M}$ and $\mathbf{N}$ commands might be

$$
\$ \text { MRANGE TMBEGIN=0.0, TMEND }=1.0, \text { MRMPLOT }=10 \$ E N D
$$

in which mountain range records are recorded every 10 turns of tracking from 0.0 to 1.0 seconds, and

$$
\text { \$MRPLOT SMOOTH=1 \$END }
$$

which directs that all of the data accumulated thus far be plotted in mountain range format with Bernstein polynomial smoothing. The default for TBASE (F) results in a fixed vertical separation between consecutive traces. If TBASE $=\mathrm{T}$, the vertical separation between consecutive traces will be proportional to the time separating their records, better simulating the mountain ranges normally depicted on an oscilloscope. ${ }^{5}$ The values for TOPTOB and/or SCALE may have to be adjusted to achieve a satisfactory effect.

If MRNBIN $\neq$ NRNBIN, the saved data is transformed to the correct number of bins for plotting by cubic spline interpolation. This feature is independent of whether the stored distribution is first smoothed. Either Bernstein polynomial smoothing $\left.{ }^{[16}\right]$ (SMOOTH = 1) or 1-2-1 averaging of adjacent bins (SMOOTH = -1) may be used. The spline interpolation can produce some smoothing depending on the particular NRNBIN and MRNBIN values. The defaults for MRNBIN and NRNBIN will usually give very smooth plots with SMOOTH $=1$, but the default value of 100 for MRNBIN may be too large for a sparsely populated distribution if SMOOTH $=0$. Either type of smoothing may be iterated by raising ITNO. The two techniques are quite different, however, and the meaning of iteration is rather different. The Bernstein polynomial smoothing is a global procedure which seeks to minimize an object function with contributions from both a smoothness measure and a squared fitting error. Iteration attempts repeated minimizations of this object function. The relative weight given to the fit is increased by increasing OBWGT; the default of 0.05 gives considerable weight to fitting. The 1-2-1 smoothing is a local weighted averaging. Iterating it broadens the span of the averaging giving 1-4-6-4-1, 1-6-15-20-15-6-1, .. smoothing for ITNO = $2,3, \ldots$ respectively. (The relative weights are $C_{i}^{2 \cdot \mathrm{ITNO}} i=1, \ldots, 2 \cdot$ ITNO.) Generally some smoothing will be required to make mountain range plots that look like those made from an accelerator beam current pickup using an oscilloscope. A couple of typical choices are SMOOTH=-1,ITNO $=2$ and $\mathrm{SMOOTH}=1, \mathrm{ITNO}=1$.

\footnotetext{
${ }^{5}$ In relativistic situations, no difference will be discerned between the plots generated with TBASE either $\mathrm{T}$ or $\mathrm{F}$.
} 
2.2.11 L Command - Low level feedback parameters

\begin{tabular}{|c|c|c|c|}
\hline \multicolumn{4}{|r|}{ L Command, Namelist /LLRF/ } \\
\hline \multirow[b]{2}{*}{ Variable } & \multicolumn{2}{|c|}{ Default } & \multirow[b]{2}{*}{ Description } \\
\hline & Value & Unit & \\
\hline PHFBON & $\mathbf{F}$ & - & Activates phase feedback \\
\hline VFBON & $\mathrm{F}$ & - & Activates voltage feedback \\
\hline NTUAVG & 1 & - & $\begin{array}{l}\text { The number of past turns to average in computing the feedback; } \\
\text { the default NTUAVG }=1 \text { represents infinite-bandwidth feedback }\end{array}$ \\
\hline NTURES & 1 & - & $\begin{array}{l}\text { The number of turns for the feedback to respond; the present } \\
\text { signal is compared to the signal of NTURES turns ago. }\end{array}$ \\
\hline IFTB & $\overline{0}$ & - & $\begin{array}{l}\text { The form of phase feedback: } \\
0 \text {-Critical damping } \\
\text { 1-Fixed }\end{array}$ \\
\hline FBFACT & 1.0 & - & The gain applied to the phase feedback \\
\hline USEWT & $\mathrm{F}$ & - & Applies weight function $\mathrm{W}$ to phase signal over NTUAVG turns \\
\hline W(1:NTUAVG) & 0.0 & - & Weight function multiplying phase signal \\
\hline DLIMIT & 5.7296 & $\operatorname{deg}$ & $\begin{array}{l}\text { The upper limit on the magnitude of the phase feedback on a } \\
\text { given turn }\end{array}$ \\
\hline VFBFCTR & 1.0 & . & The gain applied to the voltage feedback \\
\hline VLIMIT & .1 & MV & The limit on the voltage feedback applied on a given turn \\
\hline ETAJMP & 0.0 & - & The value of $\eta^{a}$ at which to "flip" the phase of the $\mathrm{RF}$ \\
\hline
\end{tabular}

${ }^{a} \eta=\gamma_{T}^{-2}-\gamma^{-2}$

The members of NAMELIST / LLRF / are read in subroutine LOWLVL and stored in COMMON /FEEDS/. The phase feedback, intended primarily to damp dipole bunch oscillations, is computed according to the following formula for ITFB $=0$ :

$$
\text { PSIADD }=\frac{\text { FBFACT } \sum_{i=1}^{\text {NTUAVG }}\left(W_{i}\left(\bar{\theta}_{n-i}-\bar{\theta}_{n-\mathrm{NRESP}-i}\right)\right.}{\pi \nu_{s} \mathrm{NTUAVG}^{2} \sum_{i=1}^{N T U V G} W_{i}}
$$

where $n$ is the current turn number, and $\nu_{s}$ is the synchrotron frequency. For ITFB $=1, \nu_{s}$ is replaced by $4.0 \times 10^{-3}$. A simple invocation of phase feedback would appear as

\section{\$LLRF PHFBON=T \$END}

The defaults imply critical damping.

The voltage feedback, intended to damp quadrupole bunch oscillations, operates according to

$$
V_{n}^{\prime}=\left(1+\frac{2 \pi \operatorname{VFBFCTR} \sum_{j=0}^{n-k}\left(<E^{2}>_{n-j}-<E^{2}>_{n-j-1}\right)}{100 \nu_{s} H_{k}}\right) * V_{n}
$$

where $k$ is the turn index when feedback starts (i.e., the turn number when the $\mathbf{L}$ command is issued with VFBON $=\mathrm{T}$ ), $n$ is the current turn number, $E$ is the energy, $V$ is the voltage before feedback, $V^{\prime}$ is the voltage after feedback, and $H_{k}$ is the height of the bucket on the $k$ th turn. The factor of 100 in the denominator is arbitrary, so the user may have to adjust VFBFCTR to obtain satisfactory results. 
2.2.12 B Command - Beam-derived potential (self-force and $Z_{\|}$)

\begin{tabular}{|c|c|c|c|}
\hline \multicolumn{4}{|r|}{ B Command, Namelist /SCHG/ } \\
\hline \multirow[b]{2}{*}{ Variable } & \multicolumn{2}{|c|}{ Default } & \multirow[b]{2}{*}{ Description } \\
\hline & Value & Unit & \\
\hline $\mathrm{A}$ & 0.002 & $\mathrm{~m}$ & Effective beam radius \\
\hline $\mathrm{B}$ & 0.05 & $\mathrm{~m}$ & Effective beam pipe radius \\
\hline ENQ & $2 . \cdot 10^{10}$ & - & Number of protons to be represented by the distribution \\
\hline NZ & 0 & - & Number of impedance values to be read from a file ${ }^{a}$ \\
\hline NR & 0 & - & Number of resonance values to be read from a file ${ }^{b}$ \\
\hline NBINSC & 100 & $\cdot$ & Number of bins for histogram of charge distribution \\
\hline MSC & 1 & - & $\begin{array}{l}\text { Collective effects are to be calculated MSC times between rf } \\
\text { cavities }^{c}\end{array}$ \\
\hline TSCON & 0. & s & $\begin{array}{l}\text { End of period starting at TIME }=0 \text {. in which beam charge is } \\
\text { ramped linearly from } 0 \text {. to ENQ }\end{array}$ \\
\hline SCON & $\mathbf{F}$ & - & Activate space charge calculation \\
\hline NBINFFT & 256 & - & Number of bins to be used in Fourier transform \\
\hline MFFT & 1 & - & Interval (in turns) between Fourier transforms \\
\hline $\mathrm{NNF}^{d}$ & 0 & - & Number of fourier harmonics to be stored in history \\
\hline $\mathrm{NF}(1: \mathrm{NNF})$ & 0 & - & Harmonic numbers of fourier spectrum components to be stored \\
\hline QREZON & $\mathrm{F}$ & - & Activate time domain calculation for high- $Q$ resonance \\
\hline NBRES & 1000 & - & $\begin{array}{l}\text { Number of time slices for time domain solution of high-Q res- } \\
\text { onator }\end{array}$ \\
\hline NIXNOIS & 0 & - & $\begin{array}{l}\text { Three-way switch to control smoothing of charge distribution } \\
-1=>1-2-1 \text { averaging of adjacent bins } \\
0=>\text { no smoothing measures } \\
1=>\text { Bernstein polynomial smoothing }\end{array}$ \\
\hline ITKNT & 1 & - & Number of iterations for either 1-2-1 or Bernstein smoothing \\
\hline OBWGT & 0.05 & - & $\begin{array}{l}\text { Weight of fitting vs. smoothing in object function for Bernstein } \\
\text { smoothing }\end{array}$ \\
\hline
\end{tabular}

${ }^{a}$ Cubic polynomial coefficient table read from FORTRAN logical unit 11; see Section 3.2 .3 for format specification.

${ }^{b}$ Resonance parameters read from FORTRAN logical unit unit 12; see Section 3.2 .4 for format specification.

'The number of such calculations per turn will be MSC*NCAV; NCAV is a parameter of the $\mathbf{R}$ command.

${ }^{d}$ For instruction in the use of NF(1:NNF), see the description following the $\mathbf{F}$ command.

The members of NAMELIST /SCHG/ are read at entry BEAMSC in subroutine FOURFIT and stored in COMMON /SPCHG/. The B command controls facilities in ESME for modeling the interactions of the beam particles with each other through both the direct particle-particle force and through wakefields excited as a consequence of the interaction of the beam with its environment (vacuum chamber, $\mathrm{rf}$ cavities, etc...). The routines activated by SCON calculate these effects using an equivalent impedance. This may be adequate for many problems. However, implicit in this approach is the assumption of a steady-state solution. ${ }^{[14]}$ This is reflected in the absence of any frequencies other than harmonics of the revolution frequency in this calculation, which utilizes the Fourier transform. If a high- $Q$ resonator is present, the absence of the transient component to the solution may misrepresent the the coupling between bunches.

Transient effects can be taken into account using the routines activated by QREZON. These calculations may be made either in conjunction with those activated by SCON or independently; 
QREZON will take precedence over SCON for the calculation of the voltage due to those resonators for which the multipliers (third parameter in the resonance file record) are zero. Implicit in the code is the assumption that the distribution being tracked is periodic, and that the resonator voltage is applied in time steps equal to the time duration of the entire distribution. The simplest way to satisfy both of these constraints is to track a distribution which spans 360 degrees of azimuth (i.e., the entire ring), and calculate the resonator voltage once per turn. It may be satisfactory in other cases to track a distribution spanning $\frac{1}{\text { FRAC }}$ of 360 degrees and calculating the voltage at FRAC equi-spaced intervals around the ring (i.e., MSC $* \mathrm{NCAV}=\mathrm{FRAC}$ ).

One of the frustrations in calculating emittance growth caused by the collective potential is spurious emittance growth of an initial bunch matched to a single particle trajectory. It is generally difficult to produce a self-consistent distribution directly. Two ways are provided to avoid the initial match problem. The parameter TSCON can be set to a value of a few synchrotron periods. The strength of the beam charge will then be ramped linearly to its target ENQ by the time TSCON, thereby approximating an adiabatic introduction of the perturbation. Another technique which may require less computing is to generate a collective potential using the $\mathbf{B}$ command and an approximate initial distribution then to use the $\mathbf{K}$ command to remove the distribution before using the $\mathbf{P}$ again to provide a bunch matched to the new potential. This cycle may need to be iterated for an exacting application to obtain an adequate approximation to self-consistency.

Under some conditions, most likely at low energies, the collective potential is very significant, and applying it only once per turn is not realistic because there is too much force-free drift between energy increments. A typical symptom of this problem is spurious bunch breakup. The parameter MSC can be set to apply the collective potential MSC $\times$ NCAV times per turn, where NCAV is the number of cavity locations in the ring set by the $\mathbf{R}$ command. However, the collective potential itself changes very little in one turn, so it is evaluated once per turn independently of MSC and NCAV.

A space charge command which utilizes ESME's capabilities to model the self-force, resistive wall impedance, and certain parasitic high- $Q$ resonances might be:

\$SCHG $\mathrm{SCON}=\mathrm{T}, \mathrm{A}=.01, \mathrm{~B}=.03, \mathrm{ENQ}=2.4 \mathrm{E} 10$,
$\mathrm{NR}=6, \mathrm{NZ}=29, \mathrm{NBINFFT}=512$ \$ND
IMPEDANCE.DAT
RESONANCE.DAT

in which the cubic polynomial coefficients for the wall impedance are read from IMPEDANCE.DAT, specified after the namelist, while the resonance values are obtained from the file RESONANCE.DAT. The impedance file is read only if $\mathrm{NZ} \neq 0$, while the resonance file is read only if NR $\neq 0$. No files should be specified if both values are 0 . Note that the number of protons specified is for $1 /$ FRAC of the machine circumference. The number of bins used in the FFT will be the lesser of NBINFFT or the storage allocation IFFT. The parameter NBINSC should be chosen so that there are an adequate number of bins over the width of the bunch(es) to provide good shape information.

There is no necessary numerical relation between NBINSC and NBINFFT. If the two are unequal, spline interpolation on a charge distribution of NBINSC bins is used to make a distribution of NBINFFT bins for the FFT. Two types of smoothing may be applied to the distribution of NBINSC bins. SMOOTH=-1 causes a local averaging with weights $1 / 4,1 / 2,1 / 4$. If ITKNT is greater than one, the smoothing is repeated effectively producing a (less local) averaging with, for example, weights $1 / 16,1 / 4,3 / 8,1 / 4,1 / 16$ for $\mathrm{ITKNT}=2$. If $\mathrm{SMOOTH}=1$, Bernstein polynomial smoothing ${ }^{[16]}$ is employed. This is a global technique in which an object function containing a least squares fitting criterion and a smoothness measure is minimized. For this case ITKNT controls the maximum number of attempts to minimize the object function. This method is limited by a requirement that NBINSC be small enough that all bunches are spanned by fewer than 100 bins and, if there are multiple bunches, that there be three or more empty bins between them. 
2.2.13 F Command - Fourier transform

\begin{tabular}{|c|c|c|c|}
\hline \multicolumn{4}{|r|}{ F Command, Namelist /FFT/ } \\
\hline \multirow[b]{2}{*}{ Variable } & \multicolumn{2}{|c|}{ Default } & \multirow[b]{2}{*}{ Description } \\
\hline & Value & Unit & \\
\hline FFTON & F & - & Activate Fourier transform calculation \\
\hline FFTOUT & $\mathrm{F}$ & - & If TRUE, Fourier transform is printed \\
\hline NBINFFT & 256 & - & Number of bins to be used in FFT \\
\hline NNF & 0 & - & Number of fourier harmonics to be stored in history \\
\hline $\mathrm{NF}(1: \mathrm{NNF})$ & 0 & - & Harmonic numbers of fourier spectrum components to be stored \\
\hline $\mathrm{MFFT}$ & 1 & - & Frequency of Fourier transform calculation \\
\hline NIXNOIS & 0 & - & $\begin{array}{l}\text { Three-way switch to control smoothing of azimuthal histogram } \\
-1=>1-2-1 \text { averaging of adjacent bins } \\
0=>\text { no smoothing measures } \\
1=>\text { Bernstein polynomial smoothing }\end{array}$ \\
\hline ITKNT & 1 & - & Number of iterations for either 1-2-1 or Bernstein smoothing \\
\hline OBWGT & 0.05 & - & $\begin{array}{l}\text { Weight of fitting vs. smoothing in object function for Bernstein } \\
\text { smoothing }\end{array}$ \\
\hline
\end{tabular}

The members of NAMELIST / FFT/ are read in subroutine FOURFIT and stored in COMMON /FOURIR/. Many of the variables in NAMELIST /FFT/ are shared by NAMELIST /SCHG/, because the Fourier transform is utilized in much of the space-charge calculation. The $\mathbf{F}$ command is intended to allow the user to examine the fourier transform of the distribution and to follow the development of selected fourier components. If, for example, one wants to track the turn-by-turn development of the first five odd fourier harmonics of the distribution, then the appropriate $\mathbf{F}$ command would be:

$$
\$ F F T \quad F F T O N=T, N B I N F F T=32, \mathrm{NNF}=5, \mathrm{NF}=1,3,5,7,9 \$ \mathrm{END}
$$

If at some point one should wish to plot the record for the amplitude of the third harmonic, then the H command should be issued to retrieve FAMPL(2). ${ }^{6}$ The harmonics of the distribution should be multiplied by the periodicity in determining harmonics of the revolution frequency. If, for example, FRAC $=7$, the fifth harmonic of the distribution corresponds to harmonic thirty-five of the beam circulation frequency.

The histogram can be smoothed before the FFT is performed. NIXNOIS $=-1$ and ITKNT $=1$ results in a straightforward averaging of bins with their immediate neighbors using relative weights of 1-2-1. Increasing ITKNT results in higher order averaging. When NIXNOIS $=1$, Bernstein polynomial smoothing is employed. ${ }^{[16]}$ The relative importance attached to fitting of the data values and smoothness is governed by OBWGT; ITKNT determines how many trials are made to reduce the object function. An ITKNT of zero is valid; it results in a well-smoothed representation of the distribution but may remove detail which is meaningful. There are other remarks on smoothing in secs. 2.2.10 and 2.2.12 where mountain range plots and collective potential calculations are discussed.

\footnotetext{
${ }^{6}$ See Section 2.2.9, History command.
} 


\subsubsection{Command - Flow contours}

\begin{tabular}{|c|c|c|c|}
\hline \multicolumn{4}{|r|}{ C Command, Namelist /FLOW/ } \\
\hline \multirow[b]{2}{*}{ Variable } & \multicolumn{2}{|c|}{ Default } & \multirow[b]{2}{*}{ Description } \\
\hline & Value & Unit & \\
\hline LINES & 2 & - & The number of flow lines to be drawn \\
\hline ELMAX & & $\mathrm{MeV}$ & Highest energy relative to $\mathrm{E}_{\mathrm{s}}=0$ \\
\hline ELMIN & & $\mathrm{MeV}$ & Lowest energy relative to $\mathrm{E}_{\mathrm{s}} ;$ ELMIN $>/=0$. \\
\hline TSTOPa & 0. & $\mathrm{~s}$ & End of interval over which maps are generated \\
\hline TTRACK $^{b}$ & 0. & $\mathbf{s}$ & Time over which periodic flow maps will be generated \\
\hline ACCELO & 1.0 & - & Number of beam turns per step between mappings \\
\hline PARTION & $\mathbf{F}$ & - & $\begin{array}{l}\text { Switch indicates if points on separate flow lines belong to different } \\
\text { partitions of the phase points }\end{array}$ \\
\hline $\operatorname{ITRAP}(1: 4)$ & 1 & - & $\begin{array}{l}\text { Flags a condition for which the } \mathbf{C} \text { command should be inter- } \\
\text { rupted; see } \mathbf{T} \text { command for values }\end{array}$ \\
\hline ETATRP & .001 & - & Trapping parameter; see $\mathbf{T}$ command \\
\hline PHISTRP & .95 & - & Trapping parameter; see $\mathbf{T}$ command \\
\hline MGRACE & 0 & - & Trapping parameter; see T command \\
\hline
\end{tabular}

aTSTOP set to 0 . when calculation complete or interrupted by an ITRAP option.

${ }^{b}$ TSTOP takes precedence; if TSTOP $=0$., TTRACK determines duration.

The $\mathbf{C}$ command is used to generate flow line maps at the plotting intervals MPLOT, which is set by the $\mathbf{O}$ command along with the other parameters controlling the graphics. It may also be used to establish a (zero-emittance) distribution to be tracked. The subroutine FLOWPRG reads the namelist /FLOW/ and stores some of the parameters in common /FLOWP/. However, FLOWPRG is a driver for many ESME subroutines so it distributes data among several common blocks.

When the $\mathbf{C}$ command is used to generate an initial distribution for tracking, TTRACK and TSTOP are set to zero so that only one set of points on flow lines is generated. It can be combined with a non-zero emittance distribution (i.e., a bunch) if desired. Such a bunch can be generated before the flow lines and the resulting collective potential will then be taken into account in generating the flow lines if the $\mathbf{B}$ command has been called first. In any case, a zero-emittance type of distribution is stored in the array PHASE above a partition KNTSC so that only the bunch(es) affect the collective potential when that calculation is active. Furthermore, the flow line points are not used in calculating beam moments and emittance.

The map produced by the $\mathbf{C}$ command can also be produced by the ICONTUR $=5$ option of the $\mathbf{O}$ command. The $\mathbf{C}$ command differs from the $\mathbf{T}$ command in not tracking any distribution turnby-turn and not calculating bunch properties or storing quantities for history plots. Because the $\mathbf{C}$ command works without a bunch-like $\left(\varepsilon_{\ell} \neq 0\right)$ distribution, it does not ordinarily incorporate the effect of a collective potential. It is possible to use $\mathbf{C}$ to generate such flow lines by first populating a bunch $(\mathbf{P})$ then invoking $\mathbf{B}$ and $\mathbf{C}$ in that order. Using the $\mathbf{K}$ command with KNTSET $=-1$ will remove the bunch if desired. 
2.2.15 K Command - Kill all or parts of the distribution

\begin{tabular}{|c|c|c|c|}
\hline \multicolumn{4}{|r|}{ K Command, Namelist/KUTS/ } \\
\hline \multirow[b]{2}{*}{ Variable } & \multicolumn{2}{|c|}{ Default } & \multirow[b]{2}{*}{ Description } \\
\hline & Value & Unit & \\
\hline KUT & 0 & - & Cut the last KUT particles from the distribution \\
\hline KNTSET & $\mathbf{0}$ & - & $\begin{array}{l}\text { Reset particle count } \\
<0 \Longrightarrow \text { KNTSC } \rightarrow 0 \text {; removes bunch-type distribution } \\
>0 \Longrightarrow \text { KOUNT } \longrightarrow 0 \text {; removes entire distribution }\end{array}$ \\
\hline $\mathrm{K} 1$ & 0 & - & Starting point for a partial removal of the distribution \\
\hline K2 & $a$ & - & End point for partial removal of distribution \\
\hline KLASS & 0 & - & Selects a partition of the distribution to be removed ${ }^{b}$ \\
\hline
\end{tabular}

${ }^{a}$ Defaults to KOUNT

${ }^{b}$ See PARTION in $\mathbf{P}$ command

The $\mathbf{K}$ command calls KARVE which reads the namelist /KUTS/ for integers which indicate what part of the current phase space distribution to kill. It is really a pastiche of several related functions which have surfaced at one or another time in SHAZAM routines (see $\mathbf{0}-\mathbf{9}$ commands). Only one option can be exercised per call, and parameters are always reset to harmless before the command returns.

\subsubsection{0 - 9 Commands - User-written SHAZAM routines}

The SHAZAM facility is intended to allow users to integrate their own routines into the code. All COMMON blocks in ESME are available to SHAZAM. As indicated in section 2.2.5, SHAZAM entry points may be called following every iteration of the difference equations using the TRAP option provided through NAMELIST /CYCLP/. In addition, SHAZAM routines may be called explicitly using commands $0-9$. Of course, any subsequent input is up to the author of the code following the appropriate SHAZAM entry point. It may be NAMELIST-directed, as ESME largely is, or there may be no input at all. The user is cautioned, however, to ensure that any subsequent input data is read; otherwise ESME will read the line where it finds itself after returning from SHAZAM and attempt to interpret it as a command. 


\subsubsection{S Command - Save tracking parameters}

The $\mathbf{S}$ command directs subroutine SAVE to write all data in COMMON blocks to an external file. It allows the user to suspend tracking at any point in the program. Once all the tracking data is SAVE'd, it may be restored simply by issuing the $\mathbf{G}$ command (see next section). Subroutine SAVE is also useful for those who might want to analyze ESME tracking data independently of the program. ${ }^{7}$ The format of the $\mathbf{S}$ command is as follows:

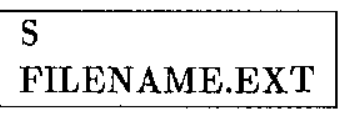

where FILENAME.EXT is the name of the external file to which the data is to be written.

\subsubsection{G Command - Get tracking parameters}

The $\mathbf{G}$ command directs subroutine GET to read data from an external file into ESME's common block data. It is intended to be used to retrieve data written using the $\mathbf{S}$ command. The $\mathbf{G}$ command format is very similar to that for the $\mathbf{S}$ command:

$$
\text { GILENAME.EXT }
$$

where FILENAME.EXT is the name of the external file to from which the data is to be read. Because $\mathbf{G}$ recovers all parameters, input data can consist of only $\mathbf{G}, \mathbf{T}$, and $\mathbf{Q}$ commands for example. It is useful for restarting a long calculation from a checkpoint or for making alternative conclusions to a common intermediate result.

\footnotetext{
${ }^{7}$ See, for example, Appendix A.
} 


\section{Chapter 3}

\section{Using The Program}

\subsection{Running the Program}

As configured, ESME may be run from a terminal or in batch mode. ${ }^{1}$ Basically, the process of running ESME consists of associating file names with FORTRAN logical units and then issuing the proper directive to execute the program. FORTRAN logical unit 5 is expected to supply the input. An appropriate DI-3000 device driver ${ }^{2}$ must be specified in order to use the graphical output routines available for ESME at Fermilab. By default, ESME chooses the device driver ${ }^{3}$ associated with node 1 to direct output, though others may be explicitly specified. ${ }^{4}$ In addition, graphical output may be written to a Metafile, and that Metafile may be used in conjunction with a translator to view the output on various devices.

The following DCL commands might typically be used in running the program:

$\begin{array}{ll}\text { \$ ASSIGN DSNAME.DAT FOR005 } & \text { (input data set) } \\ \text { \$ ASSIGN DSNAME.LIS FOR\$PRINT } & \text { (printable output) } \\ \text { \$ ASSIGN SYS\$ERROR FOR\$PRINT } & \text { (execution error output) } \\ \text { \$ ASSIGN DSNAME.PPO FOR018 } & \text { (output for post processor) } \\ \text { \$ ASSIGN DSNAME.HST FOR009 } & \text { (histogram storage) } \\ \text { \$ ASSIGN DSNAME.MRG FOR020 } & \text { (mountain range storage) } \\ \text { \$ SETDRV QMP } & \\ \text { \$ RUN ESME } & \end{array}$

They specify that ESME's input (the commands) will be read from file DSNAME.DAT, that any post-processor output ${ }^{5}$ will be written to file DSNAME.PPO, while history records will be written to the file DSNAME.HST. In addition, the device driver QMP is assigned to node 1 . Of course, it is possible to run ESME interactively, in which case the commands and namelists would be issued by the user directly. However, the batch mode of running the program is surely the preferred one. A user might decide to associate input from his terminal with some FORTRAN unit addressed through a SHAZAM routine, in which case the program can be run interactively through that channel.

Once a run is completed, ESME may have produced a number of files. If a printer driver were used for graphical output, then a graphics file will be generated which may be printed. If IDEV 6 is set to 0, then a Metafile is produced, which may be used in conjunction with a translator to

\footnotetext{
${ }^{1}$ Some of the material that follows is specific to the graphics routines described in this document, and may not be applicable to every user.

${ }^{2}$ DI-3000 is a trademark of Precision Visuals, Inc.

${ }^{3}$ SETDRV command at Fermilab.

${ }^{4}$ See IDEV in chart in Section 2.2.4, Graphical Output.

${ }^{5}$ See Appendix A.

${ }^{6}$ See Section 2.2.4, Graphical Output.
} 
generate output on physical devices. Finally, if the post-processor option ${ }^{7}$ is in effect, then ESME writes its data to the file associated with FORTRAN logical unit 18 (every MPLOT turns, or upon issuance of the $\mathbf{D}$ command). History records are written to the file associated with unit logical unit 9. These files may be processed later according to methods of the user's own choosing. A simple post-processor "shell" has been written which processes these files using routines from ESME. It is described in Appendix A.

For most applications, command procedures have been prepared which automate the process of running the program and obtaining output in a VAX-based environment. A command procedure (USEV8.COM) has been prepared which defines a number of logicals and symbols which make it possible to use ESME's programs and procedures without explicit knowledge of where they are located. On node ALMOND at Fermilab, for example, this command procedure can be invoked by entering

QUSR\$DISK4: [ESME_FILES]USEV8

Now the user has merely to prepare an input data file, and then enter the command:

\section{RESHEVAX}

to run the current generic version of ESME on the local VAX. The command procedure accomplishes its task by

1. Asking the user for an input data file.

2. Creating a subdirectory into which all of ESME's output will go.

3. Copying the command input file and any other specified files into this subdirectory.

4. Asking the user whether graphical output is to be printed and where.

5. Submitting the job to a batch queue.

\subsection{Input Structure}

In this section the format required of various input files is described. First and foremost is FORTRAN logical unit 5, which is the main input file for ESME (and often the only input file). In addition, ESME may read tables of values for the RF voltage, frequency, or phase as functions of time, and the wall impedance as a function of frequency. Finally, ESME may read a file containing the parameters for various resonant impedances.

\subsubsection{Command file}

The commands which ESME accepts have already been described in Chapter Two. Each command is indicated by a single character in the first column of a line. The following four places in the line are discarded, and the rest of the line is read $^{8}$ and echoed in the output along with the command as a comment. Following many of the commands is a namelist read. The namelist input is specified by entering a dollar sign in the second column of the input file, followed immediately by the namelist identifier, after which any variable which is a member of the namelist may be entered by specifying its name followed by an equal sign followed by the value to be assigned. The assignment of logical variables will depend on the particular machine (e.g. .TRUE. or T). The namelist is terminated by a \$END. All of the command examples given previously are valid VAX namelist entries.

\footnotetext{
${ }^{7} \mathrm{POSTP}=\mathrm{T}$ in the $\mathbf{O}$ command.

${ }^{8}$ FORTRAN format $(\mathrm{A} 1,4 \mathrm{X}, \mathrm{A} 74)$.
} 


\subsubsection{Voltage table}

In certain circumstances in which the time development of the RF voltage is rather involved, it may be advisable to provide ESME with a table describing the time-dependence of the voltage, from which the values of the voltage at a particular time can be interpolated. Such a table is read from the file specified on the line immediately following the /RF/ namelist if any of the NRF rf variations (voltage, frequency or phase) is declared to be of type $4 .^{9}$ The file is opened, assigned to FORTRAN unit 10, and read until a line specifying "Source $i$ " is read, where $i$ corresponds to the index of the source for which the tables are specified. The format of the input file will appear as:

Source $i$
Voltage
$n_{i}$
$t_{1}^{i}, v_{1}^{i}$
$t_{2}^{i}, v_{2}^{i}$
$\ldots$
Frequency
$n_{i}$
$t_{1}^{i}, f_{1}^{i}$
$t_{2}^{i}, f_{2}^{i}$
$\ldots$
Phase
$n_{i}$
$t_{1}^{i}, \phi_{1}^{i}$
$t_{2}^{i}, \phi_{2}^{i}$
$\ldots$. Source $j$
Voltage
$n_{j}$
$t_{1}^{j}, v_{1}^{j}$
$\ldots$

The order of sources (for more than one source) is arbitrary, however the input must be ordered so that $t_{2}^{i}>t_{1}^{i}$. The entry $n_{i}$ following the "Source $i$ " line indicates how many sets (i.e., lines) of values are to follow. It is not necessary to specify all three tables for a given source. It is also not necessary to specify voltage, frequency and phase tables in one place under a single "Source" heading. It is necessary, however, that if they are specified in one place, that they are ordered in the sequence: voltage, frequency, phase. Only one rf table file may be read in a given run of the program, and the entire file is read and its entries stored at one time. Therefore, even tables which are not to be used until later in the run must be provided at the time the file is read.

The table entries then determine the voltage, if an rf curve type of " 4 " is specified, using cubic spline interpolation between the provided values, and the supplied end points. For example, at time $t$, the voltage $v$ for source $i$ will be computed according to

$$
\text { for } \begin{aligned}
t<\operatorname{TVBEG}(\mathrm{I}): & \\
v & =\mathrm{VI}(\mathrm{I})
\end{aligned}
$$

$$
\text { for } \begin{aligned}
& \operatorname{TVBEG}(\mathrm{I}) \leq t \leq \operatorname{TVEND}(\mathrm{I}): \\
& t_{k}^{i}=\max t_{j}^{i} \ni t_{j}^{i} \leq t \quad 1 \leq j \leq n_{i} \\
& v=\operatorname{VI}(\mathrm{I})+(\mathrm{VF}(\mathrm{I})-\mathrm{VI}(\mathrm{I})) \times \text { spline }
\end{aligned}
$$

\footnotetext{
${ }^{9}$ See Section 2.2.2, the A Command.
} 


$$
\text { for } \begin{aligned}
t>\operatorname{TVEND}(\mathrm{I}): & \\
v & =\mathrm{VF}(\mathrm{I})
\end{aligned}
$$

where $\mathrm{VI}(\mathrm{I})$ and $\mathrm{VF}(\mathrm{I})$ are the specified voltages for source $\mathrm{I}$ at times TVBEG(I) and TVEND(I), and "spline" is the value interpolated from the table read for voltage source $i$. Note that the values supplied in the table(s) are not voltages, frequencies, or phases, but rather the fraction of those quantities between the specified initial and final points. Thus, in general, the table will run from 0.0 to 1.0 . However, the input need not be normalized; it may have a pedestal and arbitrary scale. The input is scaled before the spline is calculated. This allows one to take an if curve directly from an accelerator control file and use its shape while setting the VI and VF as desired with the A command. Note also that the interpolation procedure will only be carried out for TVBEG(I) $\leq t \leq$ TVEND(I); this is consistent with the convention for all methods of varying the voltage.

\subsubsection{Impedance table}

The $\mathbf{B}$ command allows the user to enter a cubic polynomial coefficient table for the wall impedance. This file, if required, ${ }^{10}$ must be listed on the line immediately following the namelist input. The file will be opened, assigned to FORTRAN unit 11, and NZ values of frequency (in $\mathrm{MHz}$ ) will be read, each accompanied by eight polynomial coefficients. The format of the input is as follows:

$$
\begin{aligned}
& f^{1} \\
& x_{1}^{1}, x_{2}^{1}, x_{3}^{1}, x_{4}^{1} \\
& y_{1}^{1}, y_{2}^{1}, y_{3}^{1}, y_{4}^{1} \\
& \cdots \\
& f^{2} \\
& x_{1}^{2}, x_{2}^{2}, \ldots
\end{aligned}
$$

The first value on the top line is the frequency in MHz. The four values following on the next line are the coefficients for the real part of the impedance. The four values on the third line are the coefficients for the imaginary part of the impedance. The FORTRAN format for each line is list-directed, so it is sufficient to simply list the values separated by commas or spaces in the file. The entries should be made in order of increasing frequency $\left(f^{1}<f^{2}<\ldots<f^{N Z}\right)$. The coefficients are used to compute the value of the impedance at a given frequency $f$, according to:

$$
\text { if } \begin{aligned}
f^{1} \leq f<f^{N Z}: & \\
f^{n} & =\max f^{i} \ni f>f^{i} \quad 1<i<\mathrm{NZ} \\
\Delta f & =f-f^{n} \\
Z_{r}+i Z_{i} & =x_{1}^{n}+\Delta f x_{2}^{n}+\Delta f^{2} x_{3}^{n}+\Delta f^{3} x_{4}^{n}+i\left(y_{1}^{n}+\Delta f y_{2}^{n}+\Delta f^{2} y_{3}^{n}+\Delta f^{3} y_{4}^{n}\right) \\
\text { if } f<f^{1}: & \\
Z_{r}+i Z_{i} & =x_{1}^{1}+i y_{1}^{1} \\
\text { if } f \geq f^{N Z}: & \\
Z_{r}+i Z_{i} & =x^{N} Z_{1}+i y^{N} Z_{1}
\end{aligned}
$$

\footnotetext{
${ }^{10}$ For $\mathrm{NZ}>0$, see Section 2.2 .12 .
} 


\subsubsection{Resonance table}

Resonant impedances may be specified in a simple form. The resonance values are read from the file whose name is specified following the /SCHG/ namelist, ${ }^{11}$ and the name of the impedance file, if any. This file is assigned to input unit 12. Each of the NR entries in the resonance file occupies a single line. The format for each line is list directed, where the values to be read in are:

frequency $[\mathrm{MHz}]$, real shunt impedance at resonance $[\Omega]$, multiplier, $Q$

where the multiplier, which is usually $1 .$, simply multiplies the impedance which is calculated from the frequency, shunt impedance, and $Q$ values for the resonance. However note that, as mentioned in Section 2.2.12, a multiplier of zero has a special purpose. When the time domain calculation of resonator response has been activated by setting QREZON true, those resonances with a zero multiplier will be treated with the time domain technique.

\footnotetext{
${ }^{11}$ For NR $>0$, see Section 2.2.12.
} 


\section{Chapter 4}

\section{Programming}

In this chapter some of the basic structure of the program is presented, and the use of certain VAX-based facilities in the development of the code is discussed. Though somewhat specialized, it is felt that the utility of these features to those who might be willing and able to use them is of great enough importance to warrant some description here. This chapter is primarily of interest to programmers. There is no need to make use of the material in this section in order to use the program. Furthermore, this section alone is not likely to make the reader an ESME expert. It is hoped that the material presented here will ease the process of incorporating changes and additions to the code.

\subsection{Program Basics}

The first part of this section describes the overall structure of ESME. The second section details the main tracking loop. The third section lists the important variables in ESME, which are held in COMMON and thus available in SHAZAM.

\subsubsection{Program structure}

The basic pattern of ESME is a main program which calls subroutines selected by single letter commands in the input stream. The called routine reads in any needed parameters; it and any dependent subroutines carry out calculations for a distinct phase of the calculation or for a distinct accelerator subsystem. The program is integrated by putting particle coordinates and system variables into named commons each of which contain a group of closely related quantities. Higher level subroutines communicate through common. Certain lower level routines and some utility routines shared among different functional areas pass data through calling lists. Nearly all system and coordinate variables are stored in common blocks; only loop counters and a few intermediate results are local variables. Thus, the program is divided into numerous functional modules but important variables are global. The large number of parameters often required to specify a distribution and the rf systems which act upon it encourage this structure, as well as making it easier to incorporate changes into the code. A schematic tree diagram indicating the program flow follows. 


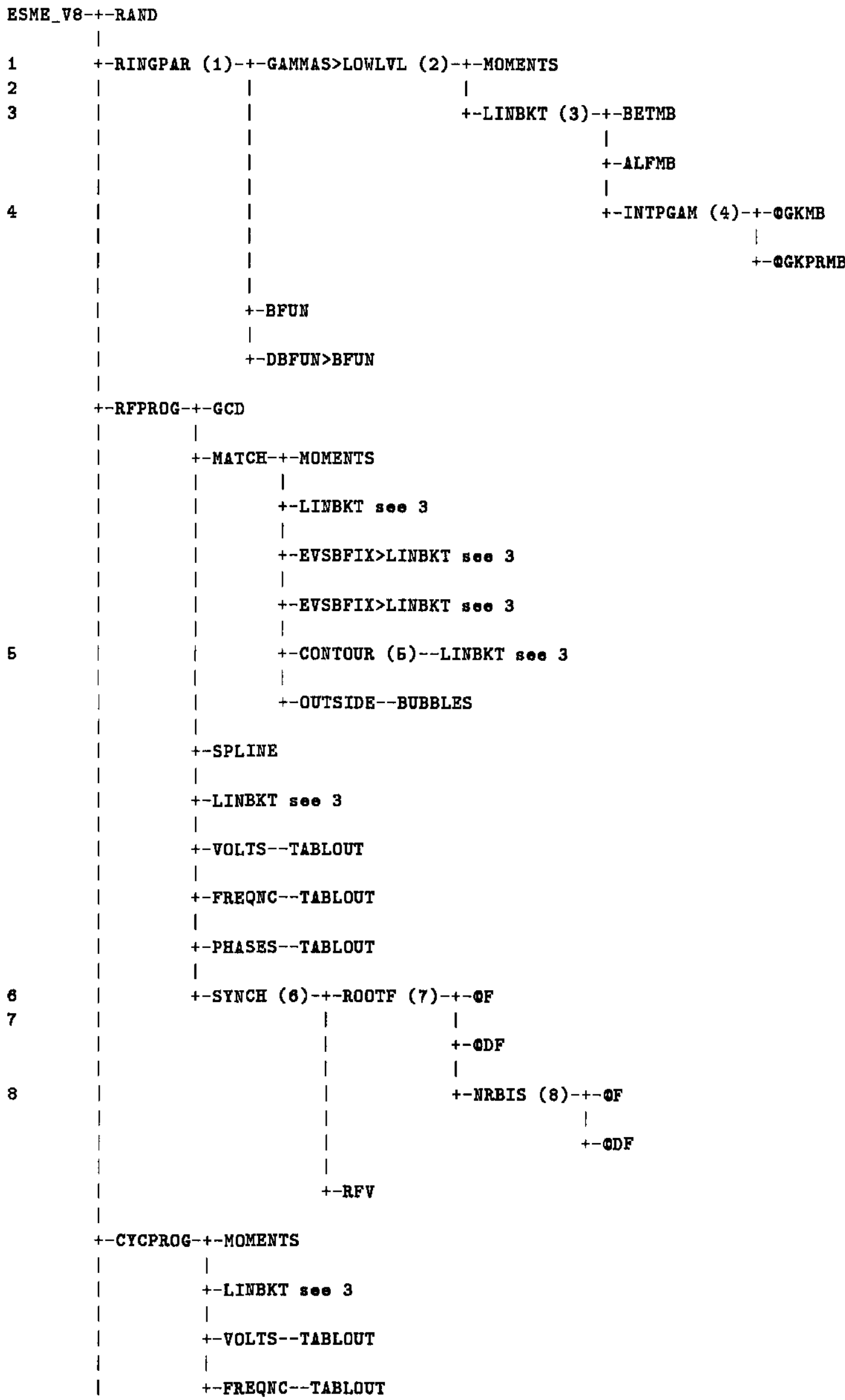




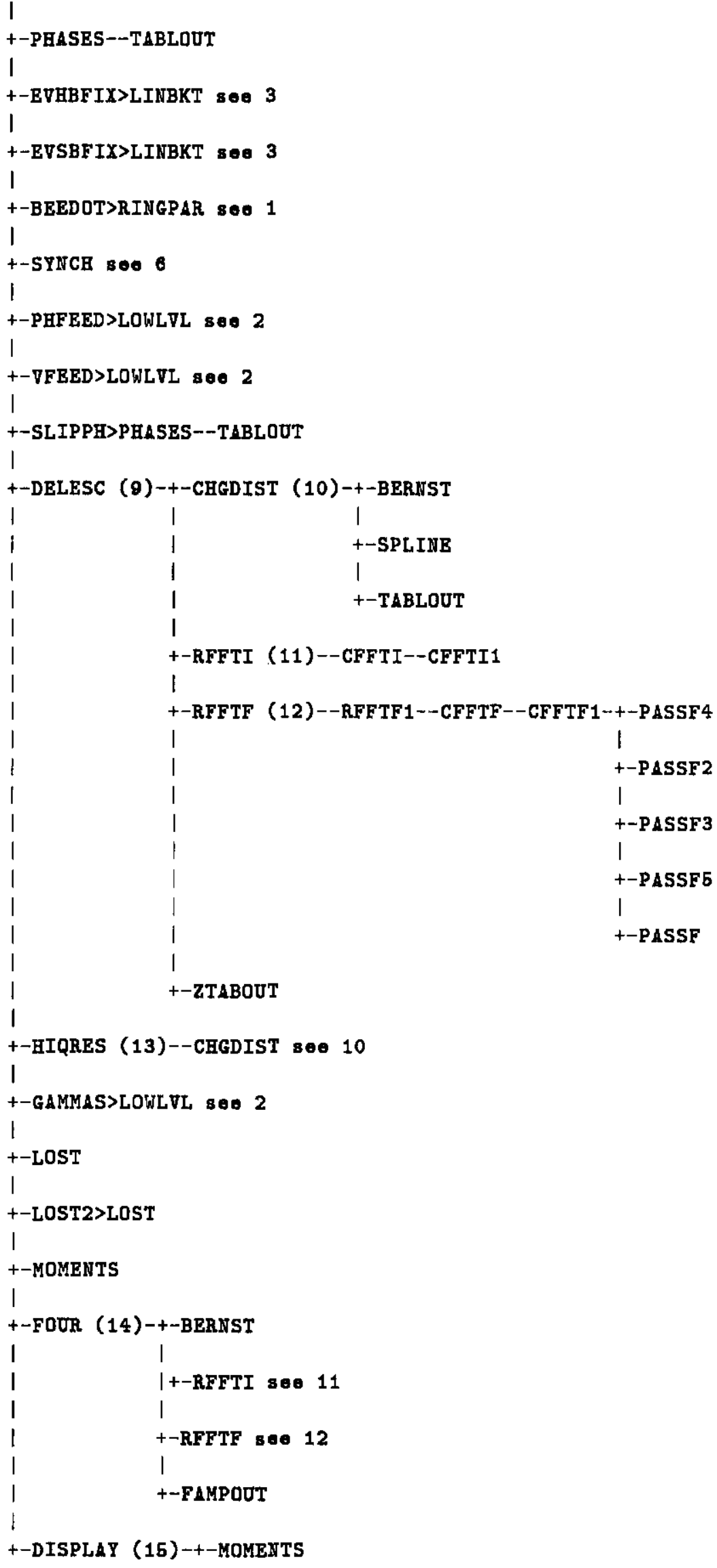




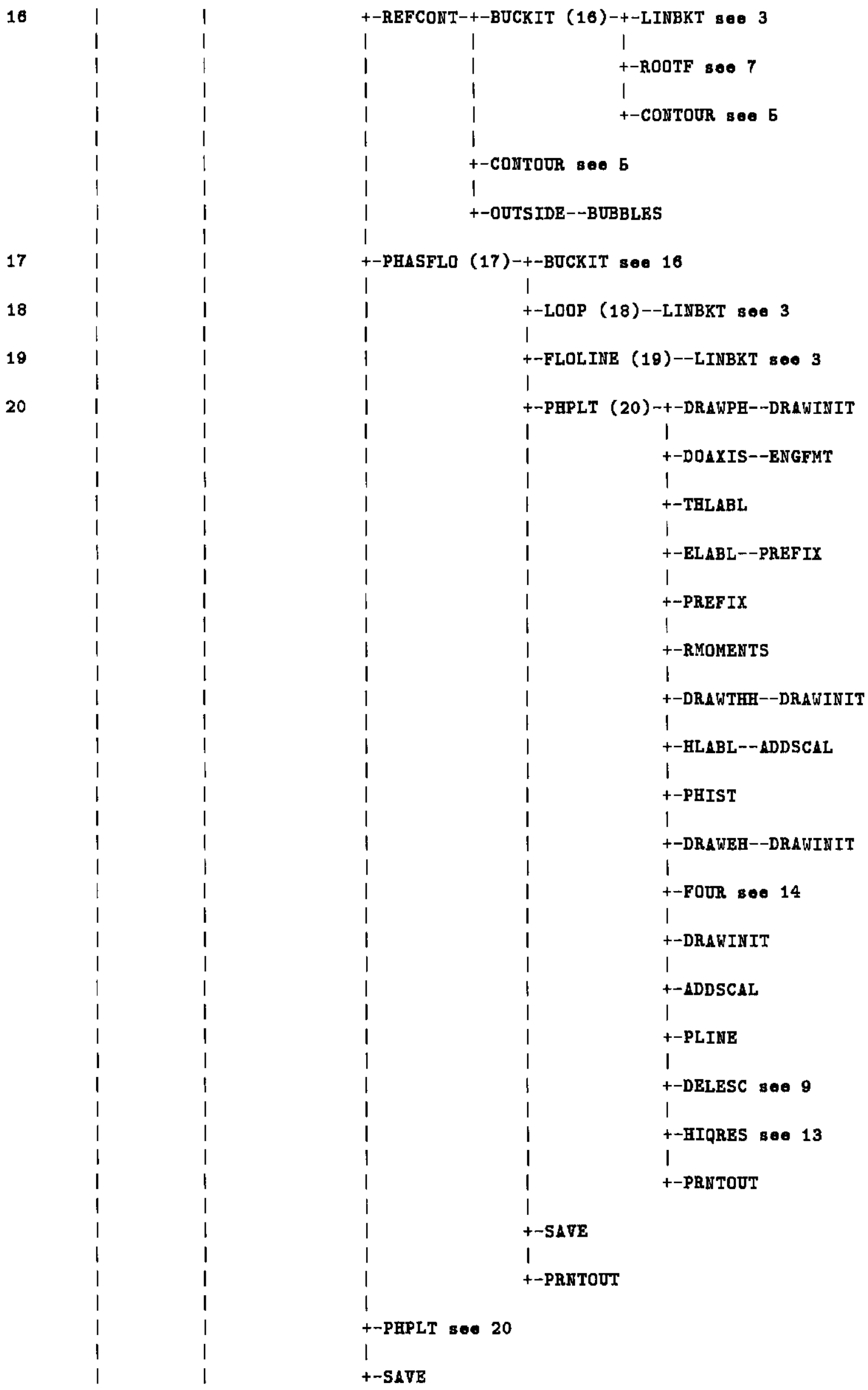




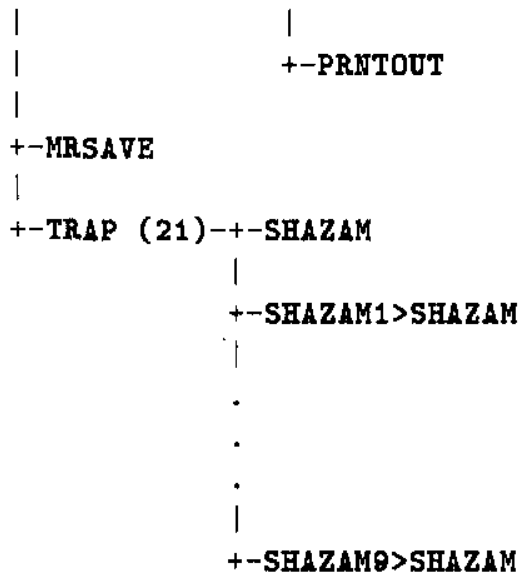




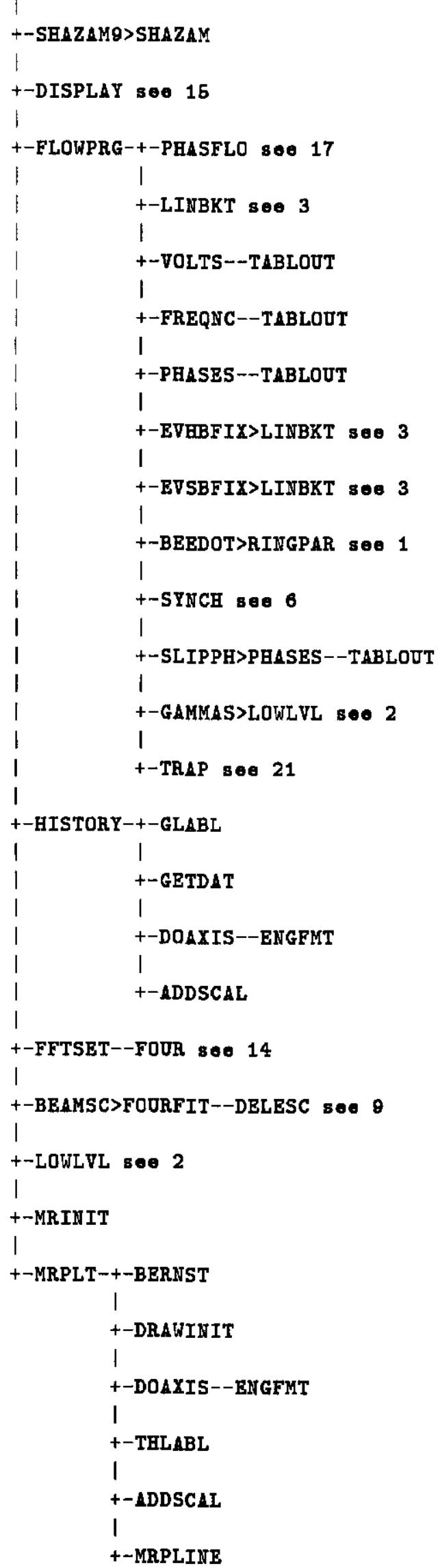




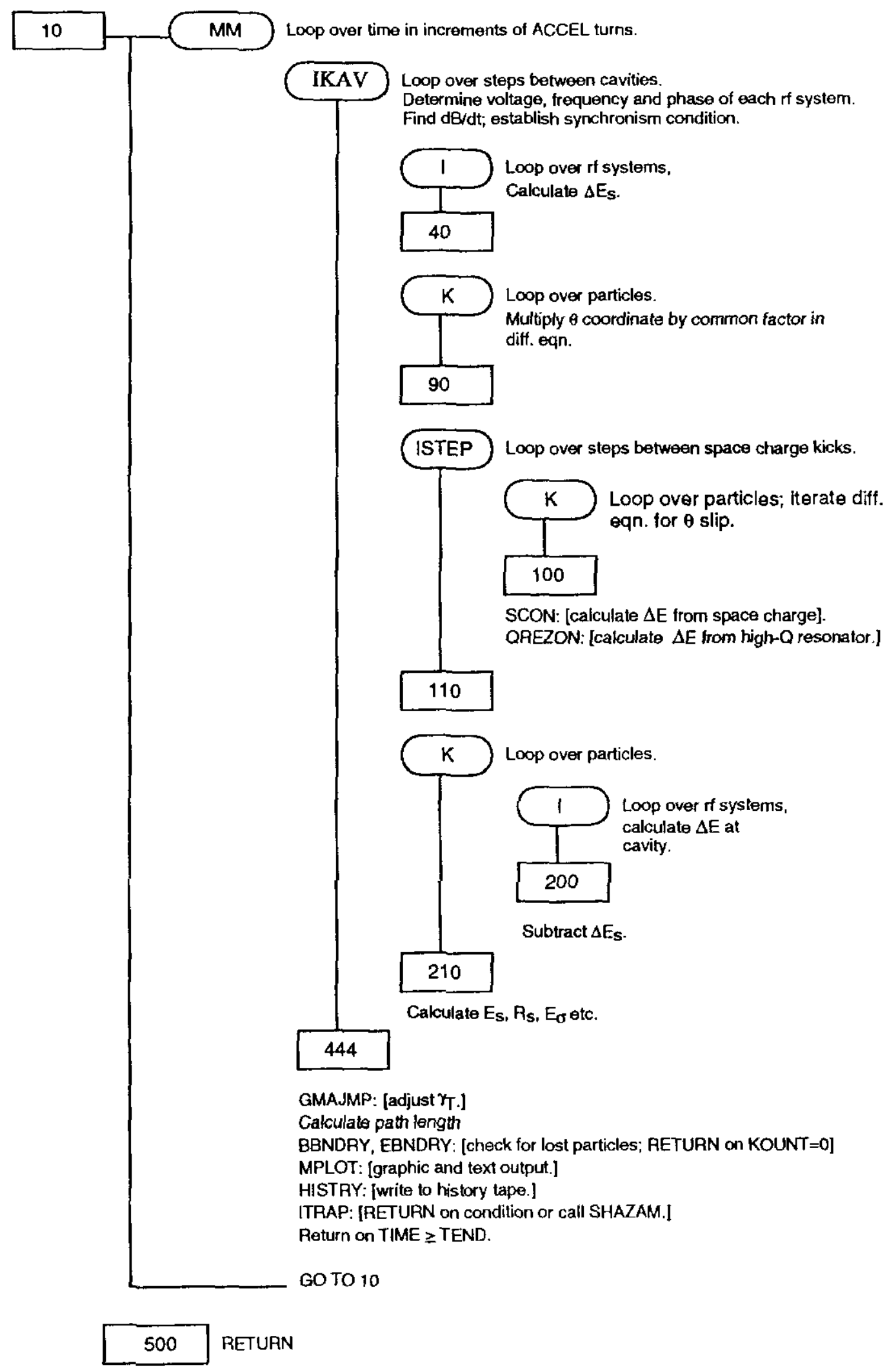

Figure 4.1: Schematic representation of the main tracking loop in ESME; see text in the main tracking loop section for details of notation. 


\subsubsection{Main tracking loop}

The fundamental mapping or tracking algorithm is contained in the subroutine CYCPROG which is called when a $\mathbf{T}$ command is encountered in the data stream. The subroutine reads data for the number of turns to track etc. and then tracks successive turns applying the difference equations to each particle on each turn. At the end of each turn the tracking duration is checked, various properties of the distribution are calculated, system parameters are updated, and tests are applied to see if any selected parameter has reached a desired endpoint. The loop structure is schematized in Fig. 4.1.1. The boxed numbers in the figure are Fortran statement numbers relating the depicted structure to the Fortran listing. These markers should help the intensely curious or thoroughly sceptical find his way through the core code. An IF loop is depicted in the diagram by its head statement number in a box to the outside of a vertical line representing the scope of the loop; a DO loop is represented with its terminating number in a box at the end of the vertical line representing its scope. The names of loop counters are given within ovals. The variable names followed by square brackets [...] are those of switches which control optional calculations; the calculation controlled is indicated by th text within the brackets.

\subsubsection{Important variables}

The various named common blocks are listed below. Each entry includes a statement of purpose and a list of all the included variables. If the variables come primarily from one subroutine, that subroutine is named on the last line of the entry; likewise, if a significant number of the variables come directly from the input data, the controlling NAMELIST is identified also. Not included are EQUIVALENCE statements which setup some inclusive arrays to simplify the GET and SAVE functions( $\mathbf{G}$ and $\mathbf{S}$ commands).

C Block parameterizing isolated or barrier bucket generation. PARAMETER (ISRC3 $=10$ ) COMMON /BKTSUP/ THL(ISRC3), THU(ISRC3)

Principal Source: RFPROG

Controlling MAMELIST: /RF/

C THE MAIN STORAGE BLOCK. CONTAINS MPHASE PHASE SPACE COORDIMATES AND

C THE POINTERS TO SEPARATE PARTITIONS OF THE DISTRIBUTION

PARAMETER (NPHASE $=100000$, NKLIM $=60$ )

COMMON /BLANK/ PHASE (0:NPHASE, 2)

COMMON /IBLANR/ KOUNT, KNTSC, KLASSES, KLIMIT ( 0 : NKLIM)

COMMON /LBLANK/ PARTION

LOGICAL PARTION

Principal Source: POPUL8

Controlling NAMELIST: /POPL8/

C BUCKET PARAMETERS TURI-BY-TURN

COMMOI /BUCKET/ PHISL, PHIUSFP, GNUS, SBCKT , HBCKT

COMMON /IBUCKET/ NFIRST, HL.AST

Principal Source: CYCPROG

C BUNCH PARAMETERS TURH-BY-TURH

COMMON /BUHCH/ THBAR, EBAR, THRMS, ERMS, EPS ILON, SBUWCH, AHORM

Principal Source: CYCPROG 
C CONTAINS MATHEMATICAL AND PHYSICAL CONSTANTS, PROGRAM CONSTANTS, AND

C CONVERSION FACTORS FROM EXTERHAL TO INTERHAL UNITS COMMON /CONST/ HALFPIE, PIE, TWOPIE, FOURPIE, RADDEG , DEGRAD, BIG , SMALL, 1 C, EMCSQ, EMCSQS, RP, QE , ZMAUGHT

Principal Source: BLOCK DATA

C MISCELLANEOUS PARAMETERS AND INTERMEDIATE RESULTS TURN-BY-TURN PARAMETER (KSRC $=10$ ) COMMON /CURRENT/ ES,PS, RS, BETAS, BETASQ, ETA, EO, PO, BETAO, ACCEL, 1 THREF, EREF, TAU, TIME , DEBFLD , PDOT , DPODT , ELO , EHI , TGCURR, GMSQINV , 2 DELEREF, DELR, RFFREQ, PHIS, DELES,

$4 \quad$ EV (KSRC), PSIO (KSRC), PSI (KSRC), FREQ (KSRC)

COMMON / ICURRENT/ M, MM, NTURIS, MHIST

COMMON /LCURRENT/ TRPSW, TRAISW

LOGICAL TRPSW, TRANSW

Principal Source: CYCPROG

C PHASE SPACE COORDINATES OF BUCKET OR OTHER CONTOUR OF INTEREST

PARAMETER (ICURVE $=5001$ )

COMMON / CURVES/ CURVE(ICURVE, 2 ), $\operatorname{TURNPT}(4,3), \mathbb{N C}$

Principal Source: BUCKET \& REFCONT

C PARAMETERS GOVERHING DURATION \& OPTIONAL FEATURES OF THE TRACKING CALCULATION PARAMETER (NTRP $=4$ )

COMMON /CYCLP/ TBEGIH, TELD, TSTART, TSTOP, TTRACK, 1 ACCELO, ETATRP, PHISTRP

COMMON /ICYCLP/ MSTEP, LGRTHM, ITRAP (NTRP), MGRACE (NTRP), NTRAP

COMMON /LCYCLP/ HISTRY, MOMITS , BBDRY, EAPROX

LOGICAL HISTRY, MOMHTS, BBDRY, EAPROX

Principal Source: CYCPROG

Controlling NAMELIST: /CYCLE/

C PARAMETERS DEFIUING FEEDBACK LOOPS (CURRENTLY PHASE \& VOLTAGE - NO RADIAL)

PARAMETER (IFBPRS $=1001$ )

COMMON /FEEDS/ DLIMIT, PLIMIT, FBFACT, VLIMIT,

1 VFBFCTR, FBPRS (IFBPRS), PSIADD, DAMPL , W(IFBPRS)

COMMON / IFEEDS/ HTUAVG, NTURES, IFTB

COMMON /LFEEDS/ PHFBON, VFBOH, USEVT

LOGICAL PHFBON, VFBON, USEWT

Principal Source: LOWLVL

Controlling NAMELIST: /LLRF/

C The parameters governing the generation of phasespace flow contours

COMMON/FLOWP/ ELMAX, ELMIH

COMMON/IFLOWP/ LIMES

Principal Source: FLOWPRG

Controlling RAMELIST: /FLOW/ 
C PARAMETERS DEFINING AND RESULTS OF FOURIER TRANSFORM OF CHARGE DISTRIBUTION

PARAMETER (IFFT $=1024$, NFMAX $=50$ )

COMMOV /FOURIR/ BH,OBWGT, FAMPL (NFMAX), FAZE(NFMAX),

$+\quad$ WSAVE $(3 *$ IFFT+15),F(IFFT), G(IFFT)

COMHON /IFOURIR/ NBINFFT, MFFT, NNF, NBSAV, NIXNOIS, ITKNT, NF (NFMAX)

COMKON /LFOURIR/ FFTON

IOGICAL FFTON

Principal Source: FFTSET

Controlling NAMELIST:/FFT/

C Parameters defining txansition gamma time dependence and

C transition phase switch timing.

COMMON /GAMJMP/ GAMPAR(5),ETAJMP

COMMON /IGAMJMP/ KINDG

COMMON /LGMAJMP/ GMAJMP

LOGICAL GHAJHP

Principal Source: RINGPAR

Controlling NAMELIST:/RING/

C PARAMETERS DEFINING DESIRED GRAPHICAL OUTPUT

PARAMETER (ISIZGM $=10000$, ISIZPH $=2000$, IGKSER $=13$, IGKSMT $=14$ )

COMMON /GRAFIX/ THPHIN, THPMAX, DEPMIN, DEPMAX, DTHCURV, DECURV,

1 THBHIN, THBMAX, EBMIN, EBMAX,

2 HBCKTN, SBCKTH, SREF, REFAREA,

3 SCBHIN, SCBMAX, RBMIN, RBMAX, DELCON,

4 XCRNR, YCRNR, XAXISL, YAXISL

COMHON /IGRAFIX/ IDEV, MPLOT, IRF, ICONTUR, IEREF, KNTLIM,

1 NBINTH, NBINE, IFBMIN, IFBMAX, NP JMP, KLPLOT, NBPFFT, IMETA

COMMON /GRAFM/ IGMARY (ISIZGM), IPHARY(ISIZPH)

COMMON /LGRAFIX/ POSTP, NODRAW, PLTSW(20), TITLE, DRWREF

LOGICAL PLTSW, TITLE, DRWREF, NODRAW, POSTP

Principal Source: GRAFSET

Controlling RAMELIST: /GRAPH/

C DESCRIPTIVE HEADING FOR GRAPHICAL OUTPUT

PARAMETER (MAXTTL=50)

COMMON /HEADING/ TITL

COMHON /IHEADING/ TITLEN

CHARACTER TITL*50

INTEGER TITLEN

Principal Source: GRAFSET

C Include specifying mountain range parameters.

C For saving data (plotting parameters are local to MRPLT).

COMMON /MRANGE/ MRTHMIHB, MRTHMAXB, TMBEGIH, TMEND

REAL MRTHMINB, MRTEMAXB, THBEGIH, TMEND

COMMON /IMRAHGE/ MRMPLOT, MRNBIN

INTEGER MRMPLOT, MRNBIN

Principal Source: MRINIT

Controlling NAMELIST: /MRANGE/ 
C THE PARAMETERS DEFINING THE INITIAL PHASESPACE DISTRIBUTION(S)

COMMON / POPLATE/ THMIN, THMAX, REMIN, REMAX,

1 SBNCH, THOFF, EOFF, THTRAN, ETRAN, SEED

COMMON /IPOPLATE/ KIND, IPOP, ITH, IE, NPOINT

Principal Source: POPUL8

Controlling NAMELIST: /POPL8/

C PARAMETERS DEFINIMG THE RF SYSTEMS

PARAMETER ( $I S R C=10)$

COMMON /RFP/

1 VI(NSRC), VF (NSRC), TVBEG (HSRC), TVEHD (ISRC), VTABL $(5,21$, ISSR),

2 FRI (NSRC), FRF (NSRC), TFBEG (HSRC), TFEND (ISSRC), FTABL $(5,21$, HSRC),

3 PSII (NSRC), PSIF (HSRC), TPBEG (HSRC), TPEHD (ISRC),

$4 \operatorname{PTABL}(5,21$, MSRC) , C1 (ISRC), C2(NSRC), DELTRF (ISRC),

5 HDECR, SDECR, PHISLIM

COMMON /IRFP/ MRF, H(USRC), HW (HSRC), HGCD, HMAX, ISYNC,

1 KURVE (NSRC), NTV (NSRC), NTABV (ISRC),

2 KURVF (ISRC), NTF (NSRC), NTABF (NSRC),

3 KURVP (NSRC), NTP (NSRC), NTABP (NSRC)

COMMON /LRFP/ VKON, FRKON, PHKON, PHSLIP, HOLDBH, HOLDBA, CNTINU,

1 VMATCH (NSRC), RFTOPH

INTEGER H, HW, HGCD, HMAX

LOGICAL VKON, FRKON, PHKON, PHSLIP, VMATCH

LOGICAL HOLDBH, HOLDBA, CNTINU(NSRC), RFTOPN

Principal Source: RFPROG

Controlling NAMELIST: /RFP/

C THE LATTICE PARAMETERS INCLUDING TIME DEPENDENCES

COMMON /RIMGP/ REQ, GAMMAT, ALPHAO, ALPHA1, ALPHA2, ALPHA3,

1 TAUINF, WOI, WOF, EKOI, EKOF, TI, TF, POI, POF , PI , PF,

2 WOIDOT, WOFDOT, EKIDOT, EKFDOT, POIDOT, POFDOT, PIDOT, PFDOT,

3 THLO, THHI, THRHG, FRAC, DES, PIPRAD

COMMON /IRIWGP/ KURVEB, ITCAV

COMMON /LRINGP/ JWRAMP, EBDRY

LOGICAL JWRAMP, EBDRY

Principal Source: RIBGPAR

Controlling NAMELIST: /RING/

C AREA TO BE USED WITHIN \& SINGLE SUBROUTIME ON $\$$ GIVEN CALL (MOSTLY GRAPHICS)

PARAMETER ( $M M A X=10000)$

COMMOH /SCRATCH/ SCRPAD (MMAX)

C Contains "spare" variables which are written to history

C along with everything else. These can be whatever the user

C wishes; these commons are available to CYCPROG and SHAZAM.

C Also contains labels for spares used in history plots.

PARAMETER (HSPARE $=10$, TITLL $=14$, UNITL $=7$ )

COMMON /SPARES/ SPARE (HSPARE)

COMMON /CSPARES/ SPLABL (MSPARE), SPUNIT (NSPARE)

CHARACTER $* 14$ SPLABL

CHARACTER $* 7$ SPUNIT

Principal Source: CYCPROG 
C PARAMETERS DEFINING THE SPACE CHARGE \& WALL IMPEDANCE ENERGY/TURN

PARAMETER (ITBOUT $=40$, IRLLEN $=30$, LEVSC $=1024$, MAXRB $=10000$ )

COMMON /SPCHG/ A, B, ENQ, TSCON, EVSCAV, BWSC,ZTABL (ITBOUT , 9),

1 EVSC (LEVSC), RESTBL (IRLLEN, 4),

2 VRES (MAXRB), RVO(IRLLEN), RVODOT (IRLLEN)

COMMON /ISPCHG/ $\mathbb{H Z}, \mathbb{H R}$, MSC, MBINSC, MBRES

COMMON /LSPCHG/ SCON, QREZON

LOGICAL, SCON

Principal Source: FOURFIT

Controlling NAMELIST:/SCHG/

\author{
C A BLOCK TO CONTAIN CPU TIME SIHCE START \\ COMMON/TIMES/ CPUBEG,CPUNOW \\ COMMON/ITIMES/ ITIME, IRCOD1, IRCOD2 \\ DOUBLE PRECISION CPUBEG, CPUHOW \\ C Record the version number for program documentation a debugging. \\ C VERNUM is the version of ESME \\ C PVER is the post-processor version number. \\ C Version 8.03 (alpha) 04 Feb 93 \\ PARAMETER (VERHUM=8.03, PVER=2.00)
}

\title{
4.2 Code Management
}

ESME has undergone a protracted evolution. The changes resulting from the facilities for generating phase space flow lines and a more refined treatment of the beam-generated potential are sufficient to mark v. 8 as a major revision. When Steve Stahl joined the effort to turn v. 6.5 into v. 7.xx, he developed a coordinated suite of command level procedures for running, compiling, and maintaining the code for use on several different computers. These procedures have been modified a little here and there, but still serve the v. 8.1 user and the effort to develop and maintain the code. The tools described below are to aid in the process of coding. The following two sections detail these tools and their use. It is not necessary to read the first section to make use of these tools, so the impatient reader may skip immediately to Section 4.2.2.

\subsubsection{Tools - an overview}

The development process has used VAX DEC/Module Management System (MMS) in conjunction with VAX DEC/Code Management System (CMS), ${ }^{1}$ and Fermilab's CDF EXPAND[18] utility. CMS is used to maintain a source-code library for ESME. MMS is used to construct the executable version of the code.

MMS is patterned after the UNIX ${ }^{2}$ make utility. At the heart of MMS is a description file, which MMS processes to determine what actions are necessary to produce an up-to-date executable version of the "target", which in the case of ESME is an executable version of the program. The description file consists of dependency "rules" and action lines. Each dependency rule consists of a target and its sources (e.g., A.EXE and A.OBJ). MMS compares the dates of the targets and sources to determine if the target is older than any of the sources. If so, the target needs to be "updated", and in that case the action specified on the action line is executed. A simple example of a description file for ESME might be:

\footnotetext{
${ }^{1}$ VAX, DEC/MMS, and DEC/CMS are trademarks of Digital Equipment Corporation.

${ }^{2}$ UNIX is a registered trademark of American Telephone and Telegraph Company.
} 


\section{ESME.EXE : ESME.OBJ \\ LINK ESME \\ ESME.OBJ : ESME.FOR \\ FORTRAN ESME}

in which all the source code for ESME is found in ESME.FOR. Of course, the description given here is incomplete. However, the underlying principle itself is very simple - that of updating only those system components necessary to build a new target. Using this system, the process of code development is simplified, since MMS can detect any changes to the common CMS library. In addition, individual users can incorporate their own changes into the code very easily.

As mentioned earlier, the Fermilab utility EXPAND was used with MMS to build the program. Had ESME been intended only for use on VAX systems, EXPAND could have been dispensed with. This utility allows the user to build the program for various machine architectures ${ }^{3}$ from the same source code, in addition to offering various pre-processor options. Of course, in cases where the compiler for the machine architecture does not reside in the environment (i.e., VAX) in which the code is prepared, MMS cannot direct the VAX to compile and link the code. However, presumably, once the source code has been prepared for the destination machine, it can be exported for compilation and linking there. The description files for v. 8 have been changed so that the Fortran include files are pre-processed by the EXPAND utility before inclusion.

\subsubsection{Using the tools}

The relevant command procedures and MMS files are found in USR\$DISK4: [ESME_FILES.MMS]. Generally, the user should first SET the appropriate CMS library and FETCH any routines to be modified. The addition of any routines which are not part of ESME will require the user to modify some of the files in USR\$DISR4: [ESME_FILES.MAKE]. Such operations will not be discussed here, though an examination of the relevant MMS files (V8INC.MMS, V8.MMS, V8SRC.MMS) should provide some illumination as to how to proceed in such a case.

Once the appropriate files have been modified, the VMS user may incorporate them into an executable version of ESME using the prepared command procedure MAKEV8.COM. This procedure then prepares either an executable or source-code version of the program using the routines supplied by the user while supplying the remainder of the routines from ESME libraries. If the procedure USEV8.COM has been invoked, it should be sufficient to simply enter the command MAKESHE. The command procedure will then

1. Ask the user if he wishes to make ESME, ESMEPLOT, or both.

2. Ask whether the output is to be executable or source code.

3. Ask for a location in which to place the output; if one is not already available, then it will be created.

4. Query the user for source files (presumably modified).

5. Query the user for pre-processor and/or compile options.

6. Submit the job to a batch queue.

The resultant executable (assuming no compile time errors) or source code file will be constructed in the specified directory. Note that the prepared procedures for running ESME will not use this version by default. If you've gotten this far, though, you probably know what to do.

\footnotetext{
${ }^{3}$ At present, EXPAND accepts the arguments VAX, CYBER, IBM, ACP_NODE, FTN77, and FPS for the /ENVIRONMEN'T qualifier.
} 


\section{Acknowledgement}

Anyone familiar with the v. 7.1 User's Guide ${ }^{[10]}$ will recognize that this note incorporates entire pages from it verbatim. Steve Stahl did much of the work for the earlier writeup, but, because he is not around to vet this product, it does not seem fair to implicate him as an author and potential target for a frustrated user. Therefore, I gratefully acknowledge here his major contributions to the evolution of versions 7.xx from v. 6.5 and his lead role in creating the v. 7.1 User's Guide. These contributions include, but are not limited to, generalization of the code, graphics improvements, critiques of the fundamentals, initial coding of the time domain option for calculating the collective potential, developing a suite of command-level (DCL) procedures, and organizing the User's Guide. For four years from early 1987 through early 1991 Steve provided the continuity and much of the substance for the development of ESME. 


\section{Appendix A}

\section{Post-Processing}

For those users who wish to process ESME data independently of the program, a post-processor option is provided. ${ }^{1}$ When this option is in effect, any plotting routine calls are substituted for by writes of ESME's common blocks (containing essentially all of the information about the current state of the simulation) to FORTRAN unit 18 using subroutine SAVE. Later, this file may be read using subroutine GET. The code for a graphics post-processor is appended here as an example. The plotting routines employed here are the same ones imbedded in ESME. This command "shell" is modelled after that of the main program. As in ESME, one-letter commands initiate various routine calls and namelist reads. Since the plotting routines are those of ESME, for which the graphical output options set in the $\mathbf{O}$ Command were specifically intended, the user can construct plots using those options set during the running of the program as retrieved from COMMON. Those employing other graphics routines may wish to implement another sort of interface entirely (e.g. menu-driven), with an entirely different set of output options.

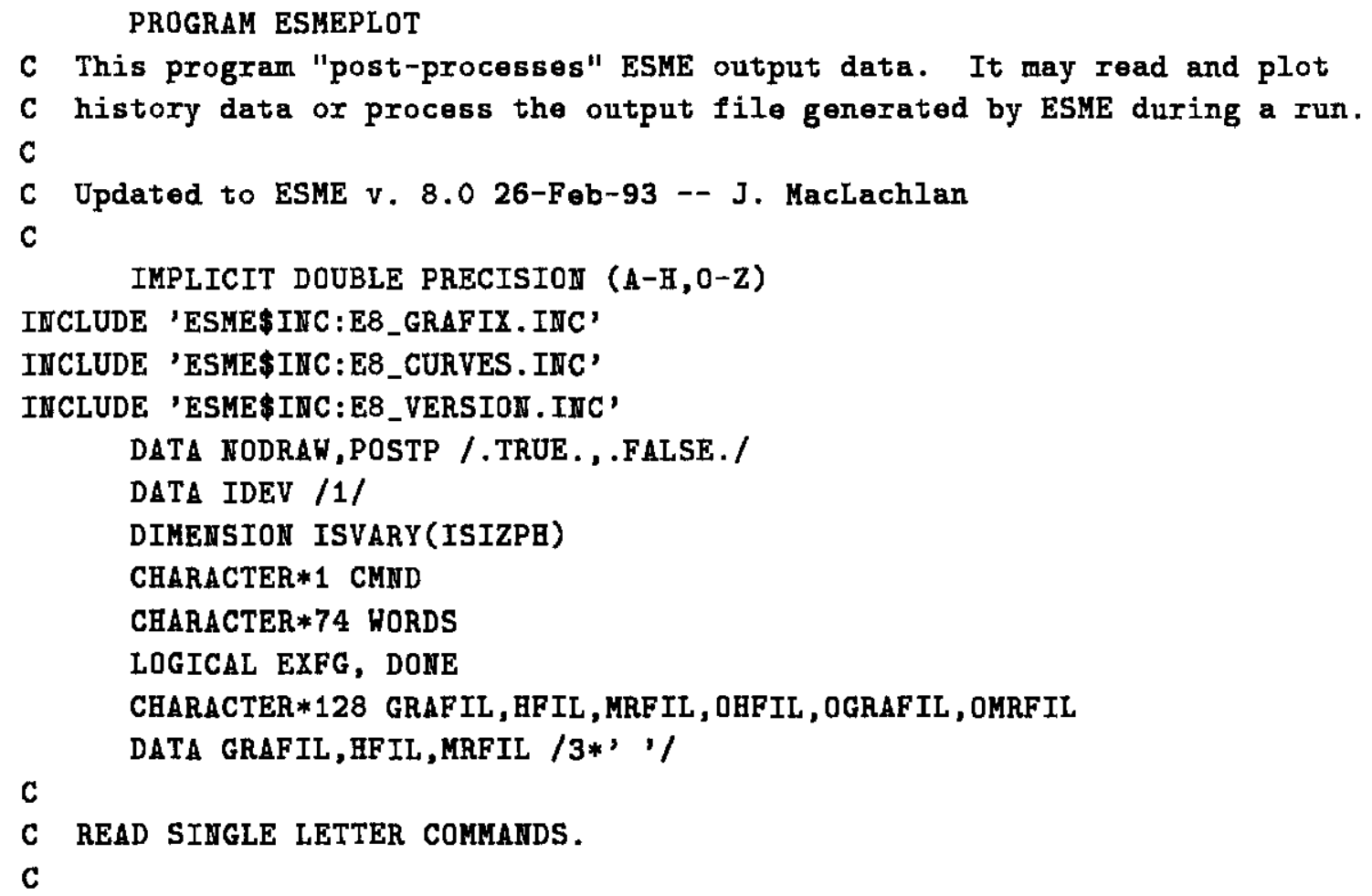




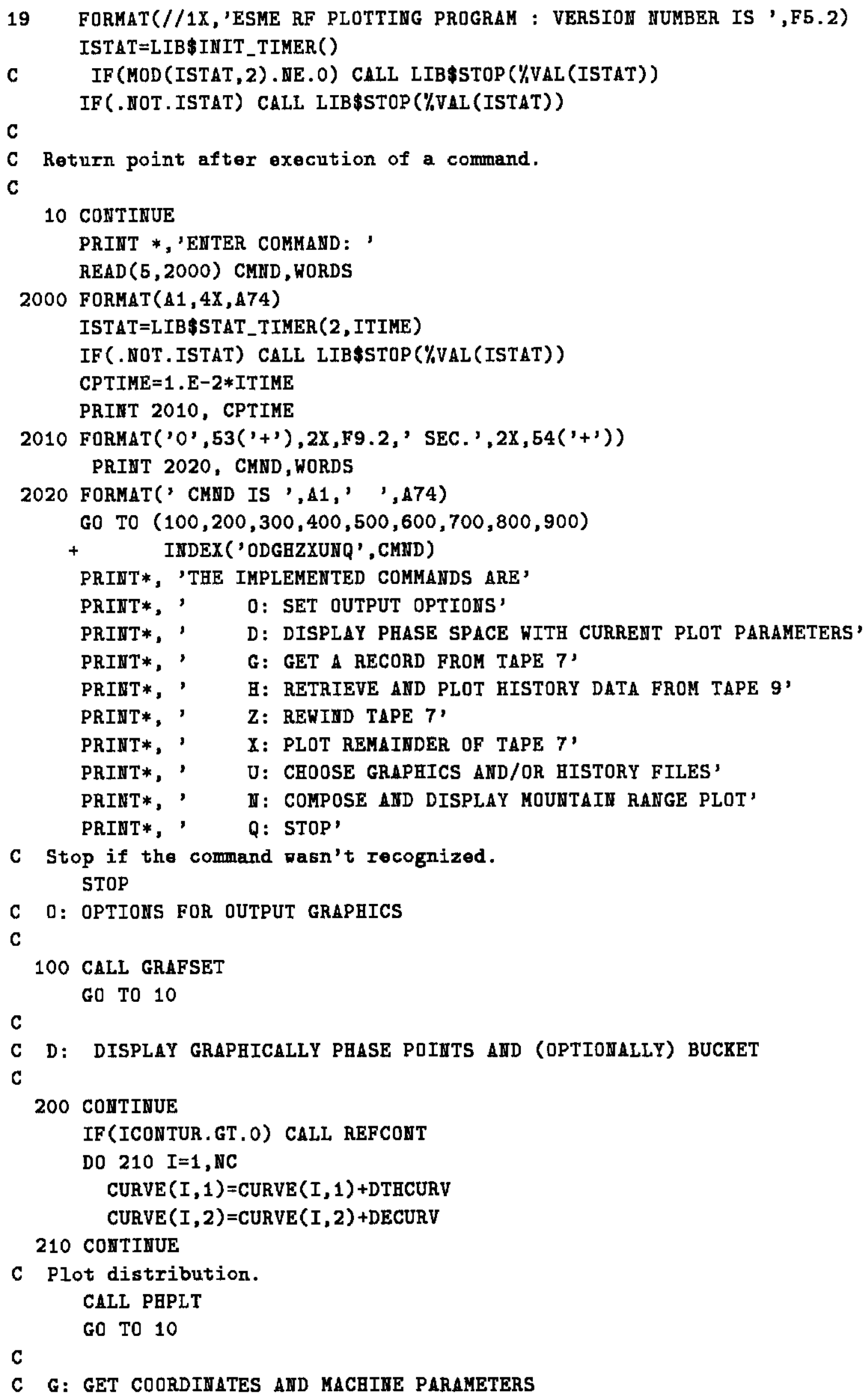


C

300 PRINT *, 'READING COORDIHATES AND MACHINE PARAMETERS'

$C$ Save logical telling us whether we have initialized

C DI-3000 or not and reset it after restoring coMMONs.

C Also save phase space plot template.

SAVWD $=$ HODRAW

C DO $310 \quad I=1$, ISIZPH

C $\operatorname{ISVARY}(I)=\operatorname{IPHARY}(I)$

C 310 CONTINUE

CALL GET (.TRUE. , ITURN, DONE)

HODRAW $=$ SAVND

C DO $320 \quad I=1$, ISIZPH

C IPHARY (I) $=$ ISVARY (I)

C 320 CONTIHUE

POSTP $=$. FALSE .

PRINT *, 'DATA FOR TURN ',ITURH,' READ'

GO TO 10

C

C H: HISTORY OF IMPORTANT PARAMETERS COLLECTED ON TAPE9 EACH STEP

C

400 CALL HISTORY (.TRUE.)

GO TO 10

C

C

C

$\mathrm{C}$

$\mathrm{C}$

500 REWIND (7)

C Save logical telling us phether we have initialized

C DI-3000 or not and reset it after restoring COMMONs. SAVWD = MODRAW

C DO $510 \mathrm{I}=1$, ISIZPH

C ISVARY (I) $=$ IPHARY (I)

C 510 COHTINUE

CALL GET (.TRUE., ITURN, DONE)

NODRAH=SAVND

C DO $520 \mathrm{I}=1$, ISIZPH

C IPHARY (I) $=$ ISVARY (I)

C 520 CONTINUE

POSTP = . FALSE .

PRINT *, 'DATA FOR TURI ', ITURN,' READ'

GO TO 10

C

c $\mathrm{X}$ : JUST PLOT EVERYTHIVG FROM HERE ON OUT

C

600 CONTINUE

C Save logical telling us whether we have initialized

C DI-3000 or not and reset it after restoring COMHONs.

SAVWD= INODRAW

CALL GET (. TRUE. , ITURH, DONE) 


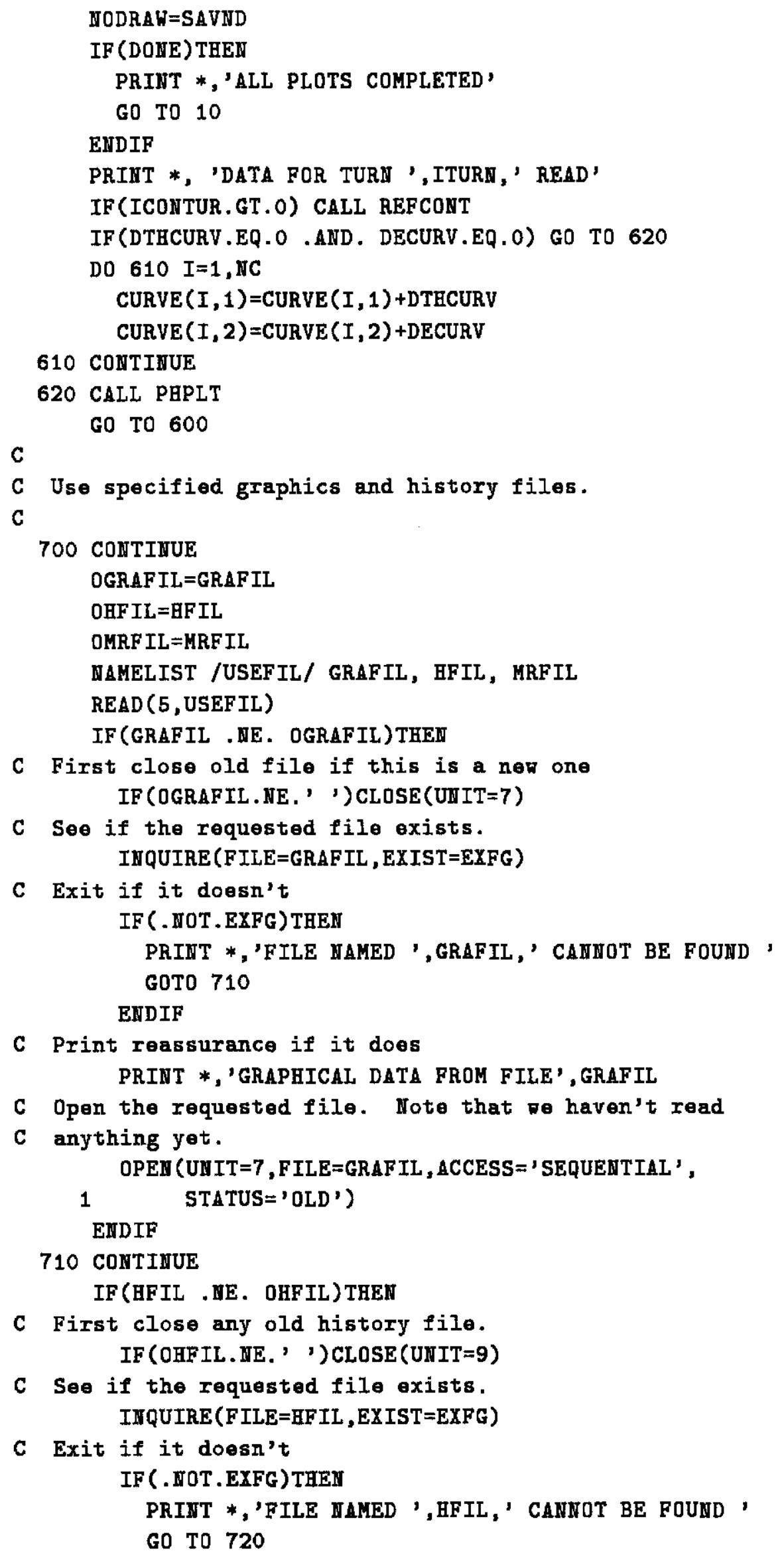


C Print reassurance if it does

PRINT *, 'HISTORY DATA FROM FILE', HFIL

C Open the requested file.

OPEN (UNIT =9 , FILE=HFIL , ACCESS= 'SEQUENTIAL',

1 STATUS='OLD')

ENDIF

720 CONTINUE

IF (MRFIL . NE. OMRFIL)THEN

C First close old file if this is a new one

IF (OMRF IL . NE.' ') CLOSE (UNIT=20)

C See if the requested file exists.

INQUIRE (FILE=KRF IL , EXIST=EXFG)

C Exit if it doesn't

IF ( . NOT . EXFG) THEN

PRINT *,'FILE HAMED ', MRFIL,' CANHOT BE FOUND '

GOTO 730

ENDIF

C Print reassurance if it does

PRINT *, 'GRAPHICAL DATA FROM FILE', MRFIL

C Open the requested file. Hote that we haven't read

C anything yet.

OPEW (UNIT=20, FILE=MRF IL , ACCESS= ' SEQUENTIAL' ,

1 STATUS= 'OLD')

ENDIF

730 CONTINUE

GO TO 10

C

C M: DISPLAY MOUNTAIN RANGE(s)

C

800 CONTINUE

CALL MRPLT

GO TO 10

C

C Q: QUIT PROGRAM ENTIRELY; HOTHIHG FURTHER TO DO

C

900 CONTINUE

PRINT *, 'QUIT COMMAND'

C

C Terminate DI-3000 and GRAFMAKER; if necessary.

C

IF (. NOT. NODRAW) CALL JCETRM(.TRUE.)

STOP

C

EID 


\section{Appendix B}

\section{Command Table Summary}

This appendix is added as a quick reference for those who wish to avoid leafing through the entire document. 


\begin{tabular}{|c|c|c|c|}
\hline \multicolumn{4}{|r|}{ R Command, Namelist/RING/ } \\
\hline \multirow[b]{2}{*}{ Variable } & \multicolumn{2}{|c|}{ Default } & \multirow[b]{2}{*}{ Description } \\
\hline & Value & Unit & \\
\hline$\overline{\mathrm{RE}} \overline{\mathrm{B}}$ & None & $\overline{\mathbf{m}}$ & The reference radius for the central orbit \\
\hline GAMMAT & None & - & Transition $\gamma$ \\
\hline A.LPHAI & None & $=$ & $\begin{array}{l}\text { Coefficient of } \Delta p / p \text { in series expansion for length difference between particle trajec- } \\
\text { tory and reference orbit }\end{array}$ \\
\hline ALPHA2 & None & - & Coefficient of $(\Delta p / p)^{2}$ in series for path length difference \\
\hline ALPHA3 & None & - & Coefficient of $(\Delta p / p)^{3}$ in series for path length difference \\
\hline WoI & None & $\mathrm{MeV}$ & Kinetic energy on the central orbit at $\mathrm{T}=\mathrm{TI}$ \\
\hline WOF & 0.0 & $\mathrm{MeV}$ & Kinetic energy on the central orbit at $\mathrm{T}=\mathrm{TF}$ \\
\hline$\overline{\mathrm{POI}}$ & None & $\mathrm{MeV} / \mathrm{c}$ & Momentum on the central orbit at $\mathrm{T}=\mathrm{TI}$ \\
\hline $\mathrm{POF}$ & 0.0 & $\mathrm{MeV} / \mathrm{c}$ & Momentum on the central orbit at $\mathrm{T}=\mathrm{TF}$ \\
\hline TI & 0.0 & s & Start time of magnetic field change \\
\hline$\overline{T F}$ & 0.0 & s & End time of magnetic field change \\
\hline TSTART & 0.0 & s & Time at which tracking begins \\
\hline FRAC & 1. & $\ddot{-}$ & $\begin{array}{l}\text { Determines azimuthal periodicity, calculation restricted to }-180^{\circ} / \text { FRAC } \leq \vartheta \leq \\
180^{\circ} / \text { FRAC }\end{array}$ \\
\hline$\overline{\mathrm{NCAV}}$ & $\mathbf{1}$ & - & Number of rf locations (default usually adequate) \\
\hline PIPRAD & 1.0 & $\mathbf{m}$ & Radius of beam pipe for particle loss \\
\hline EBDDRY & $\overline{\mathbf{F}}$ & - & Sets absorbing beam pipe walls at REQ \pm PIPRAD \\
\hline DES & 0.0 & $\mathrm{MeV}$ & Energy offset of synchronous orbit relative to reference orbit \\
\hline KURVEB & 1 & - & $\begin{array}{l}\text { Magnetic field ramp from WOI to } \overline{W O F} \text { or POI to POF: } \\
1 \text { - Linear } \\
\text { 2 - Increasing parabolic } \\
3 \text { - Biased sinusoidal } \\
\text { 4 - Decreasing parabolic } \\
5 \text { - Parabolic with final slope WOFDOT } \\
6 \text { - Parabolic with final slope POFDOT } \\
7 \text { - Cubic with zero initial slope and curvature }\end{array}$ \\
\hline WOIDOT & 0.0 & $\mathrm{MeV} / \mathrm{s}$ & Slope of parabolic ramp at TI \\
\hline WOFDOT & $\overline{0.0}$ & $\mathrm{MeV} / \mathrm{s}$ & Slope of parabolic ramp at TF \\
\hline POIDOT & 0.0 & $\mathrm{MeV} / \mathrm{c} / \mathrm{s}$ & Slope of parabolic ramp at $\overline{\mathrm{T}} \overline{\mathrm{I}}$ \\
\hline POFDOT & 0.0 & $\mathrm{MeV} / \mathrm{c} / \mathrm{s}$ & Slope of parabolic ramp at $\mathrm{TF}$ \\
\hline JNRAMP & $\mathrm{F}$ & - & $\begin{array}{l}\text { Establishes starting point of ramp as point at which program finds itself-for } \\
\text { smoothly piecing ramp segments together }\end{array}$ \\
\hline GMAJMP & $\overline{\mathbf{F}}$ & - & Set $\gamma_{\mathrm{T}}$ jump on \\
\hline KINDG & 1 & - & $\begin{array}{l}\text { Type of } \gamma_{\mathrm{T}} \text { variation: } a \\
1-\text { Linear }\left(\gamma_{\mathrm{T}}=\operatorname{GAMPAR}(1)+\mathrm{GAMPAR}(2) * \mathrm{~T}\right) \\
2 \text { - Decreasing exponential } \\
\left(\gamma_{\mathrm{T}}=\operatorname{GAMPAR}(1)+\operatorname{GAMPAR}(3) *\left(1-e^{-\mathrm{T} / \mathrm{GAMPAR}(2)}\right)\right)\end{array}$ \\
\hline GAMPAR $(1: 3)$ & 0.0 & - & Coefficients for $\gamma_{\mathrm{T}}$ variation \\
\hline
\end{tabular}

${ }^{a} \mathrm{~T}=0$ corresponding to time at which $\mathbf{R}$ command is invoked with GMAJMP $=$.TRUE. 


\begin{tabular}{|c|c|c|c|}
\hline & & & A Command, Namelist / RF \\
\hline & Det & & \\
\hline Variable & Value & Unit & Description \\
\hline NRF & 1 & - & Number of active RF sources \\
\hline $\mathbf{H}(1: 10)$ & 1 & - & Harmonic numbers of sources (integers) \\
\hline HW(1:10) & 1 & - & Voltage sources will be "active" for $-180^{\circ} / \mathrm{HW} \leq \theta \leq 180^{\circ} / \mathrm{HW}$ \\
\hline ISYNC & 0 & - & $\begin{array}{l}\text { Indicates synchronism condition to be imposed on RF: } \\
0 \text { - None, voltages and phases remain as programmed } \\
1 \text { - Phase of RF waveform shifted to synchronous, stable point } \\
2 \text { - Magnitude of RF waveform scaled to give correct synchronous energy gain } \\
3 \text { - Source } 2 \text { acts as Landau cavity to source } 1 \text {; synchronism only assured for sources } \\
1 \text { and } 2\end{array}$ \\
\hline $\mathrm{VI}(1: 10)$ & 0.0 & MV & Voltage of source I at time TVBEG(I) \\
\hline $\mathrm{VF}(1: 10)$ & 0.0 & MV & Voltage of source I at time TVEND(I) \\
\hline TVBEG(1:10) & 0.0 & s & Tine corresponding to beginning of $\mathrm{RF}$ voltage change \\
\hline TVEND $(1: 10)$ & 0.0 & $\mathbf{s}$ & Time corresponding to end of $\mathrm{RF}$ voltage change \\
\hline KURVE $(1: 10)$ & 0 & - & $\begin{array}{l}\text { Specifies type of RF voltage variation between times TVBEG and TVEND: } \\
0 \text { - None, voltage maintained at VI(I) } \\
\text { 1 - Linear } \\
2 \text { - Isoadiabatic } \\
3 \text { - Sigmoid } \\
4 \text { - Fit and cubic spline interpolation of voltage table }{ }^{a}\end{array}$ \\
\hline VKON & $\mathrm{T}$ & - & Indicates whether programmed voltage curves are to be active \\
\hline PSII(1:10) & 0 & $\operatorname{deg}$ & Phase of source I at time TPBEG(I) \\
\hline PSIF (1:10) & 0 & $\operatorname{deg}$ & Phase of source I at time TPEND(I) \\
\hline TPBEG(1:10) & 0.0 & 8 & Time corresponding to beginning of RF phase change \\
\hline TPEND $(1: 10)$ & 0.0 & $\mathbf{s}$ & Time corresponding to end of RF phase change \\
\hline KURVP(1:10) & 0 & $\cdot$ & $\begin{array}{l}\text { Specifies type of RF phase variation between times TPBEG and TPEND: } \\
0 \text { - None, phase maintained at PSII(I) } \\
1 \text { - Linear } \\
\text { 2- Quadratic } \\
4 \text { - Fit and cubic spline interpolation of phase table }{ }^{a}\end{array}$ \\
\hline PHKON & $\mathbf{F}$ & $\because$ & Indicates whether or not phase curves are to be active \\
\hline FRI $(1: 10)$ & 0.0 & $\mathbf{M H z}$ & Frequency of source I at time TFBEG(I) \\
\hline FRF $(1: 10)$ & 0.0 & $\mathrm{MHz}$ & Frequency of source I at time TFEND(I) \\
\hline TFBEG(1:10) & 0.0 & s & Time corresponding to beginning of frequency change \\
\hline TFEND $(1: 10)$ & 0.0 & s & Time corresponding to end of frequency change \\
\hline KURVF $(1: 10)$ & 0 & - & $\begin{array}{l}\text { Specifies type of frequency variation between times TFBEG and TFEND: } \\
0 \text { - None, frequency maintained at FRI(I) } \\
1 \text { - Linear } \\
\text { 2- Quadratic } \\
4 \text { - Fit and cubic spline interpolationof frequency table }{ }^{a}\end{array}$ \\
\hline FRKON & F & - & Indicates whether frequency curves are to be active \\
\hline CNTINU & $\mathrm{F}$ & - & $\begin{array}{l}\text { Sets the starting voltage, phase and/or frequency for any active sources as the } \\
\text { current values-for smoothly piecing curve segments together }\end{array}$ \\
\hline VMATCH $(1: 10)$ & $\mathbf{F}$ & - & $\begin{array}{l}\text { For source } \mathrm{I} \text {, VMATCH(I) }=\text { T results in the VI(I) being set so that source } \mathrm{I} \text { is } \\
\text { matched to the curxent distribution emittance }\end{array}$ \\
\hline HOLDBH & F & - & $\begin{array}{l}\text { If true, then voltage is to be varied so that bucket height due to source } 1^{c} \text { is } \\
\text { multiplied by HDECR on successive turns }\end{array}$ \\
\hline HDECR & $\overline{1.0}$ & - & $\begin{array}{l}\text { Factor by which bucket height (for source } 1 \text { ) is to be adjusted on successive turns } \\
\text { if HOLDBH = T }\end{array}$ \\
\hline HOLDBA & $\mathbf{F}$ & - & $\begin{array}{l}\text { If true, then voltage is to be varied so that bucket area due to source } 1^{c} \text { is multiplied } \\
\text { by SDECR on successive turns }\end{array}$ \\
\hline SDECR & 1.0 & - & $\begin{array}{l}\text { Factor by which bucket area (for source } 1 \text { ) is to be adjusted on successive tums if } \\
\text { HOLDBA }=T\end{array}$ \\
\hline PHISLIM & .95 & - & $\begin{array}{l}\text { Voltage may not be reduced such that } \sin \phi,>\text { PHISLIM using options HOLDBH } \\
\text { and HOLDBA }\end{array}$ \\
\hline PHSLIP & $\mathbf{F}$ & $\cdot$ & $\begin{array}{l}\text { Flag indicating that the phase of at least one source is to be varied to correspond } \\
\text { to a momentum offset from the synchronous valne (see DELTRF) }\end{array}$ \\
\hline DELTRF(1:10) & 0.0 & - & Momentum offet $(\Delta p / p)$ at which source $\mathrm{I}$ is to be operated \\
\hline
\end{tabular}

a Values read from file. See Section3.2.2
${ }^{b}$ Which means, in this instance, that the $\mathbf{P}$ command, or its equivalent, should precede the $\mathbf{A}$ command.

'The algorithms used to maintain the bucket height and area consider only a single source. 


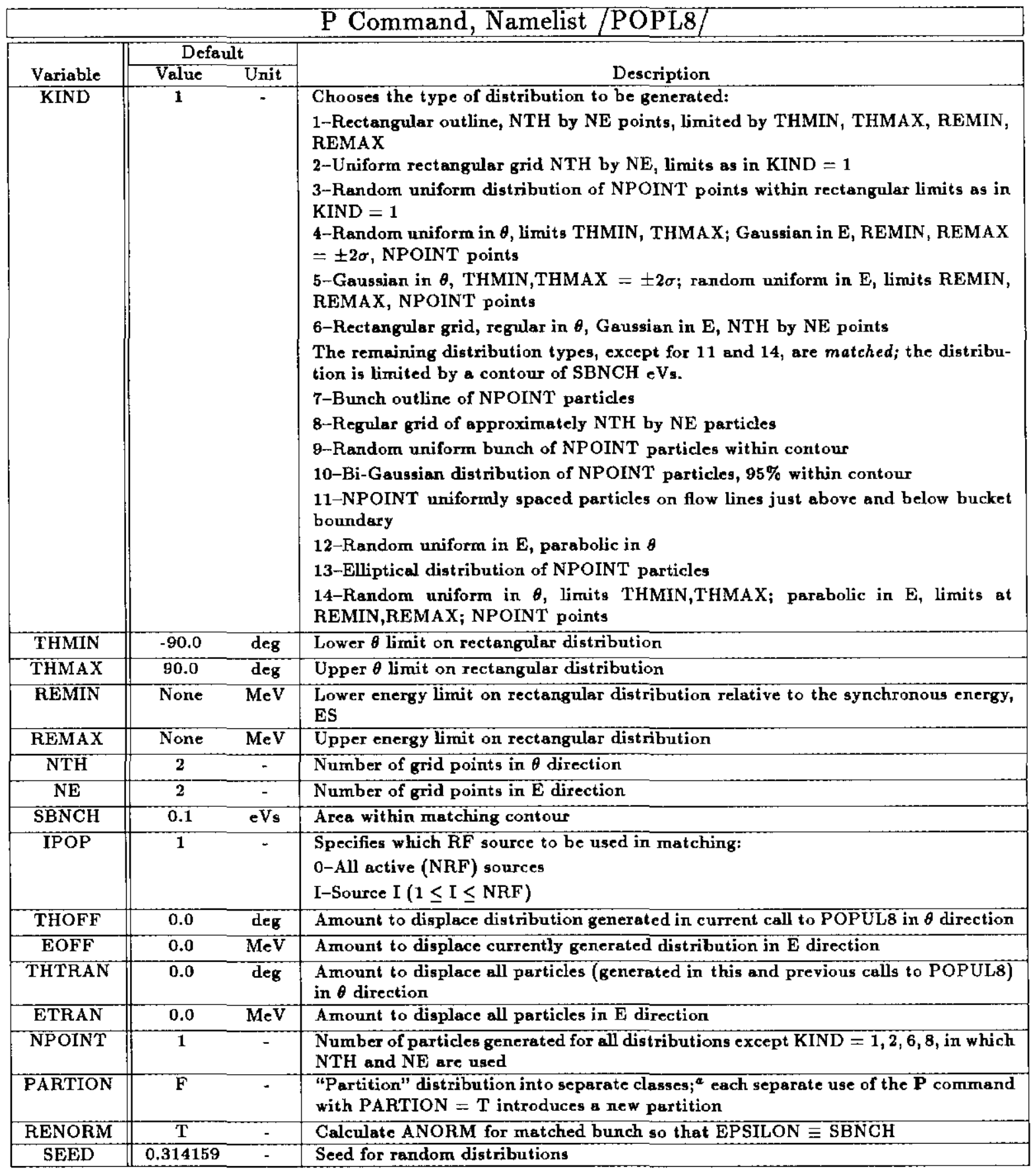

${ }^{a}$ Different classes of particles may be plotted with distinct symbols. 


\begin{tabular}{|c|c|c|c|}
\hline \multicolumn{4}{|r|}{ O Command, Namelist/GRAPH/ } \\
\hline \multirow[b]{2}{*}{ Variable } & \multicolumn{2}{|c|}{ Default } & \multirow[b]{2}{*}{ Description } \\
\hline & Value & Unit & \\
\hline MPLOT & 1000 & turn & Frequency of output; every MPLOT turns \\
\hline IDEV & 1 & $\cdot$ & Virtual device number for graphical output ${ }^{a}$ \\
\hline POSTP & $\mathbf{F}$ & - & Write all data in COMMON blocks to unit 18; do not call plotting routine \\
\hline TITLE & $\mathbf{F}$ & - & $\begin{array}{l}\text { Indicates that line immediately following NAMELIST input is to be used as a plot } \\
\text { title }^{b}\end{array}$ \\
\hline PLTSW & & & Select plot options: \\
\hline (1) & $\mathrm{T}$ & - & Draw phase space plot \\
\hline (2) & $\mathbf{T}$ & - & Plot phase space points (different symbol for each class) \\
\hline (3) & $\mathbf{F}$ & - & Interconnect points within each class \\
\hline (4) & $\mathbf{F}$ & - & Draw lines at centroid and $\pm \sigma$ \\
\hline (5) & $\mathbf{F}$ & - & Draw voltage waveform \\
\hline (6) & F & - & Set plot boundaries to turning points of contour \\
\hline (7) & $\mathbf{F}$ & - & Suppress captions, axis labels etc... \\
\hline (8) & $\mathbf{T}$ & - & Plot $\theta$ histogram \\
\hline (9) & $\mathbf{F}$ & - & Set $\theta$ histogram limits to turning points of contour \\
\hline (10) & $\mathrm{T}$ & - & Plot E histogram \\
\hline (11) & $\mathbf{F}$ & - & Set E histogram limits to turning points of contour \\
\hline (12) & $\mathbf{F}$ & - & Plot fourier amplitudes \\
\hline (13) & $\mathbf{F}$ & - & Include phases in plot of fourier spectrum \\
\hline (14) & $\mathbf{F}$ & - & Plot space charge erergy loss (per turn) vs. $\theta$ \\
\hline (15) & $\mathrm{F}$ & - & Include distribution histogram on space charge plot \\
\hline (16) & $\mathbf{F}$ & - & Plot high-Q resonator voltage \\
\hline (17) & $\mathbf{T}$ & - & Start bucket contour at unstable fixed point ${ }^{c}$ \\
\hline (18) & $\mathbf{T}$ & - & Start bucket contour at stable fixed point at $E=E_{s}+H_{b c k t}$ \\
\hline (19) & $\mathbf{F}$ & - & Plot flow line points (different symbol for each class) \\
\hline (20) & $\mathbf{F}$ & - & Interconnect flow line points within each class \\
\hline NPJMP & 1 & - & In phase space plot, plot only every NPJMPth point \\
\hline KLPLOT & 0 & - & $\begin{array}{l}\text { Select classes in phase space plot and projections (see Sec. } 2.2 .3 \text { ) } \\
0 \text {-All classes plotted } \\
1 \leq \text { KLPLOT } \leq \text { KLASSES-Plot class KLPLOT only }\end{array}$ \\
\hline IRF & 1 & $\cdot$ & $\begin{array}{l}\text { Selects voltage source for contour plotting: } \\
<0 \text {-No contour plotted } \\
0 \text {-All active (NRF) sources } \\
1 \text {-10-Source IRF }(1 \leq \text { IRF } \leq \text { NRF) }\end{array}$ \\
\hline ICONTUR & $\overline{1}$ & - & $\begin{array}{l}\text { Select the type of reference contour to plot on phase space plot } \\
0 \text {-No contour } \\
\text { 1-Bucket contour } \\
\text { 2-Contour of initial bunch area SBNCH } \\
\text { 3-Contour of the specified area REFAREA } \\
\text { 4-Contour containing } 95 \% \text { of the particles } \\
\text { 5-Flow lines chosen by LINES, ELMIN, and ELMAX }\end{array}$ \\
\hline REFAREA & 0.1 & $\mathrm{eVs}$ & Area of reference contour for ICONTUR $=3$ \\
\hline LINES & 2 & - & Number of flow lines for ICONTUR $=5$ \\
\hline ELMIN & 0. & $\overline{\mathrm{MeV}}$ & Lowest energy $w / E$, for desired flow lines \\
\hline ELMAX & 1. & $\overline{\mathrm{MeV}}$ & Energy of top flow line \\
\hline
\end{tabular}

DI-3000 specific; see 3.1 .

'This is an exception to the maintenance of NAMELIST input; TITLE is set to .FALSE. after every execution of the $\mathbf{O}$ cornmand.

At least one of PLTSW(17) or PLTSW(18) must be true for ICONTUR=1 else program sets both.TRUE. 


\begin{tabular}{|c|c|c|c|}
\hline \multicolumn{4}{|r|}{$\mathrm{O}$ Command, Namelist /GRAPH/, continued } \\
\hline \multirow[b]{2}{*}{ Variable } & \multicolumn{2}{|c|}{ Default } & \multirow[b]{2}{*}{ Description } \\
\hline & Value & Unit & \\
\hline THPMIN & $0.0^{a}$ & deg & Lower $\theta$ linit for phase space plot \\
\hline THPMAX & 0.0 & deg & Upper $\theta$ limit for phase space plot \\
\hline DEPMIN & $0.0^{6}$ & $\mathrm{MeV}$ & Lower E limit for phase space plot \\
\hline DEPMAX & 0.0 & $\mathrm{MeV}$ & Upper E limit for phase space plot \\
\hline IEREF & 1 & 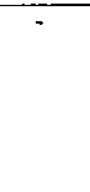 & $\begin{array}{l}\text { Determines energy origin for phase space: } \\
\text { 1-E0, the reference energy (often = ES) } \\
\text { 2-ES, the synchronous energy } \\
\text { 3-EBAR, the average particle energy } \\
\text { 4-EREF, the "reference" particle energyc }\end{array}$ \\
\hline NBINTH & 50 & $=$ & The number of bins for the $\theta$ histogram \\
\hline THBMIN & $0.0^{d}$ & $\overline{\operatorname{deg}}$ & Lower limit for $\theta$ histogram \\
\hline THBMAX & 0.0 & $\operatorname{deg}$ & Upper limit for $\theta$ histogram \\
\hline NBINE & 50 & - & The number of bins for the $E$ histogram \\
\hline EBMIN & $0.0^{e}$ & $\mathrm{MeV}$ & Lower limit for E histogram \\
\hline EBMAX & 0.0 & $\mathrm{MeV}$ & Upper limit for E histogram \\
\hline IFBMIN & $\overline{1}$ & - & Lower limit for FFT plot \\
\hline IFBMAX & $0^{f}$ & - & Upper limit for FFT plot \\
\hline SCBMIN & $0.0^{s}$ & - & Lower $\theta$ limit for space-charge plot \\
\hline SCBMAX & 0.0 & - & Upper limit for space-charge plot \\
\hline RBMIN & $0.0^{h}$ & - & Lower $\theta$ limit for resonator voltage plot \\
\hline RBMAX & 0.0 & - & Upper limit for resonator voltage plot \\
\hline DTHCURV & 0.0 & deg & Amount by which contour will be moved in $\theta$ direction \\
\hline DECURV & 0.0 & $\mathrm{MeV}$ & Amount by which contour will be moved in $\mathrm{E}$ direction \\
\hline DELCON & .01 & - & Determine bucket to precision DELCON* $360^{\circ}$ w/ RF \\
\hline KNTLIM & 500000 & - & Number of iterations of difference equation which will be attempted to close contour \\
\hline IMETA & 0 & & $\begin{array}{l}\text { Directs graphic output (HIGZ only): } \\
<0 \text { - Output written to HIGZ metafile } \\
0 \text { - Output to device selected by IDEV } \\
>0 \text { - Output to both HIGZ metafile and selected IDEV }\end{array}$ \\
\hline XCRNR & 135. & 0.001 & $\begin{array}{l}\text { Fraction of full width of plot frame between lefthand edge and bottom left corner } \\
\text { of plot }\end{array}$ \\
\hline YCRNR & 69.0 & 0.001 & Fraction of full height of plot frame between bottom edge and bottom of plot \\
\hline $\mathbf{X A X I S L}$ & 750. & 0.001 & Plot width as a fraction of frame width \\
\hline YAXISL & 475. & 0.001 & Plot height as a fraction frame height \\
\hline
\end{tabular}

a THPMIN and THPMAX both 0.0 results in a plotting range $-180^{\circ} / \mathrm{FRAC} \leq \theta \leq 180^{\circ} / \mathrm{FRAC}$.

${ }^{b}$ DEPMIN and DEPMAX both 0.0 results in a plotting range approximately the range of particle energies

${ }^{c}$ A particle which ESME tracks from the origin $(0, E S)$ as a reference.

${ }^{d}$ Limits of 0.0 for both THBMIN and THBMAX result in the plot range being the same as for the phase space plot.

'Limits of 0.0 for both EBMIN and EBMAX result in the plot range being the same as for the phase space plot.

${ }^{f}$ IFBMAX $=0$ results in the upper limit being the greatest Fourier harmonic computed.

${ }^{s}$ Limits of 0.0 for both SCBMIN and SCBMAX result in the range for the plot being $\pm 180^{\circ} /$ FRAC.

${ }^{h}$ Limits of 0.0 for both RBMIN and RBMAX result in the range being $\pm 180^{\circ} /$ FRAC.

$i$ can be DI3000 metafile if HIGZ_DI3000 is used 


\begin{tabular}{|c|c|c|c|}
\hline \multicolumn{4}{|r|}{ T Command, Namelist/CYCLE/ } \\
\hline \multirow[b]{2}{*}{ Variable } & \multicolumn{2}{|c|}{ Default } & \multirow[b]{2}{*}{ Description } \\
\hline & Value & Unit & \\
\hline TSTOPa & 0.0 & $\mathbf{s}$ & Time at which to stop tracking \\
\hline TTRACK ${ }^{6}$ & 0.0 & $\mathbf{s}$ & Duration of time to track \\
\hline MSTEP & 100 & - & Number of tracking steps (minimum) per synchrotron period \\
\hline ACCELO & 1.0 & - & Number of beam turns per tracking step (maximum) ${ }^{c}$ \\
\hline LGRTHM & 1 & - & $\begin{array}{l}\text { Select difference equations used in tracking } \\
\text { 1-Complete kinematics, expand path length to maximum order using input coeffi- } \\
\text { cients ALPHAnd } \\
\text { 2-Use the simplified difference equation } \\
\vartheta_{i, n}=\frac{r_{e, n}}{\tau_{e, n-1}} \vartheta_{i, n-1}+2 \pi \eta \frac{\Delta_{p}}{p}\end{array}$ \\
\hline $\operatorname{ITRAP}(1: 4)$ & 0 & - & $\begin{array}{l}\text { Indicates a condition for which tracking should be interrupted before time indicated } \\
\text { by TTRACK or TSTOP: } \\
\text { 0-No trap } \\
\text { 1-Trap on minimum bunch width } \\
\text { 2-Trap on minimum bunch height } \\
\text { 3-Trap for } \eta=\text { ETATRP (tolerance } \Delta \eta / \eta= \pm .01 \text { ) } \\
\text { 4-Trap for }\left|\phi_{s}\right|=\text { PHISTRP (tolerance } \Delta \phi_{s}= \pm .005 \text { ) } \\
\text { 5-Trap for } \eta>0 \text { (transition crossing) } \\
\text { 10-19-Call SUBROUTINE SHAZAM, enter at SHAZAM, SHAZAM }, \text { SHAZAM } \text {, } \\
\ldots \text { following every iteration of the difference equations }\end{array}$ \\
\hline ETATRP & .001 & - & For ITRAP $=3$; tracking stopped when $\eta=$ ETATRP \\
\hline PHISTRP & .95 & 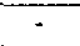 & For ITRAP $=4 ;$ tracking stopped when $\left|\sin \phi_{\bullet}\right|=$ PHISTRP \\
\hline MGRACE & $\mathbf{0}$ & - & Allow a "grace period" of MGRACE turns before trapping conditions are checked \\
\hline HISTRY & $\bar{F}$ & - & Write a history record to unit 9 following every iteration of the difference equations ${ }^{e}$ \\
\hline MOMNTS & F & $\div$ & $\begin{array}{l}\text { Compute the moments of the distribution following every iteration of the difference } \\
\text { equations }\end{array}$ \\
\hline BBDRY & $\mathbf{F}$ & - & Remove particles tracked outside of region $-180^{\circ} /$ FRAC $\leq \theta \leq 180^{\circ} /$ FRAC \\
\hline
\end{tabular}

${ }^{a}$ TSTOP is set to 0.0 when tracking is completed, or interrupted by an ITRAP option.

${ }^{b}$ TSTOP takes precedence; if TSTOP $=0.0$, then TTRACK determines duration of tracking.

'Tracking will proceed at the nearest integer to ACCEL0 (not $<1$ ), limited by MSTEP.

${ }^{d}$ See $\mathbf{R}$ command

${ }^{\mathrm{e}}$ See Section 3.2 . 


\begin{tabular}{|c|c|c|c|}
\hline \multirow[b]{3}{*}{ Variable } & \multicolumn{3}{|r|}{ H Command, Namelist/HISTRY/ } \\
\hline & \multicolumn{2}{|c|}{ Default } & \multirow[b]{2}{*}{ Description } \\
\hline & Value & Unit & \\
\hline IDEV & 1 & - & The virtual device number for output ${ }^{a}$ \\
\hline \multirow[t]{35}{*}{ NPLT $(1: 2,1: 50)$} & \multirow[t]{35}{*}{$0^{b}$} & \multirow[t]{35}{*}{-} & $\begin{array}{l}\text { "Index" of element in history records; NPLT }(1, \mathrm{I}) \text { is independent variable, NPLT }(2, \mathrm{I}) \\
\text { is dependent variable }\end{array}$ \\
\hline & & & Real records: \\
\hline & & & 1-Time \\
\hline & & & 2-PHIS, the synchronous phase in same units as vartheta ${ }^{c}$ \\
\hline & & & 3-PDOT, $d p_{s} / d t$ \\
\hline & & & 4-THBAR, the mean value of $\theta$ for the distribution \\
\hline & & & 5-EBAR, the average energy of the distribution \\
\hline & & & 6-THRMS, the rms spread in $\theta$ of the particles \\
\hline & & & 7-ERMS, the rms energy spread \\
\hline & & & 8-ES, the synchronous energy \\
\hline & & & 9-E0, the energy on the reference orbit \\
\hline & & & $\begin{array}{l}\text { 10-ES-E0 } \\
11-T H R F F \text { the arimuth of a particle tracked from (o ES) }\end{array}$ \\
\hline & & & 11-THREF, the azimuth of a particle tracked from $(0, E S)$ \\
\hline & & & 12-EREF, the energy of a particle tracked from $(0, \mathrm{ES})$ \\
\hline & & & 13-EPSILON, the emittance ${ }^{d}$ \\
\hline & & & 14-NUS, the synchrotron frequency \\
\hline & & & 15-SBCKT, the RF" "bucket" area \\
\hline & & & 16-HBCKT, the RF "bucket" height \\
\hline & & & $17-\mathrm{ETA}, \gamma_{\mathrm{T}}^{-2}-\gamma^{-2}$ \\
\hline & & & 18-ACCEL; see $T$ command \\
\hline & & & 19-TAU, synchronous revolution period \\
\hline & & & 20-PSLADD, phase feedback; see $\mathrm{I}$ command \\
\hline & & & 21-DAMPL, voltage feedback factor; see $\mathbf{L}$ command \\
\hline & & & 22-DELR, synchronous orbit radius - reference orbit radius \\
\hline & & & 23-RFFREQ, frequency of RF source 1 \\
\hline & & & Integer records: \\
\hline & & & 31-TURN NUMBER \\
\hline & & & 32-KNTSC, number of particles in $\varepsilon_{\ell} \neq 0$ partition of distribution \\
\hline & & & Array records: \\
\hline & & & 51-60-SPARE(1-10) \\
\hline & & & $101-110-E V(1-10)$ \\
\hline & & & $111-120-P S I(1-10)$ \\
\hline & & & 121-130-FREQ(I)-FRI(I), Change in frequency of source I \\
\hline & & & 201-250-FAMPL(1-50), Fourier amplitudes; see $\mathbf{F}$ command \\
\hline & & & 251-300-FAZE(1-50), Fourier phases; see $\mathbf{F}$ command \\
\hline
\end{tabular}

${ }^{a}$ DI-3000 specific; see Section 3.1.

${ }^{6}$ The default value of 0 indicates to SUBROUTINE HISTORY that all of the desired history plots have been generated; so only the first set of consecutive nonzero entries to array NPLT will generate plots.

${ }^{\text {'See }} \mathrm{A}$ command description.

${ }^{d}$ EPSILON $=$ ANORM $\tau\left(\sqrt{\sum \theta_{i}^{2} \sum E_{i}^{2}-\left(\sum \theta_{i} E_{i}\right)^{2}}\right) / N$ eVs; see text for ANORM. 


\begin{tabular}{|c|c|c|c|}
\hline \multicolumn{4}{|c|}{ M Command, Namelist/MRANGE/ } \\
\hline \multirow[b]{2}{*}{ Variable } & Default & & \multirow[b]{2}{*}{ Description } \\
\hline & Value & Unit & \\
\hline TMBEGIN & 0.0 & $\mathbf{s}$ & Time at which to start saving mountain range data \\
\hline TMEND & 0.0 & $\mathbf{s}$ & Time after which to stop saving rnountain range data \\
\hline MRMPLOT & 1 & turn & Turn interval at which to record mountain range data \\
\hline MRNBIN & 50 & - & Number of bins for mountain range histogram \\
\hline MRTHBMIN & $-180^{\circ} / \mathrm{FRAC}$ & $\mathrm{deg}$ & Minimum value of $\theta$ for mountain range \\
\hline MRTHBMAX & $180^{\circ} / \mathrm{FRAC}$ & $\operatorname{deg}$ & Maximum value of $\theta$ for mountain range \\
\hline
\end{tabular}

\begin{tabular}{|c|c|c|c|}
\hline \multicolumn{4}{|r|}{ N Command, Namelist/MRPLOT/ } \\
\hline \multirow[b]{2}{*}{ Variable } & \multicolumn{2}{|c|}{ Default } & \multirow[b]{2}{*}{ Description } \\
\hline & Value & Unit & \\
\hline MRTHPMIN & $0.0^{a}$ & deg & Minimum $\theta$ value for mountain range plot \\
\hline MRTHPMAX & 0.0 & deg & Maximum $\theta$ value for mountain range plot \\
\hline NTRACE & 100 & - & Number of traces on a page \\
\hline NSKIP & 0 & 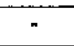 & Number of records to be "skipped" between each trace \\
\hline TOPTOB & 0.7 & - & $\begin{array}{l}\text { The fraction of the vertical range over which NTRACE traces are to be plotted } \\
\text { (approximate if } \mathrm{TBASE}=\mathrm{T} \text { ) }\end{array}$ \\
\hline SCALE & 0.3 & - & $\begin{array}{l}\text { The height of the first trace, in units in which the entire vertical range of the plot } \\
\text { is } 1.0\end{array}$ \\
\hline MSTART & $0^{b}$ & - & Turn number at which to start plots \\
\hline MSTOP & 0 & - & Turn number at which to stop plots \\
\hline TMSTART & 0.0 & $\mathbf{s}$ & Time at which to start plots \\
\hline TMSTOP & 0.0 & $\mathbf{s}$ & Time at which to stop plots \\
\hline TBASE & $\mathbf{F}$ & - & Switch causing plot trace separation to be proportional to time \\
\hline NRNBIN & 400 & - & Number of points to plot on a trace \\
\hline IDEV & 1 & - & Output device \\
\hline SMOOTH & 0 & - & $\begin{array}{l}\text { Smoothing option } \\
-1-1-2-1 \text { averaging of adjacent bins } \\
0-\text { No smoothing } \\
1-\text { Bernstein polynomial smoothing }\end{array}$ \\
\hline OBJWGT & 0.05 & - & $\begin{array}{l}\text { Weight of fitting term of object function w/ smoothing term for polynomial smooth- } \\
\text { ing }\end{array}$ \\
\hline ITNO & 1 & & Number of iterations for either 1-2-1 or Bernstein smoothing \\
\hline LIM & $\mathbf{F}$ & - & $\begin{array}{l}\text { Switch for plot ting dotted lines connecting leftmost and rightmost non-zero points } \\
\text { of consecutive traces }{ }^{c}\end{array}$ \\
\hline
\end{tabular}

${ }^{a}$ Defaults of 0.0 for MRTHPMIN and MRTHPMAX imply that data is to be plotted over its entire range.

${ }^{b}$ The defaults of 0 for MSTART and MSTOP, or 0.0 for TMSTART and TMSTOP, imply that all mountain range records are to be plotted

${ }^{\mathrm{c}} \mathrm{SMOOTH}=1$ also required. 


\begin{tabular}{|c|c|c|c|}
\hline \multirow[b]{3}{*}{ Variable } & \multicolumn{3}{|r|}{ L Command, Namelist/LLRF/ } \\
\hline & \multicolumn{2}{|c|}{ Default } & \multirow[b]{2}{*}{ Description } \\
\hline & Value & Unit & \\
\hline PHFBON & $\mathbf{F}$ & - & Activates phase feedback \\
\hline VFBON & $\mathbf{F}$ & - & Activates voltage feedback \\
\hline NTUAVG & 1 & - & $\begin{array}{l}\text { The number of past turns to average in computing the feedback; the default } \\
\text { NTUAVG = } 1 \text { represents infinite-bandwidth feedback }\end{array}$ \\
\hline NTURES & 1 & - & $\begin{array}{l}\text { The number of turns for the feedback to respond; the present signal is compared to } \\
\text { the signal of NTURES turns ago }\end{array}$ \\
\hline IFTB & 0 & $\cdot$ & $\begin{array}{l}\text { The form of phase feedback: } \\
\text { 0-Critical damping } \\
\text { 1-Fixed }\end{array}$ \\
\hline FBFACT & 1.0 & - & The gain applied to the phase feedback \\
\hline USEWT & $\mathrm{F}$ & - & Applies "weight function" W to phase signal over NTUAVG turns \\
\hline W(1:NTUAVG $)$ & 0.0 & 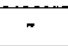 & "Weight function" multiplying phase signal \\
\hline DLIMIT & 5.7296 & deg & The upper limit on the magnitude of the phase feedback on a given turn \\
\hline VFBFCTR & 1.0 & - & The gain applied to the voltage feedback \\
\hline VLIMIT & .1 & $\overline{\mathrm{MV}}$ & The limit on the voltage feedback applied on a given turn \\
\hline ETAJMP & 0.0 & - & The value of $\eta^{a}$ at which to "flip" the phase of the RF \\
\hline
\end{tabular}

$$
{ }^{a} \eta=\gamma_{T}^{-2}-\gamma^{-2}
$$




\begin{tabular}{|c|c|c|c|}
\hline \multicolumn{4}{|r|}{ B Command, Namelist /SCHG/ } \\
\hline \multirow[b]{2}{*}{ Variable } & \multicolumn{2}{|c|}{ Default } & \multirow[b]{2}{*}{ Description } \\
\hline & Value & Unit & \\
\hline A & 0.002 & $\mathbf{m}$ & Effective beam radius \\
\hline B & 0.05 & m & Effective beam pipe radius \\
\hline ENQ & $2 \cdot \cdot 10^{10}$ & - & Number of protons to be represented by the distribution \\
\hline $\mathrm{NZ}$ & 0 & - & Number of impedance values to be read from a file $a$ \\
\hline NR & 0 & - & Number of resonance values to be read from a file ${ }^{b}$ \\
\hline NBINSC & 100 & - & Number of bins for histogram of charge distribution \\
\hline MSC & 1 & - & Collective effects are to be calculated MSC times between of cavities ${ }^{c}$ \\
\hline TSCON & 0 . & s & $\begin{array}{l}\text { End of period starting at TIME }=0 \text {. in which beam charge is ramped linearly from } \\
0 . \text { to } E N Q\end{array}$ \\
\hline SCON & $\mathbf{F}$ & 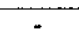 & Activate space charge calculation \\
\hline NBINFFT & 256 & $\therefore$ & Number of bins to be used in Fourier transform \\
\hline MFFT & 1 & $\because$ & Interval (in turns) between Fourier transforms \\
\hline $\mathrm{NNF}^{d}$ & 0 & $\because$ & Number of fourier harmonics to be stored in history \\
\hline $\mathrm{NF}(1: \mathrm{NNF})$ & 0 & - & Harmonic numbers of fourier spectrum components to be stored \\
\hline QREZON & $\mathrm{F}$ & - & Activate time domain calculation for high- $Q$ resonance \\
\hline NBRES & 1000 & $\because$ & Number of time slices for time domain solution of high- $Q$ resonator \\
\hline NIXNOIS & 0 & 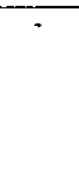 & $\begin{array}{l}\text { Three-way switch to control smoothing of charge distribution } \\
-1=>1-2-1 \text { averaging of adjacent bins } \\
0=>\text { no smoothing measures } \\
1 \Rightarrow>\text { Bernstein polynomial smoothing }\end{array}$ \\
\hline ITKNT & 1 & $\cdot$ & Number of iterations for either $1-2-1$ or Bernstein smoothing \\
\hline OBWGT & 0.05 & - & Weight of fitting vs. smoothing in object function for Bernstein smoothing \\
\hline
\end{tabular}

aCubic polynomial coefficient table read from FORTRAN logical unit 11 ; see Section 3.2 .3 for format specification. ${ }^{b}$ Resonance parameters read from FORTRAN logical unit unit 12; see Section 3.2.4 for format specification.

cThe number of such calculations per turn will be MSC*NCAV; NCAV is a parameter of the $\mathbf{R}$ command.

${ }^{d}$ For instruction in the use of $\mathrm{NF}(1: \mathrm{NNF})$, see the description following the $\mathrm{F}$ command.

\begin{tabular}{|c|c|c|c|}
\hline & & & F Command, Namelist /FFT/ \\
\hline & Def & & \\
\hline Variable & Value & Unit & Desçription \\
\hline FFTON & $\mathbf{F}$ & - & Activate Fourier transform calculation \\
\hline FFTOUT & $\overline{\mathbf{F}}$ & - & If TRUE, Fourier trarsform is printed \\
\hline NBINFFT & 256 & $\tilde{z}$ & Number of bins to be used in FFT \\
\hline NNF & 0 & - & Number of fourier harmonics to be stored in history \\
\hline $\mathrm{NF}(1: \mathrm{NNF})$ & 0 & - & Harmonic numbers of fourier spectrum components to be stored \\
\hline MFFT & 1 & - & Frequency of Fourier transform calculation \\
\hline NIXNOIS & 0 & $\overline{-}$ & $\begin{array}{l}\text { Three-way switch to control smoothing of azimuthal histogram } \\
-1=>1-2-1 \text { averaging of adjacent bins } \\
0=>\text { no smoothing measures } \\
1=>\text { Bernstein polynomial smoothing }\end{array}$ \\
\hline ITKNT & 1 & $\cdot$ & Number of iterations for either 1-2-1 or Bernstein smoothing \\
\hline OBWGT & 0.05 & - & Weight of fitting vs. smoothing in object function for Bernstein smoothing \\
\hline
\end{tabular}




\begin{tabular}{|c|c|c|c|}
\hline \multicolumn{4}{|r|}{ C Command, Namelist /FLOW/ } \\
\hline \multirow[b]{2}{*}{ Variable } & \multicolumn{2}{|c|}{ Default } & \multirow[b]{2}{*}{ Description } \\
\hline & Value & Unit & \\
\hline LINES & 2 & - & The number of flow lines to be drawn \\
\hline ELMAX & 1. & $\mathrm{MeV}$ & Highest energy relative to $E_{0}=0$ \\
\hline ELMIN & 0. & $\mathrm{MeV}$ & Lowest energy relative to $\mathrm{E}_{\mathbf{2}}$ ELMIN $>/=0$. \\
\hline TSTOPa & 0. & $\mathbf{s}$ & End of interval over which maps are generated \\
\hline TTRACK $^{6}$ & 0. & $\mathbf{s}$ & Time over which periodic flow maps will be generated \\
\hline ACCELO & 1.0 & - & Number of beam turns per step between mappings \\
\hline PARTIOON & $\mathbf{F}$ & - & $\begin{array}{l}\text { Switch indicates if points on separate flow lines belong to different partitions of the } \\
\text { phase points }\end{array}$ \\
\hline ITRAP(1:4) & 1 & - & $\begin{array}{l}\text { Flags a condition for which the } \mathbf{C} \text { command should be interrupted; see } \mathbf{T} \text { command } \\
\text { for values }\end{array}$ \\
\hline ETATRP & .001 & - & Trapping parameter; see $\mathbf{T}$ command \\
\hline PHISTRP & .95 & - & Trapping parameter; see $\mathbf{T}$ command \\
\hline MGRACE & 0 & - & Trapping parameter; see $\mathbf{T}$ command \\
\hline
\end{tabular}

a TSTOP set to 0 . when calculation complete or interrupted by an ITRAP option.

${ }^{b} \mathrm{TSTOP}$ takes precedence; if TSTOP $=0$., TTRACK determines duration.

\begin{tabular}{|c|c|c|c|}
\hline \multirow[b]{3}{*}{ Variable } & \multicolumn{3}{|r|}{ K Command, Namelist/KUTS/ } \\
\hline & \multicolumn{2}{|c|}{ Default } & \multirow[b]{2}{*}{ Description } \\
\hline & Value & Unit & \\
\hline$\overline{\mathrm{KUT}}$ & 0 & - & Cut the last KUT particles from the distribution \\
\hline KNTSET & 0 & - & $\begin{array}{l}\text { Reset particle count } \\
<0 \Longrightarrow \text { KNTSC } \longrightarrow 0 \text {; removes bunch-type distribution } \\
>0 \Longrightarrow \text { KOUNT } \longrightarrow 0 \text {; removes entire distribution }\end{array}$ \\
\hline$\overline{\mathrm{K}} 1$ & 0 & - & Starting point for a partial removal of the distribution \\
\hline K2 & a & - & End point for partial removal of distribution \\
\hline KLASS & 0 & 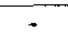 & Selects a partition of the distribution to be removed ${ }^{\delta}$ \\
\hline
\end{tabular}

a Defaults to KOUNT

${ }^{b}$ See PARTION in $\mathbf{P}$ command 


\section{Bibliography}

[1] Design Report Tevatron I Project, Fermi National Accelerator Laboratory (October 1984), Chapters 4-6

[2] J. E. Griffin, J. A. Machachlan, A. G. Ruggiero, K. Takayama, "Time and Momentum Exchange for the Production and Collection of Intense Antiproton Beams at Fermilab", IEEE Trans. Nucl. Sci. 30\#4(1983) 2630-2632

[3] J. E. Griffin, J. A. MacLachlan, Z. B. Qian, “ RF Exercises Associated with Acceleration of Intense Antiproton Bunches at Fermilab", IEEE Trans. Nucl. Sci. 30\#4(1983) 2627-2629

[4] J. A. MacLachlan, "ESME: Longitudinal Phasespace Particle Tracking - Program Documentation", Fermilab TM-1274(May 1984), unpublished (largely obsolete)

[5] J. A. MacLachlan, "Longitudinal Phasespace Tracking with Spacecharge and Wall Coupling Impedance", Fermilab FN-446 (February 1987), unpublished.

[6] P. Lucas and J. MacLachlan, "Simulation of Spacecharge Effects and Transition Crossing in the Fermilab Booster", Proc. 1987 IEEE Particle Accelerator Conference held at Washington, D.C. (16-19 March 1987) p1114.

[7] S. Stahl and C. Ankenbrandt, "Simulation of the Capture Process in the Fermilab Booster", Proc. 1987 IEEE Particle Accelerator Conference held at Washington, D.C. (16-19 March 1987)p1117

[8] P. Lucas and Q. Kerns, "Simulation of a Programmed Frequency Shift Near Extraction from the Fermilab Booster", Proc. IEEE Particle Accelerator Conference held at Washington, D.C. (16-19 March 1987)p1108

[9] S. Stahl and S. A. Bogacz, "Coupled Bunch Instability in a Circular Accelerator and Possible Cures: Longitudinal Phasespace Simulation", Phys. Rev. D37\#5(1 March 1988)1300-1306

[10] S. Stahl and J. MacLachlan, "User's Guide to ESME v. 7.1", Fermilab TM-1650 (26 Feb. 90)

[11] J. MacLachlan, "Particle Tracking in E- $\phi$ Space for Synchrotron Design \& Diagnosis", Fermilab-CONF-92/333 (Nov. 92), presented at 12 $\underline{\text { th }}$ Int'l Conf. on Appl. of Acc. in Res. and Ind., Denton TX, 4 Nov. 1992

[12] J. MacLachlan, “User's Guide to ESME v. 8.0", Fermilab TM-1835 (8 March 1993)

[13] J. MacLachlan, "An ESME Update - v. 8.05", Fermilab TM-1844 (15 June 1993)

[14] J. A. MacLachlan, "Fundamentals of Particle Tracking for the Longitudinal Projection of Beam Phasespace in Synchrotrons", Fermilab FN-481(15 April 88), unpublished.

[15] J. A. MacLachlan, “Difference Equations for Longitudinal Motion in a Synchrotron”, Fermilab FN-529(15 December 1989), unpublished. 
[16] A. Van Ginneken, "Smoothing Algorithm for Histograms of One or More Dimensions", Nucl. Inst. and Meth. in Phys. Res. A305 (1991) pp 453-461

[17] S. Stahl and S. A. Bogacz, "Simulation of Coupled Bunch Mode Growth Driven by a High-Q Resonator: A Transient Response Approach", Proc. 1989 IEEE Particle Accelerator Conference held at Chicago IL (20-23 March 1989)p1175.

[18] M. W. Eaton, "Expand and Xfort, Macro Expanders for CDF", Fermilab CDF-194(January 1986), unpublished. 